FÁBIO ALEXANDRE CASTELLI

MECÂNICA DOS FLUIDOS COMPUTACIONAL

INTEGRADA COM MODELO TÉRMICO DO CORPO HUMANO

PARA ANÁLISE DE AMBIENTES TÉRMICOS 
FÁBIO ALEXANDRE CASTELLI

\title{
MECÂNICA DOS FLUIDOS COMPUTACIONAL INTEGRADA COM MODELO TÉRMICO DO CORPO HUMANO PARA ANÁLISE DE AMBIENTES TÉRMICOS
}

\author{
Dissertação apresentada à Escola \\ Politécnica da Universidade de São Paulo \\ para obtenção do título de Mestre em \\ Engenharia \\ Área de Concentração: \\ Engenharia Mecânica \\ Orientador: \\ Prof. Dr. Guenther Carlos Krieger Filho
}


Este exemplar foi revisado e alterado em relação à versão original, sob responsabilidade única do autor e com a anuência de seu orientador.

São Paulo, de dezembro de 2012.

Assinatura do autor

Assinatura do orientador

FICHA CATALOGRÁFICA

Castelli, Fábio Alexandre

Mecânica dos fluidos computacional integrada com modelo térmico do corpo humano para análise de ambientes térmicos / F.A. Castelli. -- ed.rev. -- São Paulo, 2012.

$84 \mathrm{p}$.

Dissertação (Mestrado) - Escola Politécnica da Universidade de São Paulo. Departamento de Engenharia Mecânica.

1. Mecânica dos fluídos computacional 2. Transferência de calor I. Universidade de São Paulo. Escola Politécnica. Departamento de Engenharia Mecânica II. t. 


\section{Agradecimentos}

Agradeço primeiro a Deus por renovar minha disposição a cada novo momento em minha vida e conceder-me discernimento para elaborar este trabalho.

Aos meus pais Isidoro Filho e Dalva, que me educaram, formaram meu caráter e forneceram subsídios suficientes para que eu alcançasse meus objetivos.

A todos os meus amigos que contribuíram para este trabalho ao longo dos últimos anos. Aproveito para agradecer aos amigos Zaca e Tiquinha pelos dias de morada em São Paulo quando tive que viajar do Rio de Janeiro para concluir este trabalho. Também agradeço ao meu irmão Isidoro Neto e ao meu amigo Digo pela amizade e apoio no momento da defesa.

À minha noiva Thaminne que me fortalece e me dá segurança em seguir a vida, uma verdadeira companheira que me compreende e me acompanha há cinco anos.

Ao meu orientador Guenther que primeiro acreditou no meu potencial e depois me orientou com paciência e dedicação. Mesmo após me mudar para o Rio de Janeiro continuou a me orientar aos finais de semana e através de telefonemas e e-mails. Quero expressar meu reconhecimento pela sua competência profissional e contribuição para o meu crescimento intelectual e profissional.

Ao professor Arlindo Tribess pela contribuição para melhorar este trabalho e ao engenheiro Fernando Stancato da Empresa Brasileira de Aeronáutica, quem acompanhou o desenvolvimento do meu trabalho até a qualificação.

Em especial, ao meu amigo Anderson Morioshiro pela contribuição fundamental ao presente trabalho, ajudando-me a compreender o Modelo do Sistema Térmico do Corpo Humano e trabalhando comigo na revisão da literatura e execução da simulação integrada. 


\section{Resumo}

Neste trabalho é proposta uma metodologia numérica como ferramenta para avaliação de ambientes térmicos com manequins. A simulação de CFD do ambiente térmico em simulador comercial é integrada à simulação do sistema térmico do corpo humano realizada em código acadêmico. As soluções dos fluxos de calor e temperaturas nas peles são retroalimentadas e a transferência de informações é realizada via arquivo. A geometria do ambiente térmico é simplificada para minimizar os efeitos de problemas com a malha computacional na simulação de CFD, permitindo uma melhor análise do método interativo proposto. O manequim é separado em 15 segmentos cilíndricos representando cabeça, pescoço, tronco, braços, antebraços, mãos, coxas, pernas e pés. Cada segmento é subdividido em quatro quadrantes, totalizando 60 zonas, para capturar assimetrias térmicas e aerodinâmicas.

Foi conduzido estudo de validação geométrica de manequim virtual pela comparação de resultados dos coeficientes térmicos obtidos com CFD e resultados obtidos de ensaios experimentais da literatura. A qualidade da malha e o tratamento de parede são discutidos. Os resultados tornam evidente que uma geometria simplificada do manequim é suficiente para estudos e avaliações de ambiente térmico e de conforto térmico quando se utiliza técnicas numéricas de CFD.

Os resultados a partir da integração dos simuladores mostram que o método numérico pode ser instável nos segmentos com baixo metabolismo e baixa vazão de sangue, como nos pés e mãos. Pretende-se introduzir na metodologia proposta algum mecanismo que identifique automaticamente este fenômeno, para evitar a divergência do método e tornar a ferramenta mais robusta.

Palavras-chave: Mecânica dos Fluidos Computacional, Transferência de Calor, Ambiente Térmico. 


\section{Abstract}

In this work is proposed a new numerical methodology as a tool for thermal comfort evaluation. This method promotes the interaction of the thermal environment simulation and the thermal system of the human body simulation. The commercial CFD simulator

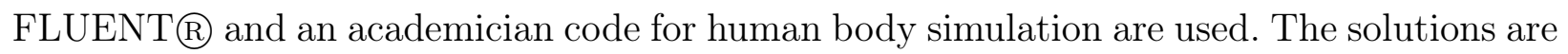
fed back and the transfer is made by file. The geometry of the room is simplified to minimize the effects of problems with the computational mesh in the CFD simulation, allowing a better analysis of the proposed interactive method. The dummy is separated into 15 cylindrical segments representing head, neck, trunk, arms, forearms, hands, thighs, legs and feet. Each segment is subdivided into four quadrants, totaling 60 zones, to capture asymmetries in the heat flux field and temperature field.

Was conducted a geometric validation of virtual dummy by comparing results of heat transfer coefficients from literature and CFD simulation. The mesh quality and near wall treatment are discussed. The results show that a simplified geometry of the dummy is sufficient for thermal environment studies and evaluations in CFD simulations.

The results from coupled simulations show that the numerical method can be unstable in the segments with low metabolism and low blood flow, as the feet and hands. So, it's intended to introduce mechanisms in the methodology to automatically identify this phenomenon and to avoid the divergence of the method to make more robust this methodology.

Keywords: Computational Fluid Dynamics, Heat Transfer, Thermal Environment. 


\section{Sumário}

Lista de Abreviaturas $\quad$ vi

Lista de Figuras $\quad$ vii

Lista de Tabelas $\quad$ ix

1 Introdução $\quad 1$

1.1 Motivações . . . . . . . . . . . . . . . . . . . . . . . . . . . . 3

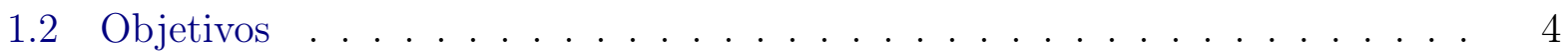

1.3 Organização do trabalho . . . . . . . . . . . . . . . . . . . . 5

2 Revisão Bibliográfica $\quad 6$

2.1 Simulação do ambiente térmico . . . . . . . . . . . . . . . . . . 7

2.2 Modelos de sistema térmico do corpo humano . . . . . . . . . . . . . . . 11

2.3 Integração de CFD com modelo de corpo humano . . . . . . . . . . . . . . . 12

3 Modelos Físicos $\quad 17$

3.1 Dinâmica dos Fluidos Computacional . . . . . . . . . . . . . . . . 18

3.1.1 Malhas computacionais . . . . . . . . . . . . . . . . . . 18

3.1.2 Equações de conservação . . . . . . . . . . . . . . . . . . . . . . . . . 19

3.1.3 Condições de contorno . . . . . . . . . . . . . . . . . . . . . . 23

3.1.4 Modelagem da turbulência . . . . . . . . . . . . . . . . . . . . . . . 24

3.1.5 Método dos Volumes Finitos . . . . . . . . . . . . . . . . . . . . 32

3.2 Modelagem da radiação térmica . . . . . . . . . . . . . . . . . . . 33

3.2 .1 Introdução . . . . . . . . . . . . . . . . . . . . . . . . . 33

3.2.2 Método dos Volumes Finitos de Ordenadas Discretas . . . . . . . . . 35

3.3 Simulador do corpo humano . . . . . . . . . . . . . . . . . . . . . . 38

3.3.1 Geometria e anatomia . . . . . . . . . . . . . . 38

3.3.2 Modelo matemático . . . . . . . . . . . . . . . . . . . . . 39

4 Simulações $\quad 44$

4.1 Validação geométrica . . . . . . . . . . . . . . . . . . . . . 44

4.1 .1 Conclusões . . . . . . . . . . . . . . . . . . . . . . 54 
4.2 Simulações integradas . . . . . . . . . . . . . . . . . . . . . 59

4.2 .1 Geometria e malha . . . . . . . . . . . . . . 59

4.2 .2 Metodologia numérica para integração . . . . . . . . . . . . . 60

4.2 .3 Condições de contorno . . . . . . . . . . . . . . . . . . 61

4.2 .4 Simulações e resultados . . . . . . . . . . . . . . . . . 62

4.2.5 Modificação no procedimento interativo . . . . . . . . . . . . 68

4.2 .6 Conclusões . . . . . . . . . . . . . . . . . . 70

$\begin{array}{lll}5 & \text { Conclusão } & 73\end{array}$

5.1 Sugestões para trabalhos futuros . . . . . . . . . . . . . . . . 75

A Avaliação experimental dos coeficientes de transferência de calor $\quad 76$

$\begin{array}{ll}\text { B Script } & 78\end{array}$

$\begin{array}{ll}\text { Referências Bibliográficas } & 81\end{array}$ 


\section{Lista de Abreviaturas}

USP Universidade de São Paulo

LETE Laboratory of Environmental and Thermal Engineering (Laboratório de Engenharia Térmica e Ambiental)

ASHRAE American Society of Heating, Refrigeranting and Air-conditioning Engineers (Associação Americana dos Engenheiros da Refrigeração, Ar Condicionado e Aquecimento)

ISO International Organization for Standardization (Organização para Padronização de Normas Técnicas)

ABNT Associação Brasileira de Normas Técnicas

CFD Computational Fluid Dynamics (Dinâmica dos Fluidos Computacional)

MSTCH Modelo do Sistema Térmico do Corpo Humano

CAD Computer Aided Design (Projeto Auxiliado por Computador)

PMV Predicted Mean Vote (Voto Médio Estimado)

MVF Método dos Volumes Finitos

EDP Equação diferencial parcial

EDO Equação Diferencial Ordinária

RTE Radiative Transfer Equation (Equação de Transferêmcia Tadiativa)

FVDOM Finite Volume Discrete Ordinates Method (Método dos Volumes Finitos de Ordenadas Discretas)

RANS Reynolds-Averaged Navier-Stokes Equations (Equações Médias das Equações de Navier-Stokes)

LES Large Eddy Simulation

DES Detached eddy simulation

RNG Renormalization Group Theory (Teoria do Grupo de Renormalização)

SST Shear Stress Transport

SIMPLE Semi-Implicit Method for Pressure-Linked Equations

IMC Índice de Massa Corporal

NHANES National Health and Nutrition Examination Survey

PIV Particle Image Velocimetry 


\section{Lista de Figuras}

1.1 Modelos necessários para análise de ambientes térmico e análise de conforto térmico. . . . . . . . . . . . . . . . . . . .

2.1 Resultados da convecção natural em cavidade. Temperatura do ar (esquerda), velocidade vertical (centro) e flutuação da velocidade vertical (direita) - extraído de Zhang et al. (2007). . . . . . . . . . . . . . . . . . . . . . . .

2.2 Resultados da convecção mista em cavidade. Temperatura (esquerda) e energia cinética turbulenta (direita) - extraído de Zhang et al. (2007). . . . . . . 10

2.3 Diagrama de conforto numérico e experimental - extraído em Nilsson (2007).

2.4 Resultados na superfície de manequim - Temperatura (esquerda), Convecção (centro) e radiação térmica (direita) - adaptado de Murakami et al. (2000). .

2.5 Resultados na superfície de manequim. Manequim com radiação solar nos membros inferiores (esquerda) e manequim livre de radiação (direita) - adaptado de Tanabe et al. (2002).

3.1 Distribuição de velocidade em camada limite de parede sólida. Adaptado de Versteeg e Malalasekera (2007).

3.2 Discretização espacial e direcional para o FVDOM. Volumes finitos (a) e discretização das direções em ângulos sólidos (b) - extraída de Modest (2003). 36

3.3 Representação geométrica utilizada no MSTCH. . . . . . . . . . . . . . . . . 39

4.1 Manequim real (a), manequim computacional simplificado (b) e manequim computacional complexo (c) . . . . . . . . . . . . . . . 45

4.2 Malha volumétrica próxima ao manequim. . . . . . . . . . . . . . . . . 46

4.3 Pluma térmica em torno do manequim complexo: insuflamento de ar a 0,05m/s. 47

4.4 Perdas de calor nas superfícies do manequim para escoamento quase estagnado (insuflamento a $0,05 \mathrm{~m} / \mathrm{s}$ ). Perdas de calor total $\left(W / m^{2}\right)$ (a) e perdas de calor

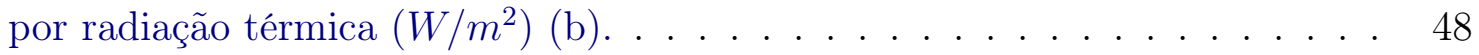

4.5 Perdas de calor total $\left(W / m^{2}\right)$ na mão do manequim complexo em simulação do escoamento a $5 \mathrm{~m} / \mathrm{s} . \ldots \ldots$. . . . . . . . . . . . . . 50

4.6 Vetores de velocidade do escoamento em plano de corte longitudinal. (a) insuflamento a $0,05 \mathrm{~m} / \mathrm{s}$, (b) insuflamento a $0,2 \mathrm{~m} / \mathrm{s}$ e (c) insuflamento a $0,5 \mathrm{~m} / \mathrm{s} . \quad 51$ 
4.7 Vetores de velocidade do escoamento em plano de corte longitudinal. (a) insuflamento a $0,8 \mathrm{~m} / \mathrm{s}$, (b) insuflamento a $3 \mathrm{~m} / \mathrm{s}$ e (c) insuflamento a $5 \mathrm{~m} / \mathrm{s}$. . .

4.8 Mapa de fluxo de calor total no manequim simplificado $\left(W / m^{2}\right)$. Simulação com insuflamento a $0,05 \mathrm{~m} / \mathrm{s}$ (a), insuflamento a $0,5 \mathrm{~m} / \mathrm{s}$ (b), insuflamento a $3 \mathrm{~m} / \mathrm{s}(\mathrm{c})$ e insuflamento a $5 \mathrm{~m} / \mathrm{s}(\mathrm{d}) \ldots \ldots \ldots \ldots$

4.9 Contorno de $y^{+}$no manequim simplificado (a) e complexo (b) para velocidade do escoamento igual a $5 \mathrm{~m} / \mathrm{s} \ldots \ldots . \ldots . \ldots . \ldots 53$

4.10 Comparação dos resultados do coeficiente de convecção: Membros superiores 55

4.11 Comparação dos resultados do coeficiente de convecção: Membros inferiores . 56

4.12 Comparação dos resultados do coeficiente de convecção: cabeça, peito, costas, pélvis e média no corpo inteiro . . . . . . . . . . . . . . . . .

4.13 Manequim cilíndrico no interior de sala com insuflamento de ar inferior. Vista isométrica (a) e vista superior (b) . . . . . . . . . . . . . . . .

4.14 Malha computacional para a simulação integrada preliminar. Malha volumétrica no domínio do escoamento (a) e malha superficial no manequim (b). . . . . . 60

4.15 Metodologia de integração numérica. . . . . . . . . . . . . . . . 61

4.16 Temperatura média da superfície da pele $\left({ }^{\circ} \mathrm{C}\right)$ em função do número da interação. Tronco, cabeça e pescoço $(\mathrm{a})$ e braços $(\mathrm{b})$. . . . . . . . . . . . . . .

4.17 Temperatura média da superfície da pele $\left({ }^{\circ} \mathrm{C}\right)$ em função do número da interação. Antebraços (a) e mãos (b). . . . . . . . . . . . . . . . . . .

4.18 Temperatura média da superfície da pele $\left({ }^{\circ} \mathrm{C}\right)$ em função do número da interação. Coxas (a) e pernas (b). . . . . . . . . . . . . . . . .

4.19 Temperatura média da superfície da pele dos pés $\left({ }^{\circ} \mathrm{C}\right)$ em função do número da interação. . . . . . . . . . . . . . . . . . . .

4.20 Temperatura média da superfície da pele dos pés $\left({ }^{\circ} \mathrm{C}\right)$ em função do número da interação. Segunda simulação - menor incremento do fator de relaxação e maior número de iterações da radiação no Fluent. . . . . . . . . . . . . . . . 67

4.21 Mecanismo de instabilização numérica. . . . . . . . . . . . . . . . . . . . . 68

4.22 Resultados da segunda bateria. Mapa de fluxo de calor por radiação (a), mapa de fluxo de calor total (a) e contorno de temperatura (c) . . . . . . . . . .

4.23 Temperatura média da superfície da pele $\left({ }^{\circ} \mathrm{C}\right)$ das mãos, obtido em simulação integrada com modificação no procedimento interativo . . . . . . . . . . 70

4.24 Temperatura média da superfície da pele $\left({ }^{\circ} \mathrm{C}\right)$ dos pés, obtido em simulação integrada com modificação no procedimento interativo . . . . . . . . . .

A.1 Esquemático experimental (de Dear et al.) . . . . . . . . . . . . . 


\section{Lista de Tabelas}

3.1 Parâmetros do modelo geométrico. . . . . . . . . . . . . . . . . . . 39

3.2 Coeficientes de transferência de calor utilizados no MSTCH. . . . . . . . . . 42

4.1 Segmentos dos manequins e áreas superficiais. . . . . . . . . . . . . . . 45

4.2 Parâmetros das camadas de prisma das malhas computacionais - altura e número de elementos. . . . . . . . . . . . . . . . . . . 46

4.3 Coeficientes de transferência de calor por radiação $h_{r}$ e por conveç̧ão natural $h_{c}$ para velocidade de escoamento abaixo de $\left.0,1 \mathrm{~m} / \mathrm{s} .{ }^{*}\right)$ coeficiente experimental. . . . . . . . . . . . . . . . . . . . . . . 49

4.4 Variação percentual dos coeficientes de transferência de calor por radiação $h_{r}$ e por convecção natural $h_{c}$ em relação aos resultados experimentais. . . . . 49

4.5 Valor médio do $y^{+}$ponderado pela área nos segmentos. . . . . . . . . . 54

A.1 Constantes A e b das equações de regressão $h_{c}=A v^{b}$ para o coeficiente de convecção forçada em função da velocidade do escoamento (de Dear et al.,

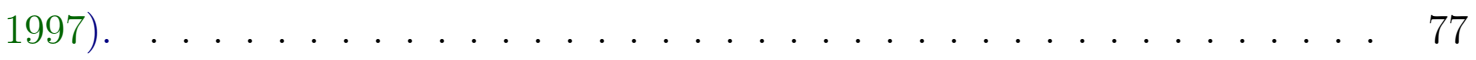




\section{Capítulo 1}

\section{Introdução}

A indústria tem investido recursos para o desenvolvimento de técnicas aplicadas ao conforto térmico, tanto voltado aos consumidores e clientes finais dos produtos ofertados quanto para a força de trabalho envolvida na produção. A satisfação, a preferência dos consumidores e a produtividade dos trabalhadores contribuem para a competitividade empresarial.

Neste sentido, as empresas e a academia têm se esforçado em melhorar as ferramentas disponíveis e em desenvolver novas metodologias para a análise de ambientes térmicos com vistas a propiciar condições de conforto térmico e para a fabricação de equipamentos e materiais voltados ao conforto.

Segundo Guan et al. (2003c), um modelo completo para análise do conforto térmico deve incluir:

a) Um modelo físico de troca de calor e um modelo de vestimenta para tratar da interação entre o corpo humano e o ambiente;

b) Um modelo de termorregulação fisiológica do corpo humano que simule o corpo humano em termos dos sistemas passivo e ativo;

c) Um modelo de sensação térmica psicológica para prever a resposta do ser humano ao ambiente baseado nas informações dos dois modelos anteriores.

Os dois primeiros modelos - modelo físico de troca de calor com o ambiente e modelo de termorregulação fisiológica - são suficientes para análise de ambientes térmicos. A inclusão de um modelo psicológico é fundamental para ferramentas que visem avaliação de conforto térmico (Tribess, 2008). Um modelo psicológico pode ser uma ferramenta para mensurar o conforto ou satisfação com o ambiente térmico, como alguma correlação obtida experimentalmente ou cartas de sensação térmica de cinco pontos: muito quente, quente, neutro, frio e muito frio. A Fig.1.1 relaciona os modelos citados com as formas de análise.

O modelo de Fanger é o primeiro modelo completo de análise de conforto térmico (Fanger, 1972) e o mais amplamente citado e utilizado. O modelo de Fanger foi desenvolvido para troca de calor sob regime permanente. O modelo geométrico é bastante simplificado, por 


\section{Conforto térmico}

\section{Ambiente térmico}

Modelo físico

Modelo de termorregulação

Modelo psicológico

Figura 1.1: Modelos necessários para análise de ambientes térmico e análise de conforto térmico.

isso o modelo desenvolvido por Fanger é limitado para avaliações de conforto global ${ }^{1}$. O efeito da vestimenta é contabilizado como resistência térmica adicional, a termorregulação é descrita pela temperatura da pele e pela troca de calor por transpiração e a sensação térmica é descrita pelo voto médio estimado, PMV.

Outro modelo de larga utilização é o modelo de Gagge (Gagge et al., 1971). Este é baseado no balanço de energia em regime transiente e também considera resistência térmica adicional da roupa. O corpo humano é representado por um cilindro dividido em duas camadas concêntricas - o núcleo e a pele - mais um reservatório de sangue. A sensação térmica é descrita pelo índice de temperatura efetiva, quer seja a temperatura de um ambiente com o ar saturado e estagnado que provoca a mesma sensação térmica que o ambiente real.

Os trabalhos posteriores concentraram esforços em aumentar a aplicabilidade dos modelos pela introdução de ferramentas com capacidade para modelar mais fenômenos responsáveis pelo conforto térmico. Foram introduzidos modelos multi-segmentados e multi-camadas em substituição ao modelo de cilindro único, para melhorar a discretização do corpo humano. Também foram incluídos modelos mais detalhados do sistema circulatório, do sistema termorregulador, da respiração e da vestimenta. Uma evolução histórica e descrição dos modelos são apresentadas na seção 2.2 .

Nas últimas décadas os programas de Dinâmica dos Fluidos Computacional (CFD Computational Fluid Dynamics) surgiram como alternativa para análise de ambientes térmicos, sobretudo a partir da década de 1990. Com a dinâmica dos fluidos computacional as equações governantes do escoamento fluidodinâmico são resolvidas numericamente. Tem-se, portanto, um modelo físico para troca de calor entre o corpo humano e o meio envolvente. A roupa pode ser modelada como uma resistência térmica adicional. A temperatura da pele

\footnotetext{
${ }^{1}$ avaliação global considera o corpo humano como um todo, sem discriminar os vários segmentos do corpo
} 
ou dissipação térmica são condições de contorno.

As ferramentas de CFD são substitutas de ensaios experimentais, especialmente por evitar a construção de protótipos quando os custos são proibitivos. Atualmente, a fragilidade das ferramentas de CFD reside na modelagem da turbulência. Muitos esforços têm sido realizados para modelar os efeitos da turbulência no interior do escoamento e no escoamento próximo às paredes. Os desenvolvedores pretendem validar os programas de CFD para um número cada vez maior de tipos de escoamentos. Outros objetivos dos desenvolvedores são reduzir os custos computacionais e popularizar as ferramentas com programas de interface com usuário mais amigáveis.

Neste início de século XXI tem se verificado uma tendência em aliar ferramentas numéricas de CFD com modelos térmicos do corpo humano para resolver interativamente as trocas de calor no corpo humano e no meio envolvente. Esta é uma metodologia robusta para análise de ambientes térmicos. Tanto as propriedades do escoamento quanto as propriedades do corpo humano são calculados separadamente pelos modelos e as soluções são retroalimentadas como condição de contorno. Na seção 2.3 é apresentada a evolução histórica e são discutidas algumas metodologias de interação já implementadas.

No Departamento de Engenharia Mecânica da EPUSP vêm sendo desenvolvidas pesquisas em análise de ambientes térmicos há mais de uma década. Ferreira (1997) desenvolveu modelo térmico de corpo humano composto por um único cilindro representando o corpo humano. O interior do cilindro é dividido em camadas representando os tecidos do corpo humano: pele, gordura, músculo e osso. O trabalho considera condução de calor apenas na direção radial. Ferreira (2001) incluiu condução de calor tridimensional e desenvolveu modelo multisegmentado, composto por 15 elementos cilíndricos com seções transversais elípticas para representar a cabeça, tronco, braços, antebraços, mãos, coxas, pernas e pés. A partir do ano de 2000 foram iniciadas pesquisas em conforto térmico com ensaios experimentais em câmara climatizada representando ambientes de escritório (Leite, 2003). Algumas publicações comparam os ensaios com simulações de CFD. A partir de 2006 foram realizadas pesquisas envolvendo experimentos e simulações numéricas de CFD em mock-ups de cabines aeronáuticas. de Moura (2009) focou ensaios experimentais e Stancato (2009) realizou ensaios experimentais e simulações numéricas em cabine de aeronave.

\subsection{Motivações}

As soluções para conforto térmico, em geral, qualquer que seja o objetivo, devem visar também um melhor desempenho energético, pela adoção de técnicas de menor custo possível porém com rendimento adequado, conforme as condições climáticas que o ambiente de interesse está sujeito. Dentre os objetivos destacam-se o atendimento às normas vigentes para a saúde e o bem-estar dos ocupantes, a melhoria da produtividade e a melhor satisfação dos clientes finais. 
A lei brasileira $n^{\circ} 6.514$ de 22 de dezembro de 1977 estabelece critérios para ventilação adequada, vestimenta adequada e limites aceitáveis de conforto térmico nos artigos 176, 177 e 178, respectivamente. A norma brasileira NBR-16401 (ABNT, 2008) e as normas internacionais ISO-7730 e ASHRAE 55 estabelecem faixas de temperatura e de umidade relativa do ar para definir zonas de conforto.

Romero (2004) mostra que a qualidade do ar e o conforto térmico são apontados por usuários como os fatores mais importantes de bem-estar em ambientes climatizados de edificações. A demanda e a expectativa por melhores níveis de conforto são crescentes. Destacamse neste cenário, além dos projetos de arquitetura, os setores automobilístico e aeronáutico, onde são crescentes as pesquisas envolvendo conforto térmico. Também há preocupação com conforto térmico para animais, especialmente para atender a legislação vigente e alcançar maiores níveis de produtividade, como na atividade leiteira e de corte. São exemplos de técnicas de conforto nestas atividades a adoção de ventiladores e de aparelhos de ar condicionado e a diminuição da densidade de área ocupada pelos animais.

Para uma avaliação de ambiente térmico são necessários um modelo para transferência de calor com o meio envolvente e um modelo de termorregulação fisiológica do corpo humano. As ferramentas para análise de ambientes térmicos atuais exploram cada um desses modelos separadamente. Desta forma, um próximo passo em busca de uma ferramenta mais consistente é integrar as duas metodologias.

\subsection{Objetivos}

O objetivo principal deste presente trabalho é integrar a simulação numérica do ambiente térmico com a simulação numérica do sistema térmico de corpo humano, para avaliar as propriedades obtidas em ambos os modelos, quer sejam os campos de velocidade, de temperatura, as trocas térmicas por radiação e convecção, as respostas do sistema termorregulatório do corpo humano e a temperatura do corpo humano nos diversos segmentos. Pretende-se, desta forma, estabelecer uma ferramenta mais robusta para análises de ambientes térmicos. Visando aumentar a aplicabilidade da ferramenta é desejável que a metodologia proposta seja consistente para a avaliação de ambientes não homogênios. Os demais objetivos que acompanham o escopo principal desta dissertação são:

- investigar a influência da malha computacional nas simulações numéricas;

- definir modelo de turbulência adequado para simulação numérica de ambiente térmico;

- definir tratamento de parede adequado para simulação numérica de ambiente térmico;

- definir uma metodologia para integrar simulador do ambiente interno com simulador térmico do corpo humano;

- investigar a estabilidade numérica da metodologia de integração proposta. 


\subsection{Organização do trabalho}

O presente trabalho é organizado da seguinte maneira: No capítulo 2 é realizada uma revisão bibliográfica de trabalhos voltados à simulação numérica de ambientes térmicos e do corpo humano. No item 2.1 são discutidos os modelos de turbulência e sua aplicabilidade para avaliar ambientes internos e escoamentos com convecção natural, forçada ou mista. Também é discutida a modelagem da radiação térmica e da pluma térmica. No item 2.2 é apresentada uma evolução histórica dos modelos para avaliação do conforto térmico baseados na resposta do corpo humano, desde os modelos semi-empíricos do final da década de 1960 até os modelos analíticos e ferramentas numéricas. No item 2.3 são apresentados trabalhos envolvendo a integração das duas abordagens. São discutidas metodologias para o processo iterativo, as condições de contorno e a discretização do corpo humano.

No capítulo 3 são apresentados os métodos numéricos utilizados nas simulações no presente trabalho. No item 3.1 são apresentados e discutidos os métodos em CFD: malhas computacionais, modelos de turbulência, modelos de tratamento de parede e métodos para a discretização das equações envolvidas. No item 3.2 é apresentado o modelo de radiação térmica que é acoplado ao simulador de CFD. No item 3.3 é descrito o Modelo do Sistema Térmico do Corpo Humano (MSTCH) que é utilizado neste trabalho.

No capítulo 4 as simulações realizadas neste trabalho e seus resultados são discutidos. Na seção 4.1 é apresentado estudo de validação geométrica de dois manequins computacionais, a partir de resultados experimentais dos coeficientes de transferência de calor, extraídos da literatura. A qualidade das malhas e os desempenhos de cada geometria são discutidos. Na seção 4.2 são apresentadas as simulações com integração de simulação de CFD com Modelo de Sistema Térmico do Corpo Humano (MSTCH). São discutidas as geometrias e a qualidade da malha utilizada na simulação de CFD. Há uma discussão sobre estabilidade numérica e é apresentada proposta para corrigir a instabilidade numérica durante o processo interativo.

No apêndice A é apresentada uma breve revisão bibliográfica de trabalhos contendo avaliação experimental dos coeficientes de transferência de calor e são apresentados os resultados experimentais para o estudo de validação numérica de manequim na seção 4.1. No apêndice B é apresentado o script utilizado para integrar as ferramentas de CFD com MSTCH em ambiente LINUX. 


\section{Capítulo 2}

\section{Revisão Bibliográfica}

Em modelagem de conforto térmico distinguem-se duas classes de modelos. Há os Modelos de Sistema Térmico de Corpo Humano (MSTCH) que enfocam a transferência de calor no interior do corpo humano e as simulações de Dinâmica dos Fluidos Computacional (CFD) que calculam numericamente o escoamento em torno do corpo humano. Os MSTCH desenvolveram-se bastante desde a década de 1960. Os primeiros modelos eram empíricos, como em Fanger (1967). As respostas térmicas do corpo humano aos estímulos externos eram calculadas com equações baseadas em estudos estatísticos. Gradualmente, os MSTCH progrediram com a implementação de modelos analíticos e técnicas numéricas.

Os modelos de CFD, por sua vez, utilizam técnicas numéricas para resolver as equações que governam o escoamento do fluido e a transferência de calor. A popularização das ferramentas de CFD ocorreu fruto do vertiginoso desenvolvimento dos computadores e da capacidade de armazenamento, aumento da versatilidade e generalidade dos métodos numéricos para simular os problemas de engenharia e relativa simplificação para aplicação das técnicas computacionais (Maliska, 2004), por exemplo através de programas para simulação com interfaces mais amigáveis. O custo computacional e de tempo era demasiado para os primeiros computadores. Os programas de CFD evoluíram muito durante as duas últimas décadas. Atualmente, as técnicas em CFD são validadas para uma classe maior de problemas e novas técnicas surgem para modelar diferentes fenômenos no escoamento.

A simulação do corpo humano com MSTCH e a simulação do ambiente térmico com CFD são simulações complementares que podem ser integradas. Esta é uma metodologia vantajosa que vem sendo explorada por centros de pesquisa. As informações calculadas por ambos os modelos devem ser retroalimentadas. Desta forma, algumas condições de contorno são adaptadas durante o processo interativo, tornando ambas as simulações mais consistentes. Há muitos trabalhos que discutem e até implementam esta integração. No entanto, os resultados ainda são incipientes.

A seguir são apresentadas discussões a respeito da modelagem de conforto térmico. A primeira parte deste capítulo concentra-se na discussão da simulação do ambiente térmico com ferramentas de CFD. A segunda parte concentra-se na discussão dos MSTCH e a ter- 
ceira parte na discussão da integração de CFD com MSTCH. No apêndice A é apresentada uma breve revisão bibliográfica de estudos experimentais com avaliação dos coeficientes de transferência de calor, para estudo de validação dos modelos numéricos na seção 4.1.

\subsection{Simulação do ambiente térmico}

O ambiente térmico em torno de manequim pode ser calculado com simulação de CFD. Em geral, determinam-se os campos de velocidades e de temperatura do escoamento e a transferência de calor nas paredes e superfícies do corpo humano. Na maioria das vezes as temperaturas nas paredes e no corpo são condições de contorno prescritas antes do processo iterativo, bem como as propriedades do escoamento - velocidade, temperatura ou pressão - nas seções de insuflamento e exaustão do ar. Quando a concentração de umidade no ar é importante pode-se incluir a equação para transporte da umidade no CFD. Ainda, um modelo de radiação térmica poderá ser incluído.

Nos escoamentos de baixo número de Mach é comum utilizar modelo para escoamento incompressível. Todavia, nos problemas envolvendo conforto térmico, normalmente ocorre a formação de pluma térmica nas regiões mais próximas e acima das superfícies quentes do corpo humano, devido ao empuxo provocado pela queda da massa específica do ar com o aumento da temperatura, isto quando o número de Grashof ${ }^{1}$ supera o número de Reynolds ${ }^{2}$. Nestes casos, deve-se adotar um modelo de escoamento compressível para contabilizar esta variação da massa específica. Uma alternativa de baixo custo computacional é utilizar o modelo de Boussinesq, pois este admite massa específica variável apenas no termo responsável pelo empuxo dentro do sistema de equações.

A radiação térmica é importante no conforto térmico, sobretudo porque os escoamentos típicos apresentam baixa velocidade, assim a participação da convecção tende a ser menor. Murakami et al. (2000) e Kilic e Sevilgen (2008) mostram que a transferência de calor por radiação corresponde a mais de $35 \%$ do total de calor perdido por um manequim. Os mesmos autores obtêm perdas de calor por transpiração superiores a $20 \%$ e perdas por respiração pouco inferiores a $10 \%$. Os modelos numéricos de radiação podem ser incorporados à simulação das equações de transporte do CFD. A solução da energia por ambos os modelos pode ocorrer de forma acoplada ou desacoplada. Já a transpiração e a respiração costumam ser modeladas por equações empíricas nos MSTCH (Modelos do Sistema Térmico do Corpo Humano). No entanto, já existem trabalhos que simulam estes fenômenos. Gao e Niu (2005), por exemplo, utilizam condição de contorno para insuflamento periódico em nariz de manequim. Desta forma, os efeitos sobre o escoamento, como a distribuição de contaminantes, podem ser avaliados satisfatoriamente.

Um problema ainda não resolvido em CFD é a modelagem da turbulência. A simu-

\footnotetext{
${ }^{1}$ número de Grashof é um adimensional que expressa a relação entre as forças de empuxo e as forças viscosas na convecção natural

${ }^{2}$ número de Reynolds é um adimensional que expressa a relação entre forças de inércia e forças viscosas
} 
lação das menores escalas da turbulência só é viável para escoamento com baixo número de Reynolds, devido ao alto custo de computação e de tempo. Existem alguns modelos que representam a turbulência sem a necessidade de simular as menores escalas. Os modelos RANS (Reynolds Averaged Navier-Stokes Equations ou equações médias de Navier-Stokes) substituem as equações governantes instantâneas do escoamento por equações médias. Este procedimento requer a inclusão de novas equações ao sistema de equações original. Nesta classe são bastante difundidos os modelos $k-\epsilon$ e $k-\omega$ de duas equações. Os modelos LES (Large Eddy Simulation), por sua vez, calculam diretamente as maiores escalas e modelam apenas as menores escalas, definidas por um filtro. Os modelos DES são intermediários, já que utilizam modelo RANS no escoamento próximo às paredes e LES no escoamento afastado. Os modelos RANS, LES e DES (Detached Eddy Simulation) são discutidos com maior profundidade em (Wilcox, 1994).

Há muitas discussões a respeito dos modelos de turbulência no âmbito de análise de ambiente térmico. Gao e Niu (2005) dizem que os modelos $k-\epsilon$ (Wilcox, 1994) para baixo Reynolds e $k-\epsilon$ da Teoria de Grupo de Renormalização (RNG - Renormalization Group Theory) são os mais utilizados para a simulação do escoamento ao redor do corpo humano. Entende-se por modelos para baixos Reynolds aqueles modelos desenvolvidos para simular a camada limite sem função de parede. Os autores também defendem que o modelo $k-\epsilon$ para baixo Reynolds apresenta melhor desempenho para perda de calor na superfície de manequins e que $k-\epsilon$ padrão ou RNG $k-\epsilon$ são suficientes quando a ênfase é dada ao campo do escoamento. Sorensen e Voigt (2003) obtiveram resultados qualitativos aceitáveis com o modelo $k-\epsilon$ para baixo Reynolds. Nos resultados de CFD cerca de $40 \%$ do fluxo de calor deve-se à convecção e $60 \%$ à radiação, concordando com os ensaios experimentais onde $43 \%$ deve-se à convecção e $57 \%$ à radiação. As comparações entre os resultados numéricos e os resultados experimentais obtidos por técnica de PIV (Particle Image Velocimetry) ainda mostram que os resultados são satisfatórios, porém as velocidades verticais na pluma obtida por CFD são ligeiramente maiores, aproximadamente $10 \%$ superior em região $10 \mathrm{~cm}$ acima da cabeça do manequim $-0,275 \mathrm{~m} / \mathrm{s}$ contra $0,25 \mathrm{~m} / \mathrm{s}$.

Stamou e Katsiris (2006) discutem modelo para escoamento laminar e os modelos de turbulência SST $k-\omega, k-\epsilon$ padrão e RNG $k-\epsilon$. São realizadas comparações com resultados experimentais do escoamento em torno de manequim térmico em escritório. O modelo SST $k-\omega$ (Wilcox, 1994) apresentou os melhores resultados, no entanto exige malha mais refinada nas paredes. Os demais modelos mostraram-se suficientes para uma análise qualitativa do escoamento médio.

Zhang et al. (2007) trazem uma investigação mais aprimorada a respeito dos modelos de turbulência. Os autores testam os modelos de duas equações v2f (Wilcox, 1994), SST $k-\omega$ e RNG $k-\epsilon$, além de LES e DES. Os modelos são analisados em escoamento particulares como convecção natural, conveç̧ão mista, convecção forçada e forte convecção natural. A convecção natural é modelada por uma cavidade bidimensional estreita com uma de suas faces aquecida e a face oposta resfriada. A convecção mista é modelada por cavidade 

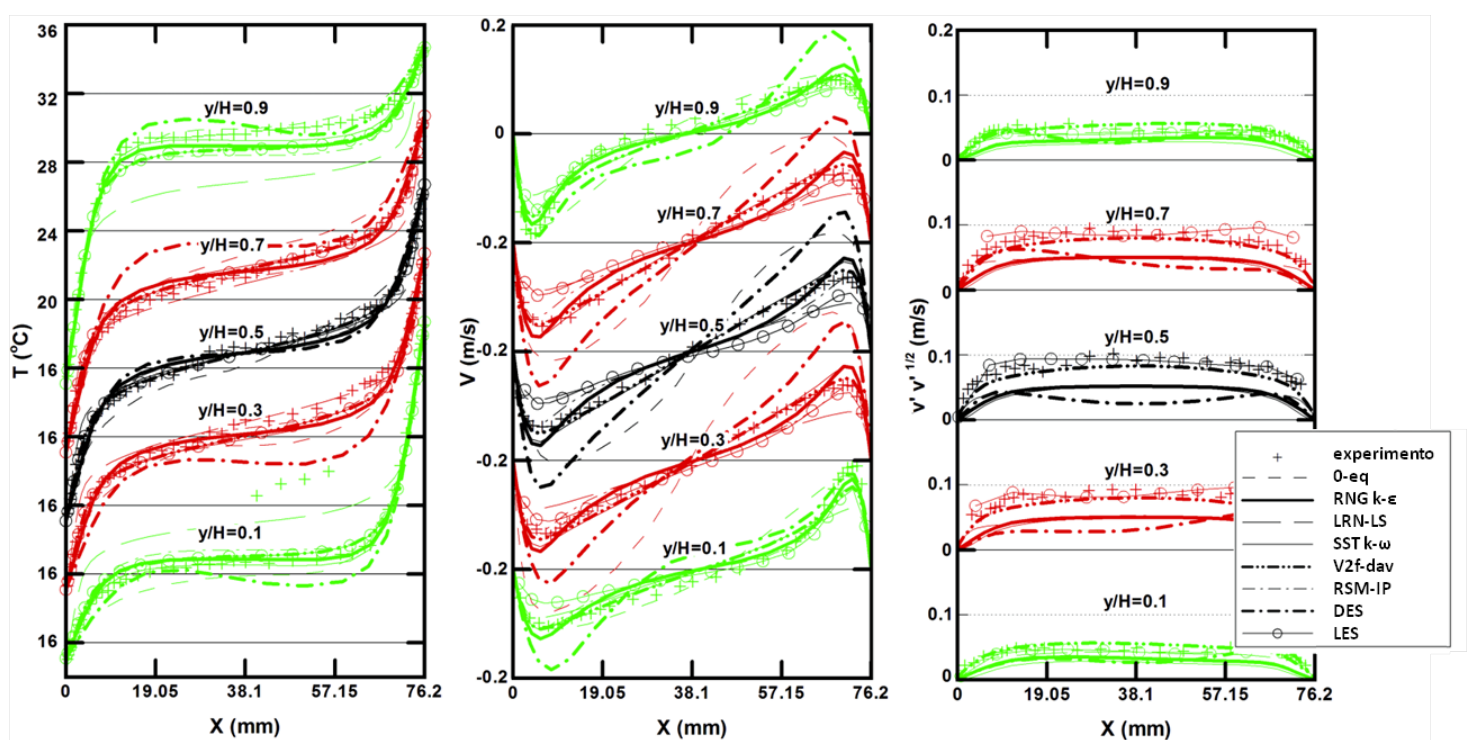

Figura 2.1: Resultados da convecção natural em cavidade. Temperatura do ar (esquerda), velocidade vertical (centro) e flutuação da velocidade vertical (direita) - extraído de Zhang et al. (2007).

quadrada bidimensional, com insuflamento de ar a $0,57 \mathrm{~m} / \mathrm{s}$ em um dos cantos. Uma das paredes é mantida fria a $15^{\circ} \mathrm{C}$ e as demais são mantidas quentes a $35,5^{\circ} \mathrm{C}$. A convecção forçada é modelada com escoamento isotérmico a $25^{\circ} \mathrm{C}$ e insuflamento de ar a $3 \mathrm{~m} / \mathrm{s}$ em um dos cantos. O escoamento com forte convecção natural é modelado em sala com parede de fogo, com potência térmica de $9,1 \mathrm{~kW}$. Os autores sumarizam as seguintes conclusões para cada tipo particular de escoamento:

Convecção natural: $\mathrm{O}$ modelo LES e principalmente o v2f apresentaram os melhores desempenhos. Segundo (Zhang et al., 2007), o modelo RNG $k-\epsilon$ subestima a derivada da velocidade vertical em relação à coordenada horizontal $\left(\frac{\partial v}{\partial x}\right)$, conforme mostra a Fig.(2.1). Isto afeta o cálculo do termo de produção da energia cinética turbulenta, prejudicando ainda mais os resultados.

Convecção mista: LES e v2f também têm os melhores desempenhos. A Fig.(2.2) mostra os resultados. O modelo SST $k-\omega$ tem desempenho ruim para energia cinética turbulenta. O autor sugere uma validação para o modelo em escoamento com baixa turbulência.

Convecção forçada: O modelo SST $k-\omega$ novamente apresenta resultados ruins. A princípio deveria apresentar desempenho similar ao $k-\epsilon$ nas regiões mais afastadas da parede. Por esta razão, a função de mistura ${ }^{3}$ deve ser validada em situações envolvendo alta turbulência em regiões afastadas de paredes, como em problemas típicos de conforto térmico.

Forte convecção natural: Todos os modelos de turbulência apresentaram bons resultados quanto à velocidade média. O modelo RNG $k-\epsilon$ subestima a flutuação da velocidade turbulenta na região próxima ao piso.

Zhai et al. (2007) sumarizam os progressos na modelagem da turbulência para simulação

\footnotetext{
${ }^{3}$ a função de mistura conduz ao modelo $k-\omega$ em regiões próximas às paredes e ao modelo $k-\epsilon$ em regiões distantes da parede, em função da distância para a parede mais próxima à célula.
} 

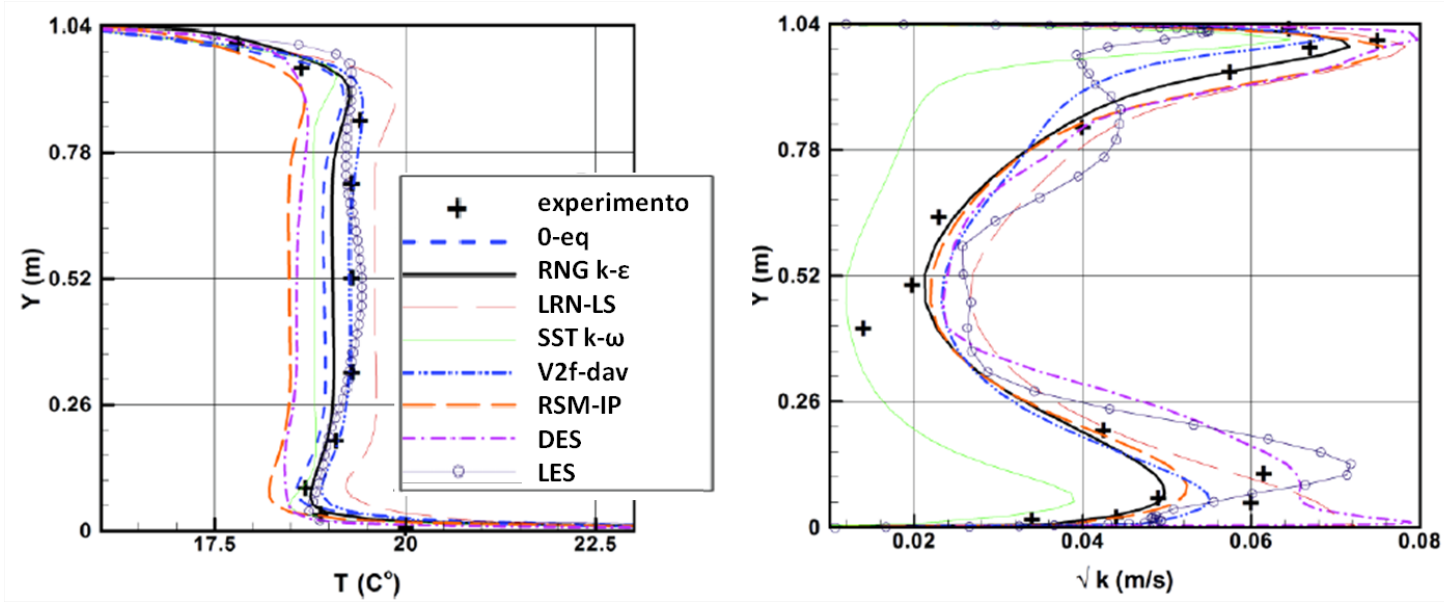

Figura 2.2: Resultados da conveç̧ão mista em cavidade. Temperatura (esquerda) e energia cinética turbulenta (direita) - extraído de Zhang et al. (2007).

do escoamento em ambientes interiores. São identificados os modelos com maior potencial para modelar a distribuição do ar. Os seguintes aspectos podem ser levantados baseando-se nos trabalhos citados:

- O modelo $k-\epsilon$ padrão com função de parede é ainda muito utilizado e fornece resultados aceitáveis a um baixo custo computacional. O modelo apresenta dificuldades em situações especiais como convecção natural e grande gradiente de temperatura;

- O modelo RNG $k-\epsilon$ fornece resultados similares ou um pouco superior;

- Modelos de zero ou uma equação com coeficientes sintonizados são apropriados para escoamentos similares, tanto quanto modelos mais desenvolvidos (às vezes até melhor);

- O modelo Reynolds Stress pode capturar alguns detalhes do escoamento não modelados pelos modelos $k-\epsilon$. As melhoras podem não ser justificadas devido ao custo computacional e tempo de processamento;

- O modelo $k-\omega$ é um candidato em potencial para simular ambientes fechados com boa acurácia e estabilidade numérica. Estudos indicam que SST $k-\omega$ tem desempenho melhor que $k-\epsilon$ padrão e RNG $k-\epsilon$. No entanto, ainda falta uma avaliação sistemática deste modelo para escoamentos no interior de ambientes. Devem ser realizados estudos de validação em escoamento com pouca turbulência. A função de mistura deve ser mais bem analisada e compreendida;

- Modelo LES fornece previsões mais detalhadas e acuradas do escoamento em interiores, por isso é importante para o entendimento dos mecanismos do escoamento. No entanto, a demanda computacional torna o seu uso proibitivo para a maioria dos problemas;

- Modelo DES pode ser uma opção intermediária, mas ainda requer estudos, melhoras e validações. 


\subsection{Modelos de sistema térmico do corpo humano}

Os primeiros trabalhos em conforto térmico com enfoque para a saúde e produtividade do trabalhador datam da década de 1930 na Inglaterra, período logo após o grande crescimento da industrialização. Vernon e Warner (1932) apud de P. Xavier e Bedford (1936) apud de P. Xavier efetuaram estudos empíricos com operários em indústrias. Após a segunda guerra mundial, a partir da década de 1960, aumentou muito o número de trabalhos envolvendo modelos do sistema térmico do corpo humano (MSTCH), notadamente em virtude da revolução nas relações trabalhistas. Stolwijk (1970) apud Tanabe et al. (2002) desenvolveu um modelo matemático de termorregulação que inclui a anatomia e fisiologia do corpo humano e processos de transferência de calor internos e externos ao corpo humano.

Fanger (1972) desenvolveu um modelo baseado em resultados experimentais desenvolvido em câmara climatizada. As respostas no corpo humano são avaliadas por modelos empíricos. O modelo apresenta muitas limitações. O balanço térmico no interior do corpo humano é calculado para regime permanente. Consequentemente, o modelo torna-se válido, apenas, em condições de conforto, por isso é limitado para uma faixa de atividade física e de condições ambientais. Outra limitação é que o modelo fornece uma avaliação global ${ }^{4}$ de conforto térmico.

Posteriormente ao trabalho de Fanger outros modelos foram desenvolvidos. Foi gradativa a inserção de novas tecnologias para diminuir as limitações. Hoje, a maior parte dos MSTCH modelam o sistema passivo, o sistema termorregulador, a respiração e a transpiração. Alguns modelos incluem a vestimenta como resistência térmica adicional.

Gagge et al. (1971) introduziram um modelo formulado para regime transiente. O modelo de Pennes é utilizado para calcular a transferência de calor entre sangue e tecidos. Este modelo resulta num sistema de equações diferenciais ordinárias com solução numérica. Os autores também introduziram um modelo de sistema termorregulador. As temperaturas na pele e no interior do corpo são comparadas com valores de referência para controlar os mecanismos vasomotor, de produção de suor e os calafrios. O modelo de Gagge ainda limitase a análises de conforto global. O corpo humano é representado por um único cilindro, dividido em duas camadas. É utilizada a análise concentrada nas camadas, por isso também é denominado modelo de 2-nodos de Gagge.

Entre os anos de 1970 e 1990 foram desenvolvidos modelos multi-segmentados e multicamadas, como os modelos de Wissler (1985) apud Ferreira (2001), Takemori et al (1995) apud Ferreira (2001), Fiala et al. (1999), Ferreira (2001) e Tanabe et al. (2002). Estes modelos possibilitaram análises de conforto térmico local ${ }^{5}$. Os modelos passaram a discretizar o corpo humano em cilindros de base circular, divididos em camadas concêntricas para melhor representar os diferentes tecidos do corpo humano. Também foram criados modelos

\footnotetext{
${ }^{4}$ subentende-se como uma avaliação do corpo como um todo, sem discriminar as várias partes do corpo humano.

${ }^{5}$ Diferente da análise global, permite uma análise de conforto localmente nos segmentos do corpo humano
} 
mais completos do sistema circulatório e introduzidos modelos de respiração que distribuem espacialmente as perdas de calor devido ao ar inspirado e expirado, ao longo da cabeça, pescoço e peito.

Fiala et al. (1999) desenvolveram modelo multi-segmentado composto por uma esfera, para representar a cabeça, e 14 cilindros para representar os demais segmentos do corpo humano. Cada segmento é subdividido em cérebro, pulmão, osso, músculo, víscera, gordura e pele. Uma inovação do modelo de Fiala et al. é considerar três setores angulares nos elementos. Isto é vantajoso porque contabiliza as assimetrias de transferência de calor entre o corpo e o ambiente. O modelo de Fiala et al. utiliza modelo de circulação de sangue de Pennes e considera transferência de calor contra-corrente entre artérias e veias. É implementado o mesmo modelo de respiração utilizado por Fanger: 45\% do calor transferido na respiração são perdidos nos músculos da face, $25 \%$ nos músculos do pescoço e $30 \%$ no pulmão. O modelo considera condução de calor nos tecidos unidimensional, na direção radial.

Ferreira (2001) desenvolveu modelo composto por 15 cilindros apresentando seção transversal elíptica. Esta é uma característica inovadora que melhora a representabilidade do corpo humano. Outra vantagem do modelo de Ferreira é considerar condução tridimensional nos segmentos. Ferreira também utiliza modelo de circulação do sangue de Pennes e considera transferência de calor contra-corrente entre artérias e veias. São dois reservatórios de sangue em cada cilindro, um de sangue arterial e outro venoso. É utilizado o mesmo modelo de respiração proposto por Fanger. As equações de condução de calor são resolvidas numericamente pelo Método dos Volumes Finitos (MVF).

Posteriormente, alguns pesquisadores concentraram-se no desenvolvimento de modelos multi-nodos com análise concentrada, como no modelo de Gagge et al., porém mais complexos pela inclusão de novas ferramentas para modelar os fenômenos de transferência de calor e inclusão de geometrias multi-segmentadas para permitir avaliações de conforto local. Tanabe et al. (2002) utilizam modelo de 65-nodos baseado no modelo de Stolwijk (1970) apud Tanabe et al. (2002). O corpo humano é dividido em 16 segmentos, cada qual com quatro nós representando os tecidos do corpo humano: pele, gordura, músculo e núcleo. O reservatório de sangue central é representado por um único nó. Portanto, são 16x4 camadas de tecido mais um reservatório de sangue central, totalizando 65 nós. As camadas de tecido trocam calor por condução entre si e o reservatório de sangue troca calor por convecção com as quatro camadas. Cada nó apresenta uma equação de balanço onde são incluídas demais termos de transferência de calor, como respiração, evaporação e transferência de calor com o ambiente.

\subsection{Integração de CFD com modelo de corpo humano}

Uma análise completa de conforto térmico implica em resolver tanto a transferência de calor no interior do corpo humano quanto fora, no meio envolvente. Nas últimas décadas, os 


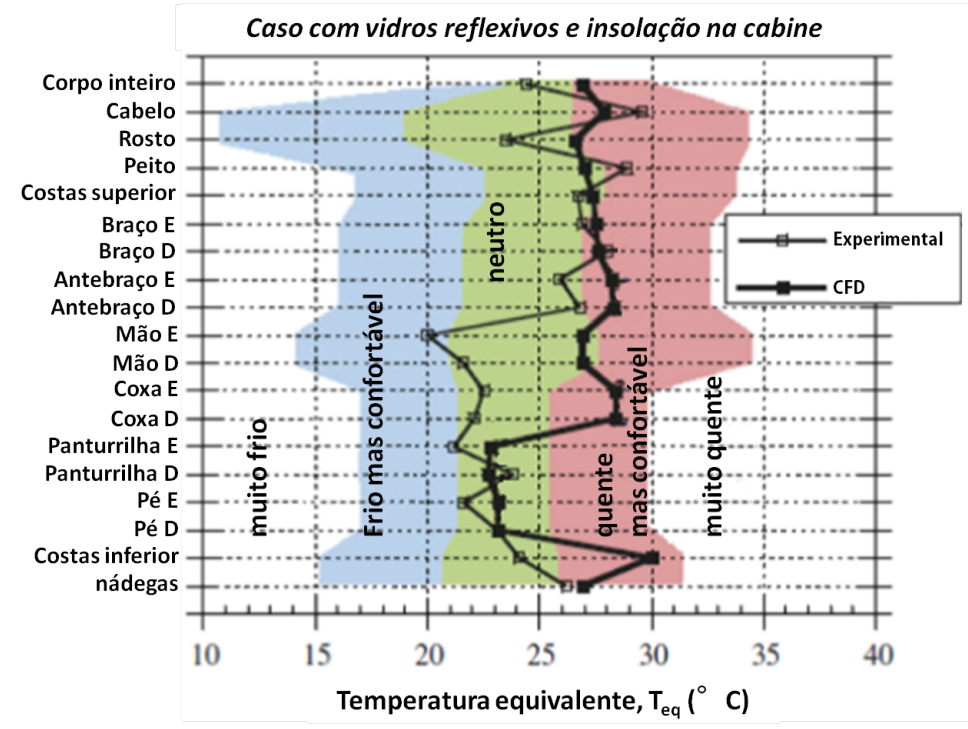

Figura 2.3: Diagrama de conforto numérico e experimental - extraído em Nilsson (2007).

MSTCH e as ferramentas de CFD desenvolveram-se paralelamente. Os MSTCH tornaram-se muito complexos e as ferramentas de CFD foram aprimoradas pelos desenvolvedores e validadas para várias aplicações. Nos últimos anos surgiram muitos trabalhos que integram estas duas metodologias. Atualmente, os pesquisadores e analistas em conforto térmico procuram por técnicas mais consistentes e confiáveis baseando-se neste acoplamento.

Notadamente, os modelos mais simples são melhores para implementar nas ferramentas de CFD. Correlações empíricas como o modelo de Fanger podem ser aplicadas diretamente nas condições de contorno. Gao e Niu (2005) utilizam a correlação dada por Fanger $t_{\text {pele }}=35,77-0,028 M$. O metabolismo $M$ é a única variável independente que interfere na temperatura do manequim. Este procedimento fornece uma avaliação global. Nilsson (2007) também utiliza modelo empírico, porém a temperatura do manequim é calculada continuamente num processo interativo com o programa de CFD. Para isso, Nilsson (2007) implementa uma sub-rotina FORTRAN em programa comercial de CFD. A avaliação de conforto é realizada localmente em manequim com 18 segmentos. Ainda, Nilsson (2007) elabora uma ferramenta para criar os diagramas de conforto diretamente, a partir dos resultados da simulação numérica. O autor propõe uma equação relacionando a temperatura de equilíbrio do manequim e a resistência térmica da vestimenta com a porcentagem de voto médio MTV definido em Fanger (1972). A Fig.2.3 mostra resultados para manequim no interior de um caminhão, sujeito à radiação solar na parte mais superior do corpo. Os resultados são melhores em ambientes mais uniformes.

Também surgiram trabalhos propondo uma integração mais completa de ferramenta de CFD com MSTCH. De uma forma geral, as simulações integradas partem de condições de contorno preliminares definidas geralmente para o modelo de CFD ou modelo MSTCH ou ainda modelo de Radiação Térmica. As soluções obtidas por cada um dos modelos são retroalimentadas como novas condições de contorno. Geralmente, as condições de contorno calculadas são as temperaturas superficiais do manequim e perdas de calor através da pele. 
O processo interativo é repetido várias vezes conforme o critério de parada, normalmente até convergirem as condições de contorno calculadas.

Murakami et al. (2000) integraram o modelo de 2-nodos de Gagge com simulação de CFD. São incluídos a equação de transporte de umidade e o modelo de radiação térmica. O modelo de 2-nodos ainda é bastante simples, porém os autores o adaptaram para avaliação local. É utilizada uma geometria do corpo humano bastante simples. No início da integração são utilizadas condições de contorno preliminares do corpo humano e do ambiente térmico, como metabolismo, temperatura da pele e temperatura do escoamento. O modelo de Gagge parte o processo iterativo, calculando a solução no corpo humano e fornecendo condições de contorno para a simulação de CFD. Os modelos de CFD e radiação térmica calculam o escoamento e a temperatura das paredes da sala acopladamente. Os resultados das simulações são retroalimentados. O processo é repetido até convergir a temperatura nas superfícies do manequim.

Os resultados em Murakami et al. concordam com os valores esperados. A temperatura calculada na região que representa os pés é menor que a média para o corpo inteiro, como mostra a Fig.(2.4). A perda de calor diminui no sentido do escoamento, tal como no problema de transferência de calor numa placa plana aquecida. As maiores perdas por radiação térmica concentram-se na região que representa o tronco do manequim, onde o fator de forma para as paredes da sala é maior.

Outros autores obtiveram resultados semelhantes. Kilic e Sevilgen (2008) utilizaram modelo de 2-nodos de Gagge também adaptado para avaliação de conforto local, no entanto utilizam geometria mais fiel ao corpo humano. O corpo humano é dividido em 17 segmentos. As maiores perdas de calor ocorrem nos pés, provavelmente devido à menor espessura da camada limite na região mais próxima ao insuflamento de ar. Além disso, a circulação sanguínea nos membros - pés e mãos - é menor. Kilic e Sevilgen obtiveram temperaturas também menores nas mãos.

Tanabe et al. (2002) utilizaram uma geometria bastante fiel ao corpo humano e integraram simulação de CFD com modelo 65-nodos ${ }^{6}$. Os autores também incluíram equação de transporte de umidade no simulador de CFD e modelo de radiação térmica. A malha do manequim conta com 1.542 elementos superficiais. Para a simulação da radiação térmica o manequim é mais detalhado, contando com 4.396 elementos.

No processo interativo entre os modelos de CFD e de MSTCH parte-se de condições de contorno preliminares e de um pré-cálculo da radiação solar absorvida. São realizados cálculos de CFD, de radiação térmica e de MSTCH, nesta sequência. O processo é repetido várias vezes. Os resultados obtidos em estudo de caso concordam com os valores esperados. A Fig.(2.5) mostra as temperaturas superficiais obtidas em dois manequins. O manequim à esquerda recebe radiação solar nas pernas e por isso apresenta-se com temperaturas maiores nesta região.

\footnotetext{
${ }^{6}$ modelo multi-nodos com quatro camadas em cada um dos 16 segmentos. São 4x16 camadas mais um reservatório de sangue.
} 


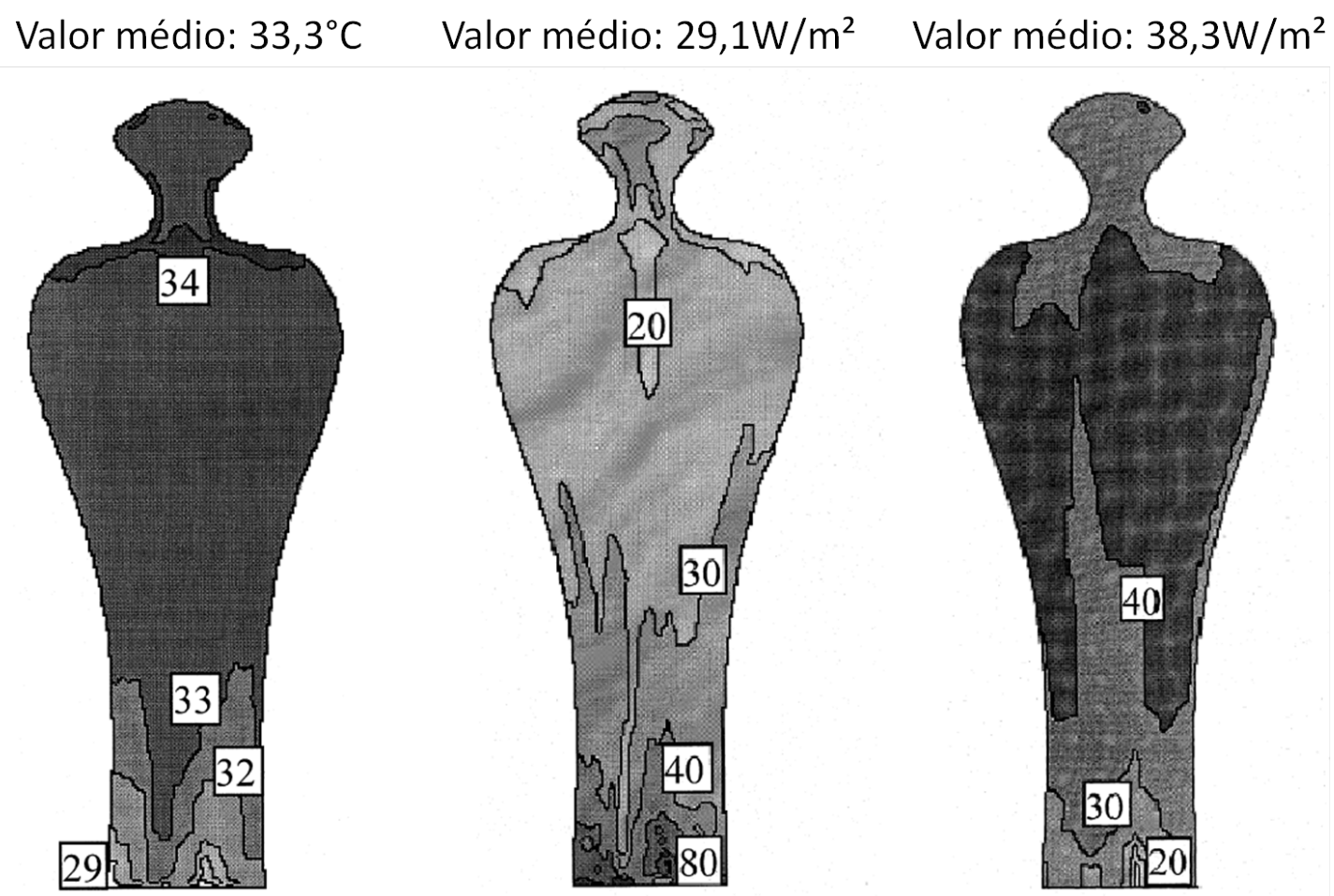

Figura 2.4: Resultados na superfície de manequim - Temperatura (esquerda), Convecção (centro) e radiação térmica (direita) - adaptado de Murakami et al. (2000).

Yang et al. (2007) integram ferramenta comercial de CFD com modelo de (Fiala et al., 1999). Os autores utilizam um manequim bastante fiel ao corpo humano, obtido por técnica de escaneamento a laser. Este maior detalhamento é vantajoso nos estudos de conforto térmico, sobretudo para calcular melhor a transferência de calor na pele e predizer a pluma térmica. Nas simulações de Yang et al. a transferência de informações, entre os programas de CFD e de MSTCH, é realizada via arquivo. Uma rotina escrita em FORTRAN é incluída no programa de CFD. Os resultados obtidos por ambos os modelos são retroalimentados e o processo interativo é repetido até o critério de parada.

Alguns trabalhos na literatura - Sorensen e Voigt (2003) e Gao e Niu (2005) - utilizam geometrias de manequim bastante complexas e fiéis ao corpo humano com a finalidade de calcular melhor as perdas de calor através da pele. Esta abordagem também pode contribuir para a precisão de outros resultados como distribuição do escoamento e previsão da pluma térmica, contudo é necessária uma investigação da influência geométrica sobre os resultados, pois a precisão dos modelos matemáticos e numéricos empregados em CFD e MSTCH podem tornar o incremento do detalhamento geométrico desnecessário, fazendo elevar o custo computacional sem acrescentar significativa precisão nos resultados de interesse para avaliação de ambientes térmicos.

Os MSTCH tomaram preferência por manequins multi-segmentados - Fiala et al. (1999), Ferreira (2001) e Tanabe et al. (2002). Uma análise de conforto térmico local oferece melhores respostas ao analista de conforto. inda, pode ser vantajoso dividir radialmente os segmentos do corpo humano para contabilizar as assimetrias do ambiente térmico. Outra tendência é 


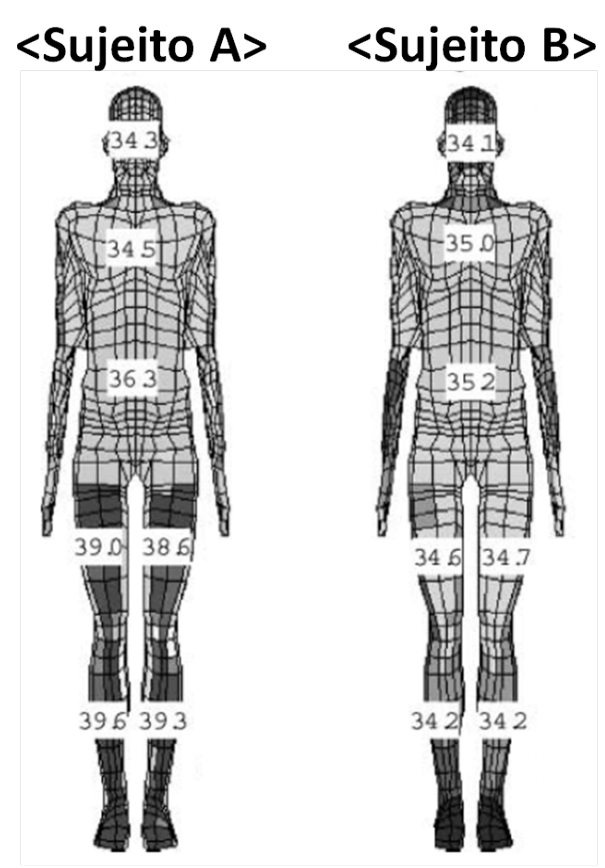

Figura 2.5: Resultados na superfície de manequim. Manequim com radiação solar nos membros inferiores (esquerda) e manequim livre de radiação (direita) - adaptado de Tanabe et al. (2002).

contabilizar demais processos de transferência de calor além da convecção, como radiação térmica e transferências de calor na transpiração e na respiração. 


\section{Capítulo 3}

\section{Modelos Físicos}

O escoamento em torno de manequim, aqui denominado ambiente térmico, é calculado por métodos numéricos da Dinâmica dos Fluidos Computacional (ou CFD). Numa primeira etapa devem ser identificadas a geometria e o domínio do escoamento de interesse, suas condições de contorno e os fenômenos físicos envolvidos. São utilizadas ferramentas CAD (Projeto Auxiliado por Computador ou Computer Aided Design) para desenhar o domínio computacional do escoamento. Em seguida, o domínio do escoamento é discretizado numa malha computacional. No presente trabalho é utilizado o software ICEM@ da ANSYS para gerar a malha. Antes de processar a simulação deve-se escolher as equações de interesse e os modelos matemáticos conforme o tipo de fluido e fenômenos físicos envolvidos. No simulador de CFD as equações governantes do escoamento são resolvidas iterativamente pelo MFV no domínio computacional discretizado. Neste trabalho é utilizado o simulador comercial

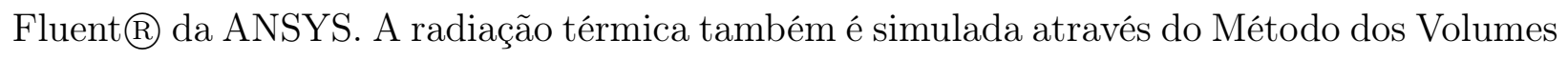
Finitos de Ordenadas Discretas (FVDOM - Finite Volume Discrete Ordinates Method). O processo iterativo termina quando os resíduos das equações resolvidas convergem. Após a simulação é realizada a leitura e interpretação dos resultados. Maliska (2004) divide didaticamente as simulações de CFD em três etapas:

- pré-processamento: geração da geometria, geração da malha computacional e definição das condições de contorno apropriadas;

- processamento;

- pós-processamento: extração das quantidades de interesse.

As variáveis fluidodinâmicas presentes nas equações governantes são resolvidas ao nível dos elementos da malha computacional. As ferramentas de pós-processamento disponíveis permitem visualizar o domínio geométrico e a malha computacional, plotar contornos das variáveis escalares, vetores de velocidade e traçadores de particular e realizar animações. Para avaliações de ambiente térmico são importantes os contornos de temperatura e de fluxo de calor nas superfícies do manequim e a temperatura e velocidade no escoamento próximo. 
A condição térmica do corpo humano também é calculada por método numérico. Os mais modernos simuladores do sistema térmico do corpo humano discretizam o corpo humano em segmentos cilíndricos, como cabeça, pescoço, braços, mãos, antebraços, pernas, canelas, pés, peito, costas e abdômen. Os segmentos também são discretizados em camadas internas para representar os tecidos do corpo humano, como pele, músculos e ossos. As condições de contorno são parâmetros ambientais e individuais, como temperatura do ar e nível de atividade física, respectivamente. Aqui é utilizado o modelo de Ferreira e Yanagihara (2009) que utiliza o MVF para calcular as equações de transferência de calor.

A seguir são apresentados e discutidos os métodos numéricos de CFD, descritos em Versteeg e Malalasekera (2007). São apresentadas as equações governantes do escoamento, os tipos de condições de contorno e as equações adicionais para a modelagem da turbulência. Também é discutido o Método dos Volumes Finitos (MVF) e as técnicas envolvidas, como métodos de discretização, de acoplamento pressão-velocidade e de solução do sistema de equações. Posteriormente, é apresentado o modelo de radiação utilizado, também descrito em Versteeg e Malalasekera (2007). No final é apresentado o modelo do sistema térmico do corpo humano descrito em Ferreira e Yanagihara (2009).

\subsection{Dinâmica dos Fluidos Computacional}

\subsubsection{Malhas computacionais}

Malha computacional é uma representação do domínio do escoamento discretamente, por células ou volumes de controle menores, onde são calculadas as variáveis das equações governantes do escoamento e da transferência de calor. Ferziger e Peric (2002) e Blazek (2001) discutem mais aprofundamente os tipos de malha.

Blazek (2001) distingue dois tipos de malhas: estruturadas e não estruturadas. Nas malhas estruturadas os vértices ou nós apresentam identificação única e se equivalem às malhas cartesianas. Há vantagens em termos de memória no armazenamento das variáveis calculadas e de velocidade para acessar os vizinhos dos nós durante o processamento. Os elementos são quadriláteros numa malha 2-D e hexaédrico numa malha 3-D.

Numa malha não estruturada os nós ou vértices não apresentam ordenamento padrão, contudo são mais flexíveis para o tratamento de geometrias complexas. As malhas não estruturadas apresentam elementos triangulares numa malha 2-D e elementos tetraédricos numa malha 3-D. Também podem ser incorporados, junto às paredes, elementos quadriláteros numa malha 2-D e prismas e pirâmides numa malha 3-D, para tratar as camadas limites. Outra vantagem das malhas não estruturadas é o fato de haver algoritmos para gerar elementos triangulares e tetraédricos automaticamente, independentemente da complexidade da geometria (Blazek, 2001).

Neste trabalho são utilizadas malhas não estruturadas e mistas, com elementos tetraédricos na maior parte do domínio e elementos prismáticos junto às superfícies do manequim. 
Durante a geração das malhas foram utilizados os algoritmos Octree (Shephard e Georges, 1991) para gerar uma malha prematura e Delaunay (Cebeci et al., 2005). Da malha obtida por algoritmo Octree aproveita-se os elementos bidimensionais nas superfícies. Os elementos volumétricos da malha prematura são excluídos. Com o algoritmo Delaunay é obtida uma segunda malha volumétrica com maior qualidade. Por último, a camada de prismas é gerada a partir dos elementos superficiais, empurrando os elementos volumétricos mais próximos. Durante a etapa de geração de malha também são aplicados algoritmos para melhorar a qualidade da malha segundo a distribuição e formato dos elementos de malha.

\subsubsection{Equações de conservação}

As equações governantes da mecânica dos fluidos são equações de conservação definidas a partir da lei da conservação de massa, da conservação da quantidade de movimento pela $2^{a}$ lei de Newton e da conservação da energia pela da $1^{a}$ lei da termodinâmica. As equações representam matematicamente os seguintes enunciados:

- a massa do escoamento é conservada;

- a taxa de variação da quantidade de movimento é igual à soma das forças externas aplicadas ao fluido num volume de controle;

- a taxa de variação da energia é igual à soma do calor adicionado mais o trabalho realizado sobre o fluido num volume de controle.

Para o desenvolvimento das equações governantes é considerado um pequeno volume de dimensões finitesimais $\delta x, \delta y$ e $\delta x$ para descrever a taxa de variação das propriedades do fluido, quer seja o menor volume de controle em que as propriedades macroscópicas da matéria não são influenciadas por moléculas individuais. As propriedades do fluido que dependem do espaço e do tempo são escritas nas faces do volume conforme os dois primeiros termos da expansão em série de Taylor (Versteeg e Malalasekera (2007)).

\section{Conservação da massa}

A lei da conservação de massa pode ser descrita conforme a Eq.3.1 desenvolvida em Versteeg e Malalasekera (2007). O primeiro termo ao lado esquerdo da equação representa a taxa de incremento de massa num elemento de fluido. $\rho$ é a massa específica do fluido e $\delta x$, $\delta y$ e $\delta z$ são as dimensões do volume de controle considerado. Os termos à direita da equação representam a taxa líquida de massa para dentro do elemento de fluido, em que $u, v$ e $w$ são as velocidades do escoamento nas coordenadas $x, y$ e $z$ respectivamente.

$$
\frac{\partial}{\partial t}(\rho \delta x \delta y \delta z)=\left(\rho u-\frac{\delta(\rho u)}{\delta x} \frac{1}{2} \delta x\right) \delta y \delta z-\left(\rho u+\frac{\delta(\rho u)}{\delta x} \frac{1}{2} \delta x\right) \delta y \delta z+
$$




$$
\begin{aligned}
& +\left(\rho v-\frac{\delta(\rho v)}{\delta y} \frac{1}{2} \delta y\right) \delta x \delta z-\left(\rho v+\frac{\delta(\rho v)}{\delta y} \frac{1}{2} \delta y\right) \delta x \delta z+ \\
& +\left(\rho w-\frac{\delta(\rho w)}{\delta z} \frac{1}{2} \delta z\right) \delta x \delta y-\left(\rho w+\frac{\delta(\rho w)}{\delta z} \frac{1}{2} \delta z\right) \delta x \delta y
\end{aligned}
$$

A equação de conservação de massa pode ser reescrita cancelando-se os termos em repetição. Ainda, a equação pode ser escrita de forma compacta, como na Eq.3.2, utilizandose o operador divergente. O primeiro termo representa a variação temporal da massa por unidade de volume e o segundo termo é o termo de convecção que contabiliza a evasão de massa através das faces do volume de controle considerado.

$$
\frac{\partial \rho}{\partial t}+\operatorname{div}(\rho \vec{u})=0
$$

Para escoamentos incompressíveis vale $d i v \vec{u}=0$, portanto o termo convectivo na equação é nulo. Por conseguinte, o incremento de massa também será nulo conforme a Eq.3.2. Portanto, para fluidos incompressíveis valerá a Eq.3.3.

$$
\operatorname{div} \vec{u}=\frac{\partial u}{\partial x}+\frac{\partial v}{\partial y}+\frac{\partial w}{\partial z}=0
$$

\section{Equações de momento}

As Eqs.3.4, 3.5 e 3.6 são as equações de momento nas componentes $x, y$ e $z$, obtidas em Versteeg e Malalasekera (2007). Os termos à esquerda representam a taxa de incremento da quantidade de movimento por unidade de volume do fluido. Os termos após o sinal de igualdade representam a soma das forças de superfície que atuam nas faces de um elemento de fluido. $p$ é a pressão do escoamento e $\tau_{i j}$ é tensão de cisalhamento na face $i$ do volume de controle e direção $j$. As forças de corpo, como força gravitacional, eletromagnética, de Coriolis e centrífuga, são introduzidas nos termos fontes $S_{M x}, S_{M y}$ e $S_{M z}$.

$$
\begin{gathered}
\rho \frac{D u}{D t}=\frac{\partial\left(-p+\tau_{x x}\right)}{\partial x}+\frac{\partial \tau_{y x}}{\partial y}+\frac{\partial \tau_{z x}}{\partial z}+S_{M x} \\
\rho \frac{D v}{D t}=\frac{\partial \tau_{x y}}{\partial x}+\frac{\partial\left(-p+\tau_{y y}\right)}{\partial y}+\frac{\partial \tau_{z y}}{\partial z}+S_{M y} \\
\rho \frac{D w}{D t}=\frac{\partial \tau_{x z}}{\partial x}+\frac{\partial \tau_{y z}}{\partial y}+\frac{\partial\left(-p+\tau_{z z}\right)}{\partial z}+S_{M z}
\end{gathered}
$$

Para fluidos newtonianos as tensões viscosas $\tau_{x x}, \tau_{y y}, \tau_{z z}, \tau_{x y}, \tau_{x z}$ e $\tau_{y z}$ são proporcionais 
à taxa de deformação do fluido. Portanto, podem ser reescritas em função da viscosidade molecular $\mu$ e em função das derivadas parciais das velocidades nas faces do volume de controle. Após um remanejamento, as equações de momento são reescritas conforme as Eqs.3.7, 3.8 e 3.9. Estas são as equações de Navier-Stokes para fluido newtoniano.

$$
\begin{gathered}
\rho \frac{D u}{D t}=-\frac{\partial p}{\partial x}+\operatorname{div}[\operatorname{grad}(u) \mu]+S_{M x} \\
\rho \frac{D v}{D t}=-\frac{\partial p}{\partial y}+\operatorname{div}[\operatorname{grad}(v) \mu]+S_{M y} \\
\rho \frac{D w}{D t}=-\frac{\partial p}{\partial z}+\operatorname{div}[\operatorname{grad}(w) \mu]+S_{M z}
\end{gathered}
$$

Os termos à esquerda são as derivadas totais da quantidade de movimento. O primeiro termo após o sinal de igualdade é o termo de pressão, o segundo termo é o termo difusivo e o terceiro termo é o termo fonte.

No modelo utilizado a derivada total da quantidade de movimento é decomposta nos termos transiente e advectivo. A força de campo gravitacional $\rho \vec{g}$ é contabilizada no termo fonte.

\section{Conservação da energia}

Versteeg e Malalasekera (2007) obtém a Eq.3.10 para o transporte da energia. O primeiro termo antes do sinal de igualdade é a taxa de incremento de energia no fluido, em que $E$ é a energia específica do fluido, definido como a energia interna $i$ mais a energia cinética $\frac{1}{2}\left(u^{2}+v^{2}+w^{2}\right)$. O primeiro e o segundo termo após o sinal de igualdade são a taxa de realização de trabalho pelas forças de pressão e de cisalhamento, respectivamente. O terceiro é o termo de difusão que representa a condução térmica conforme lei de Fourier através das faces do volume de controle considerado. $k$ é o coeficiente de condução térmica e $T$ é a temperatura do escoamento. O último termo $S_{E}$ é o termo fonte, em que deve ser acomodado o saldo devido à radiação.

$$
\begin{array}{r}
\frac{\rho D E}{D T}=-\operatorname{div}(p \vec{u})+\left[\frac{\partial\left(u \tau_{x x}\right)}{\partial x}+\frac{\partial\left(u \tau_{y x}\right)}{\partial y}+\frac{\partial\left(u \tau_{z x}\right)}{\partial z}+\frac{\partial\left(v \tau_{x y}\right)}{\partial x}+\right. \\
\left.+\frac{\partial\left(v \tau_{y y}\right)}{\partial y}+\frac{\partial\left(v \tau_{z y}\right)}{\partial z}+\frac{\partial\left(w \tau_{x z}\right)}{\partial x}+\frac{\partial\left(w \tau_{y z}\right)}{\partial y}+\frac{\partial\left(w \tau_{z z}\right)}{\partial z}\right]+\operatorname{div}(\operatorname{kgradT})+S_{E}
\end{array}
$$

A equação da energia pode ser reescrita em termos da energia interna somente. Basta subtrair da energia total a energia cinética obtida a partir da multiplicação da equação de 
momento na direção $x, y$ e $z$ com a velocidade $u, v$ e $w$ respectivamente. No escoamento incompressível o divergente do vetor velocidade div $\vec{u}$ é nulo e a energia interna é diretamente proporcional à temperatura conforme $i=c T$, em que $c$ é o calor específico. Após desenvolvimento analítico obtém-se a seguinte equação da energia escrita em função da temperatura, para fluido incompressível:

$$
\begin{array}{r}
\rho c \frac{D T}{D t}=\operatorname{div}(\text { kgradT })+\tau_{x x} \frac{\delta u}{\delta x}+\tau_{y x} \frac{\delta u}{\delta y}+\tau_{z x} \frac{\delta u}{\delta z}+ \\
+\tau_{x y} \frac{\delta v}{\delta x}+\tau_{y y} \frac{\delta v}{\delta y}+\tau_{z y} \frac{\delta v}{\delta z}+\tau_{x z} \frac{\delta w}{\delta x}+\tau_{y z} \frac{\delta w}{\delta y}+\tau_{z z} \frac{\delta w}{\delta z}+S_{i}
\end{array}
$$

A equação da energia interna é escrita em termos da entalpia total $H$ no modelo de CFD utilizado, conforme a Eq.3.12. Os termos antes do sinal de igualdade representam a derivada total da entalpia decomposta nos termos transiente $\frac{\partial(\rho H)}{\partial t}$ e advectivo $\operatorname{div}(\rho \vec{u} H)$. O primeiro termo após o sinal da igualdade é o termo difusivo. $k$ é a condutividade térmica e $c_{p}$ é o calor específico a pressão constante. O termo fonte $S_{h}$ serve para incluir termos não conservativos. No presente trabalho o termo fonte deve incluir parcela devido à radiação térmica calculado pelo modelo de radiação térmica.

$$
\frac{\partial(\rho H)}{\partial t}+\operatorname{div}(\rho \vec{u} H)=\operatorname{div}\left(\frac{k}{c_{p}} \nabla H\right)+S_{h}
$$

Para escoamento incompressível não são incluídas a energia cinética nem a participação da pressão quando a solução é baseada na pressão. A participação das tensões de cisalhamento também não é incluída para escoamentos de baixa velocidade, uma vez que a dissipação viscosa tende a ser muito menor que a condução térmica nestes casos.

\section{Equação de estado}

As três leis de conservação dão origem a cinco equações: uma para conservação da massa, três equações para conservação da quantidade de movimento nas componentes $x, y$ e $z$ e uma equação para conservação da energia. Também é considerada uma equação de estado para fechar o sistema de equações nas incógnitas $\rho, u, v, w, T$ e $p$. Esta equação de estado pode ser formulada para escoamento compressível ou incompressível, quando a massa específica é constante.

Neste trabalho é considerado modelo para escoamento incompressível com solução baseada na pressão. Para contabilizar a pluma térmica é utilizado o modelo de Boussinesq que considera massa específica do fluido variável apenas no termo de empuxo $\left(\rho-\rho_{0}\right) g$ acomodado no termo fonte da equação de momento. A aproximação de Boussinesq impõe $\rho=\rho_{0} \beta\left(T-T_{0}\right) g$, em que $\rho_{0}$ é a massa específica de referência, com valor constante, $T_{0}$ é a temperatura operativa e $\beta$ é o coeficiente de expansão térmica. O modelo de Boussinesq pode ser aplicado 
nos escoamentos sem combustão ou sem reações químicas e quando há pequena variação de temperatura $\beta\left(T-T_{0}\right) \ll 1$ (Fluent Inc. (2006)).

\subsubsection{Condições de contorno}

As equações diferenciais parciais (EDP) podem ser classificadas matematicamente em três tipos de equações: elípticas, parabólicas e hiperbólicas. A Equação de Laplace é um exemplo de equação elíptica. As propriedades se propagam para todas as direções, tal como num problema de difusão. Nos problemas parabólicos e hiperbólicos as propriedades se propagam em direções preferenciais, como num problema predominantemente convectivo, portanto permitem procedimento de marcha durante a solução. Em problemas hiperbólicos a difusão é desprezível. Fortuna (2000) e Maliska (2004) discutem mais aprofundamente os tipos de equações.

As equações governantes da mecânica dos fluidos apresentam classificação matemática mista. Os termos advectivos das equações de Navier-Stokes exibem comportamento parabólico. A solução se propaga na direção do escoamento, não exigindo condições de contorno a jusante do escoamento. Já os termos difusivos e de pressão são termos elípticos. As informações se propagam para todas as direções, portanto requerem condições de contorno em toda fronteira do domínio.

É desejável que as EDP's apresentem solução única que dependa continuamente das condições auxiliares (de contorno e inicial). Há três tipos básicos de condições de contorno para as variáveis do escoamento. A condição de contorno será do tipo Dirichlet se a propriedade for especificada na fronteira, do tipo Neumann se o gradiente normal ou tangencial for especificado na fronteira, ou do tipo Robin se a condição de contorno for uma combinação linear entre Dirichlet e Neumann. A escolha ideal da condição de contorno depende do tipo do escoamento e das equações simuladas. A estabilidade numérica também é um critério para escolha dos tipos de condição de contorno.

Neste trabalho, nas paredes sólidas é utilizada condição Dirichlet para velocidade (condição de não escorregamento: $u_{\text {fluido }}=u_{\text {parede }}$ ) e condição Dirichlet para temperatura, i.e., paredes e pele com temperatura constante. Também poderia-se prescrever o fluxo de calor na pele do manequim (Neumann).

Nas fronteiras onde é insuflado o ar, pode-se prescrever velocidade fixa ou vazão constante (Dirichlet). A pressão e a temperatura também são prescritas (Dirichlet). Nas fronteiras onde ocorre a exaustão do escoamento pode-se prescrever pressão constante (Dirichlet) ou adotar gradiente normal de velocidade nulo (Neumann). Neste último caso a fronteira deverá estar distante do escoamento perturbado para tornar válida a condição de contorno.

As condições de contorno devem ser transferidas aos elementos de malha adjacentes à fronteira do domínio do escoamento. A seção 3.1.5 discute algumas formas de realizar esta tarefa em simuladores que utilizam o Método dos Volumes Finitos. 


\subsubsection{Modelagem da turbulência}

A maioria dos escoamentos na natureza são turbulentos, apresentando, portanto, flutuações randômicas e caóticas na velocidade e na pressão. A turbulência é essencialmente tridimensional, sendo caracterizada pela presença de estruturas rotacionais correlacionadas, também denominadas turbilhões ou eddies, com ampla faixa de escalas de comprimentos e de tempo. Segundo Kolmogorov (Pope (2000)) o escoamento turbulento apresenta uma cascata de energia. A energia cinética é transferida dos maiores turbilhões, com escalas de comprimento e de tempo da ordem de grandeza do escoamento médio, para os menores turbilhões, devido ao processo de estiramento dos vórtices (ou vortex stretching).

O custo computacional para calcular numericamente as menores escalas de comprimento e de tempo é proibitivo, dada a oferta tecnológica atual. É necessário utilizar, então, malhas muito refinadas e simulações com passos de tempo muito pequenos, suficiente o bastante para capturar as menores escalas da turbulência. Para contornar a limitação tecnológica e o custo computacional e de tempo, foram desenvolvidos alguns modelos capazes de incluir os efeitos da turbulência sobre o resultado da simulação numérica. Tennekes e Lumley (1972) e Pope (2000) discutem a turbulência. Versteeg e Malalasekera (2007) e Wilcox (1994) discutem os modelos de turbulência com ênfase maior na aplicação em métodos numéricos de CFD.

\section{Equações Médias de Navier-Stokes}

A escolha adequada do modelo de turbulência depende do grau de acuracidade exigido, dos tipos de fenômenos físicos envolvidos e do tipo de escoamento. Deve-se considerar as capacidades e limitações de cada modelo antes de escolhê-lo.

Neste trabalho é utilizado o modelo de turbulência $k-\epsilon$ que pertence à classe dos modelos RANS (Reynolds-averaged Navier-Stokes Equations). Este modelo utiliza a média de Reynolds nas equações de Navier-Stokes. Os modelos RANS contabilizam efeitos da flutuação turbulenta diretamente sobre um escoamento médio. As variáveis presentes nas equações governantes (componentes da velocidade, pressão, temperatura e demais quantidades transportadas) são reescritas utilizando-se decomposição de Reynolds, portanto contabilizando o termo médio e o de flutuação à variável instantânea, por exemplo $u=U+\tilde{u}$ para a velocidade na direção $x$. O modelo $k-\epsilon$ foca mecanismos que afetam a energia cinética turbulenta $k$.

A Eq.3.13 é a equação média da continuidade e as Eqs.3.14, 3.15 e 3.16 são as equações médias de Navier-Stokes, obtidas a partir da média de Reynolds aplicadas às respectivas equações. Versteeg e Malalasekera (2007) demonstram o desenvolvimento analítico.

$$
\frac{\partial \rho}{\partial t}+\operatorname{div}(\rho \vec{U})=0
$$




$$
\begin{aligned}
& \frac{\partial(\rho U)}{\partial t}+\operatorname{div}(\rho U \vec{U})=-\frac{\partial P}{\partial x}+\operatorname{div}[\operatorname{grad}(U) \mu]+ \\
& +\left[-\frac{\partial\left(\rho \overline{\tilde{u}^{2}}\right)}{\partial x}-\frac{\partial(\rho \tilde{\tilde{u} \tilde{v}})}{\partial y}-\frac{\partial(\rho \tilde{u} \tilde{w})}{\partial z}\right]+S_{M x} \\
& \frac{\partial(\rho V)}{\partial t}+\operatorname{div}(\rho V \vec{U})=-\frac{\partial P}{\partial y}+\operatorname{div}[\operatorname{grad}(V) \mu]+ \\
& +\left[-\frac{\partial(\rho \overline{\tilde{u} \tilde{v}})}{\partial x}-\frac{\partial\left(\rho \overline{\tilde{v}^{2}}\right)}{\partial y}-\frac{\partial(\rho \overline{\tilde{v} \tilde{w}})}{\partial z}\right]+S_{M y} \\
& \frac{\partial(\rho W)}{\partial t}+\operatorname{div}(\rho W \vec{U})=-\frac{\partial P}{\partial z}+\operatorname{div}[\operatorname{grad}(W) \mu]+ \\
& +\left[-\frac{\partial(\rho \overline{\tilde{u} \tilde{w}})}{\partial x}-\frac{\partial(\rho \tilde{\tilde{v} \tilde{w}})}{\partial y}-\frac{\partial\left(\rho \overline{\tilde{w}^{2}}\right)}{\partial z}\right]+S_{M z}
\end{aligned}
$$

As equações médias apresentam termos adicionais às equações governantes da seção 3.1.2. Os termos entre colchetes nas equações de Reynolds são tensões turbulentas que juntas formam o tensor de Reynolds. São três tensões normais: $\tau_{x x}=-\rho \overline{\tilde{u}^{2}}, \tau_{y y}=-\rho \overline{\tilde{v}^{2}}, \tau_{z z}=$ $-\rho \overline{\tilde{w}^{2}}$, e seis tensões cisalhantes: $\tau_{x y}=\tau_{y x}=-\rho \overline{\tilde{u} \tilde{v}}, \tau_{x z}=\tau_{z x}=-\rho \overline{\tilde{u} \tilde{w}}$ e $\tau_{y z}=\tau_{z y}=$ $-\rho \overline{\tilde{v} \tilde{w}}$. Não se podem descartar estes termos. A flutuação das componentes da velocidade são estatisticamente independentes. Não necessariamente o tensor de Reynolds apresentará estes termos nulos. Além disso, as tensões cisalhantes turbulentas, em geral, são maiores que as tensões viscosas em um escoamento turbulento.

Nos modelos RANS é utilizada a proposta de Boussinesq, de 1877, que estabelece uma analogia entre a tensão viscosa e o tensor de Reynolds através da lei da viscosidade de Newton. Na proposta o tensor de Reynolds é proporcional à taxa de deformação do escoamento médio por uma viscosidade equivalente, denominada viscosidade turbulenta $\mu_{t}$. O tensor de Reynolds, nas equações de Reynolds, é reescrito como na Eq.3.17. É utilizada notação indicial. No último termo tem-se a energia cinética turbulenta $k$ e o delta de Kronecker $\delta_{i j}$.

$$
\tau_{i j}=-\rho \tilde{\tilde{u}_{i} \tilde{u}_{j}}=\mu_{t}\left(\frac{\partial U_{i}}{\partial x_{j}}+\frac{\partial U_{j}}{\partial x_{i}}\right)-\frac{2}{3} k \delta_{i j}
$$

onde $\delta_{i j}=\left\{\begin{array}{ll}1 & \text { quando } i=j, \\ 0 & \text { quando } i \neq j .\end{array}\right.$ é o delta de Kronecker

No modelo de CFD utilizado no presente trabalho, a condutividade térmica $k$ é subs- 
tituída pela condutividade térmica efetiva $k_{e f f}$, escrita em função do número de Prandtl inverso efetivo $\alpha$ e da viscosidade efetiva $\mu_{\text {eff }}$ no modelo $k-\epsilon$ RNG, conforme a Eq.3.18. O modelo $k-\epsilon$ RNG utiliza uma função para $\alpha$. Este varia suavemente desde 1 nas regiões dominadas pela viscosidade, como próximo às paredes, até 1,393 em regiões com escoamento desenvolvido e alto número de Reynolds.

$$
k_{e f f}=\alpha c_{p} / \mu_{e f f}
$$

\section{Modelo $k-\epsilon$}

A maneira como a viscosidade turbulenta é modelada caracteriza o modelo de turbulência. No modelo de comprimento de mistura de Prandtl e no modelo $k-\epsilon$ utiliza-se a relação $\mu_{t}=C \rho \vartheta \ell$, de onde a viscosidade turbulenta é proporcional à escala de velocidade da turbulência $\vartheta(\mathrm{m} / \mathrm{s})$ e à escala de comprimento da turbulência $\ell(\mathrm{m})$.

As escalas turbulentas podem ser definidas em função da energia cinética turbulenta $k \mathrm{e}$ da taxa de dissipação da energia cinética turbulenta $\epsilon$ conforme as relações:

$$
\begin{aligned}
& \vartheta=k^{\frac{1}{2}} \\
& \ell=\frac{k^{\frac{3}{2}}}{\epsilon}
\end{aligned}
$$

Resulta, portanto, uma relação entre a viscosidade turbulenta $\mu_{t}$ e as escalas turbulentas $\vartheta$ e $\ell$. energia cinética turbulenta $k$ e sua taxa de dissipação $\epsilon$, como mostra a Eq.3.19.

$$
\mu_{t}=C \rho \vartheta \ell=\rho C_{\mu} \frac{k^{2}}{\epsilon}
$$

Para resolver a viscosidade turbulenta são introduzidas duas novas equações de transporte: a energia cinética turbulenta $k$ e a taxa de dissipação da energia cinética turbulenta $\epsilon$. A Eq.3.20 é a equação de transporte para $k$. A energia cinética turbulenta é obtida pela multiplicação das componentes da equação instantânea de momento pela respectiva componente da velocidade. O primeiro termo à esquerda é a taxa de variação temporal de $k$ e o segundo termo representa o transporte de $k$ por advecção. $\mathrm{O}$ primeiro termo à direita representa o transporte por difusão turbulenta, em que $\sigma_{k}$ é o inverso do número de Prandtl turbulento para $k$. O segundo termo à direita é a taxa de produção de $k$, em que $S_{i j}$ é o tensor taxa de deformação média. O último termo à direita é a taxa de destruição de $k$, escrita em função da sua taxa de dissipação $\epsilon$. A Eq.3.21 é a equação de transporte para $\epsilon$ (ou taxa de dissipação de $k$ ) que é obtida ad hoc por analogia com a equação de $k$. As equações contêm cinco constantes de ajuste: $C_{\mu}, \sigma_{k}, \sigma_{\epsilon}, C_{1 \epsilon}$ e $C_{2 \epsilon}$. 


$$
\begin{gathered}
\frac{\partial(\rho k)}{\partial t}+\operatorname{div}(\rho k \vec{U})=\operatorname{div}\left[\frac{\mu_{t}}{\sigma_{k}} \operatorname{grad}(k)\right]+2 \mu_{t} S_{i j} . S_{i j}-\rho \epsilon \\
\frac{\partial(\rho \epsilon)}{\partial t}+\operatorname{div}(\rho \epsilon \vec{U})=\operatorname{div}\left[\frac{\mu_{t}}{\sigma_{\epsilon}} \operatorname{grad}(\epsilon)\right]+C_{1 \epsilon} \frac{\epsilon}{k} 2 \mu_{t} S_{i j} . S_{i j}-C_{2 \epsilon} \rho \frac{\epsilon^{2}}{k}
\end{gathered}
$$

Existem diferentes versões do modelo $k-\epsilon$. No presente trabalho é utilizado $k-\epsilon$ RNG. A literatura aponta que o modelo RNG fornece bons resultados a baixo custo computacional para problemas envolvendo conforto térmico (Gao e Niu, 2005; Kilic e Sevilgen, 2008). Este modelo é derivado das equações instantâneas de Navier-Stokes a partir de uma técnica estatística mais rigorosa, denominada "teoria do grupo de renormalização" (renomarlization group theory). O modelo RNG é similar em forma ao $k-\epsilon$ padrão, mas apresenta avanços que melhoram a acuracidade e a aplicabilidade do modelo para um maior grupo de escoamentos.

As Eqs.3.22 e 3.23 são as equações de transporte de $k$ e de $\epsilon$ no modelo RNG, implementadas no simulador Fluentß. $G_{k}$ representa a geração de energia cinética turbulenta devido ao gradiente da velocidade média, $G_{b}$ é a geração de energia cinética turbulenta devido ao empuxo em escoamentos com pluma térmica e $Y_{M}$ representa a contribuição taxa de dilatação nos escoamento turbulentos compressíveis. $R_{\epsilon}$ e $C_{2 \epsilon} \rho \frac{\epsilon^{2}}{k}$ são termos de destruição de $\epsilon . R_{\epsilon}$ destina-se aos escoamentos com maior estiramento dos vórtices. Fluent Inc. (2006) mostra o desenvolvimento analítico dos termos $G_{k}, G_{b}, Y_{M}, R_{\epsilon}, C_{3 \epsilon}, \mu_{e f f}$ e $\alpha . S_{k}$ e $S_{\epsilon}$ são termos fontes.

$$
\begin{gathered}
\frac{\partial(\rho k)}{\partial t}+\frac{\partial\left(\rho k u_{i}\right)}{\partial x_{i}}=\frac{\partial}{\partial x_{j}}\left(\alpha_{k} \mu_{e f f} \frac{\partial k}{\partial x_{j}}\right)+G_{k}+G_{b}-\rho_{\epsilon}-Y_{M}+S_{k} \\
\frac{\partial(\rho \epsilon)}{\partial t}+\frac{\partial\left(\rho \epsilon u_{i}\right)}{\partial x_{i}}=\frac{\partial}{\partial x_{j}}\left(\alpha_{\epsilon} \mu_{e f f} \frac{\partial \epsilon}{\partial x_{j}}\right)+C_{1 \epsilon} \frac{\epsilon}{k}\left(G_{k}+C_{3 \epsilon} G_{b}\right)-C_{2 \epsilon} \rho \frac{\epsilon^{2}}{k}-R_{\epsilon}+S_{\epsilon}
\end{gathered}
$$

Foram utilizados os valores $C_{1 \epsilon}=1,42$ e $C_{2 \epsilon}=1,68$. A viscosidade turbulenta é calculada como no modelo $k-\epsilon$ padrão, conforme Eq.3.19. Contudo, $C_{\mu}=0,0845$ para o RNG ao invés de 0,09 no modelo padrão. Também não foi habilitada a modificação para escoamento rotacional (swirl modification) presente no Fluent@, que também modificaria o cálculo da viscosidade turbulenta $\mu_{t}$. O inverso do número de Prandtl $\alpha$ é calculado por fórmula derivada da teoria RNG. $\alpha_{k}$ e $\alpha_{\epsilon}$ variam suavemente desde 1, 0 em regiões dominadas pela viscosidade, como próximo às paredes, até 1,393 nas regiões com escoamento desenvolvido e alto número de Reynolds. 


\section{Tratamento de parede}

O modelo de turbulência $k-\epsilon$ foi elaborado para escoamentos de alto número de Reynolds com o espectro de turbulência desenvolvido. As equações do modelo de turbulência e as constantes de ajustes não são adequadas para resolver o escoamento nas regiões próximas às paredes, onde há uma fina camada viscosa.

Didaticamente, a camada limite junto à parede sólida pode ser dividida em três subcamadas: uma subcamada viscosa dominada pela viscosidade molecular, uma subcamada logarítmica onde a turbulência é preponderante e uma zona de transição. O perfil de velocidade pode ser descrito em função da velocidade adimensional $u^{+}$e distância adimensional $y^{+}$. A Eq.3.24 é denominada lei de parede. $u_{\tau}$ é a velocidade de fricção, igual a $(\tau / \rho)^{1 / 2}$.

$$
u^{+}=\frac{U}{u_{\tau}}=f\left(\frac{\rho u_{\tau} y}{\mu}\right)=f\left(y^{+}\right)
$$

Existem duas metodologias para modelar o escoamento próximo à parede - função de parede, do inglês wall function, e modelo de parede, com denominação em inglês near-wall modeling approach no Fluent@.

As funções de parede não resolvem a região da camada limite afetada pela viscosidade (subcamada viscosa e camada de amortecimento), por isso não requerem malha computacional refinada na região da camada limite afetada pela viscosidade. São utilizadas fórmulas semi-empíricas para conectar as condições de contorno junto às paredes à solução ao longe, onde o escoamento é turbulento completamente desenvolvido. Estas fórmulas são obtidas a partir de experimentos com escoamentos simples bastante explorados na literatura, como escoamento em placa plana e escoamento de Couette.

A Fig.3.1 mostra a distribuição de velocidade e as equações que descrevem a subcamada viscosa e a camada logarítmica segundo experimento de escoamento em placa plana (Klebanoff, 1955 apud Versteeg e Malalasekera (2007)). A subcamada viscosa é bastante fina $\left(y^{+}<5\right)$. A subcamada logarítmica, em geral, pode ser descrita para $30<y^{+}<500$.

Os modelos de parede (near wall modeling approach), por sua vez, modificam o modelo de turbulência para permitir a solução da região afetada pela viscosidade com uma malha adequadamente refinada nesta região, de forma que eleva o custo computacional.

As funções de parede exigem menor custo computacional. Além disso, são válidas para a maioria dos escoamentos de alto Reynolds onde as variáveis do escoamento variam mais rapidamente ao longo da região afetada pela viscosidade. As funções de parede apresentam limitações para escoamentos que diferem do escoamento em placa plana, como escoamento com swirl ou com gradiente adverso de pressão, quando há desprendimento da camada limite. Os modelos de parede (near wall modeling approach), ao contrário, apresentam maior potencial para calcular os diversos tipos de escoamento.

Neste trabalho é utilizado o tratamento de parede aprimorado, denominado enhanced 


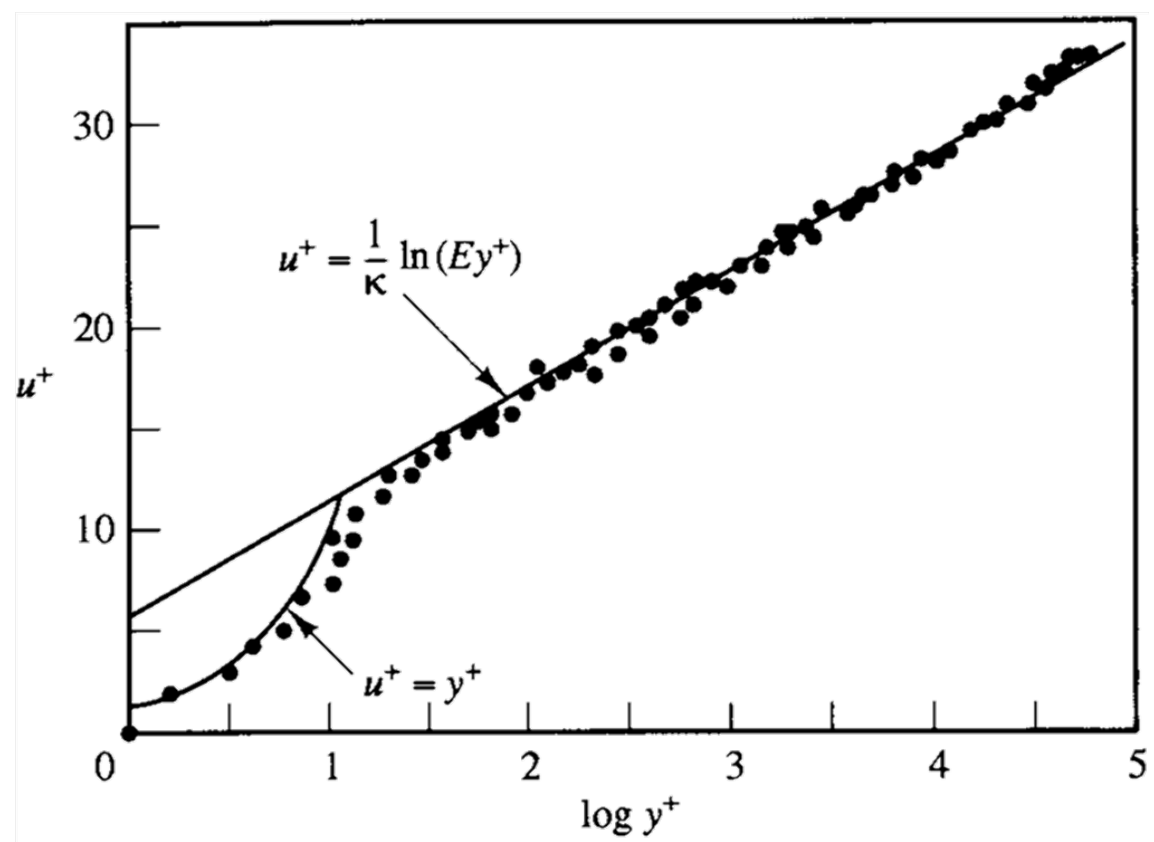

Figura 3.1: Distribuição de velocidade em camada limite de parede sólida. Adaptado de Versteeg e Malalasekera (2007).

wall treatment no Fluent@. Este modelo combina as duas metodologias para modelar o escoamento próximo às paredes. Para malhas suficientemente refinadas, quando $y^{+} \approx 1$, o tratamento de parede aprimorado (enhanced) remete ao modelo de parede de duas camadas.

$\mathrm{O}$ modelo de duas camadas utiliza o número de Reynolds turbulento $R e_{t}$ conforme a Eq.3.25 para subdividir o domínio do escoamento na região afetada pela viscosidade $\left(R e_{t}<\right.$ 200) e região turbulenta plenamente desenvolvida $\left(R e_{t}>200\right)$. O termo y é a distância normal do centro do elemento de malha adjacente à parede até a parede.

$$
R e_{t} \equiv \frac{\rho y \sqrt{k}}{\mu}
$$

Se o $R e_{t}>200$ no volume de controle junto à parede então as equações do modelo $k-\epsilon$ seguem inalteradas e uma função de parede é aplicada para conectar a condição de contorno na parede ao elemento da malha. Quando $R e_{t}<200$ utiliza-se o modelo de uma-equação de Wolfstein (1969) apud Fluent Inc. (2006). A Eq.3.19 para a viscosidade turbulenta é substituída pela Eq.3.26. Assim,

$$
\mu_{t, 2 \text { camadas }}=\rho C_{\mu} \ell_{\mu} \sqrt{k}
$$

em que $\ell_{\mu}$ é uma escala de comprimento função da distância até a parede e do número de Reynolds, conforme $\ell_{\mu}=y C_{l}^{*}\left(1-e^{-R e_{y} / A_{\mu}}\right)$.

No tratamento de parede aprimorado (enhanced) a descrição da viscosidade turbulenta 
segundo o modelo de duas camadas é utilizada parcialmente. Pela proposta de Jongen (1992) apud Fluent Inc. (2006), a viscosidade turbulenta é definida como na Eq.3.27.

$$
\mu_{t, \text { aprim }}=\lambda_{\epsilon} \mu_{t}+\left(1-\lambda_{\epsilon}\right) \mu_{t, 2 \text { camadas }}
$$

O fator de suavização $\lambda_{\epsilon}$ conecta as viscosidades desde a região turbulenta plenamente desenvolvida, descrita por $\left(\mu_{t}\right)$ segundo o modelo de turbulência $k-\epsilon$ (Eq.3.19), até a região viscosa, descrita por $\left(\mu_{t, 2 \text { camadas }}\right)$. No modelo adotado neste trabalho $\lambda_{\epsilon}$ é definido conforme a Eq.3.28. Nas regiões afastadas de paredes o fator $\lambda_{\epsilon}$ é unitário e nas regiões muito próximas de paredes o fator é nulo.

$$
\lambda_{\epsilon}=\frac{1}{2}\left(1+\tanh \left(\frac{R e_{y}-200}{A}\right)\right)
$$

$A$ é um parâmetro definido por $A=\frac{\left|\Delta R e_{y}\right|}{\tanh (0,98)}$ que determina a espessura do fator de suavização. Tipicamente, $\Delta R e_{y}$ é fixado entre $5 \%$ a $20 \%$ do valor do Reynolds crítico $\left(R e_{y}^{*}=\right.$ 200).

A taxa de dissipação da energia cinética turbulenta $\epsilon$ também é modificada no modelo de duas camadas. O fator de suavização $\lambda_{\epsilon}$ conecta a solução para a região turbulenta plenamente desenvolvida, conforme sua equação de transporte no modelo $k-\epsilon$ (Eq.3.21), com a solução para a região afetada pela viscosidade, conforme a Eq.3.29.

$$
\epsilon=\frac{k^{3 / 2}}{\ell_{\epsilon}}
$$

Na equação acima $k$ é a energia cinética turbulenta e $\ell_{\epsilon}$ é uma escala de comprimento, obtida conforme a Eq.3.30, em que $\kappa$ é a constante de Von Kármán, igual a 0, 4187.

$$
\ell_{\epsilon}=y \kappa C_{\mu}^{-3 / 4}\left(1-e^{-R e_{y} / 2 \kappa C_{\mu}^{-3 / 4}}\right)
$$

A temperatura também recebe tratamento de parede. A camada limite é subdividida numa subcamada de condução térmica e numa subcamada logarítmica para a região onde os efeitos da turbulência são preponderantes sobre a condução.

O modelo utilizado no presente trabalho é baseado no método de Kader (1981) apud Fluent Inc. (2006). Uma única formulação para temperatura conecta os perfis de temperatura laminar $T_{\text {lam }}^{+}$e turbulento $T_{\text {turb }}^{+}$através do fator de suavização $\Gamma$, conforme

$$
T^{+} \equiv \frac{\left(T_{w}-T_{p}\right) \rho c_{p} u^{*}}{\dot{q}}=e^{\Gamma} T_{l a m}^{+}+e^{\frac{1}{\Gamma}} T_{\text {turb }}^{+}
$$


em que o índice subescrito $w$ indica que a propriedade é avaliada na parede e o índice $p$ indica que a propriedade é avaliada no ponto "p" distante da parede. $\dot{q}$ é o fluxo de energia térmica através da parede e $u^{*}$ é a velocidade adimensional calculada no modelo $k-\epsilon$ padrão pela proposta de Launder e Spalding apud Fluent Inc. (2006), conforme a Eq.3.32. $C_{\mu}$ é constante de ajuste do modelo de turbulência $k-\epsilon$ e $k_{p}$ é a energia cinética turbulenta no ponto "p".

$$
u^{*} \equiv \frac{u_{p} C_{\mu}{ }^{1 / 4} / k_{p}{ }^{1 / 2}}{\tau_{w} / \rho}
$$

O fator de suavização $\Gamma$ é função do número de Prandtl molecular Pr e da distância até a parede, conforme a equação que se segue.

$$
\Gamma=-\frac{0,01\left(\operatorname{Pr}^{+}\right)^{4}}{1+5 \operatorname{Pr}^{3} y^{+}}
$$

O tratamento de parede aprimorado calcula $T_{\text {lam }}^{+}$e $T_{\text {turb }}^{+}$de forma similar à formulação para função de parede da velocidade, conforme as Eqs.3.34 e 3.35 implementadas no Fluent@B. Porém, os números de Prandtl em ambas as equações são substituídos pelos números de Schmidt. $P$ é um parâmetro que depende de $\operatorname{Pr}$ e de $P r_{t}$, e $u_{c}^{+}$é o valor de $u^{+}$ na camada de transição fictícia entre a região turbulenta e laminar.

$$
\begin{gathered}
T_{\text {lam }}^{+}=\operatorname{Pr}\left(u_{\text {lam }}^{+}+\frac{\rho u^{*}}{2 \dot{q}} u^{2}\right) \\
T_{\text {turb }}^{+}=\operatorname{Pr}_{t}\left(u_{\text {turb }}^{+}+P+\frac{\rho u^{*}}{2 \dot{q}}\left(u^{2}-\left(\frac{P r}{P r_{t}}-1\right)\left(u_{c}^{+}\right)^{2}\left(u^{*}\right)^{2}\right)\right)
\end{gathered}
$$

As velocidades adimensionais laminar $u_{\text {lam }}^{+}$e turbulenta $u_{\text {turb }}^{+}$são calculadas pelas Eqs.3.36 e 3.37 no modelo implementado. A Eq.3.37 é uma equação diferencial ordinária desenvolvida a partir de aproximações devidas a White e Cristoph (1971) e Huang et al. (1993) apud Fluent Inc. (2006). A solução é analítica.

$$
\begin{gathered}
u_{\text {lam }}^{+}=y^{+}\left(1+\frac{\alpha}{2} y^{+}\right) \\
\frac{d u_{\text {turb }}^{+}}{d y^{+}}=\frac{1}{\kappa y^{+}}\left[S^{\prime}\left(1-\beta u^{+}-\gamma\left(u^{+}\right)^{2}\right)\right]^{1 / 2},
\end{gathered}
$$


em que

$$
S^{\prime}= \begin{cases}1+\alpha y^{+} & \text {quando } y^{+}<y_{s}^{+} \\ 1+\alpha y_{s}^{+} & \text {quando } y^{+} \geq y_{s}^{+}\end{cases}
$$

e

$$
\begin{aligned}
\alpha & =\frac{\mu}{\rho^{2}\left(u^{+}\right)^{3}} \frac{d p}{d x} \\
\beta & =\frac{\sigma_{t} q_{w}}{\rho c_{p} u^{+} T_{w}} \\
\gamma & =\frac{\sigma_{t}\left(u^{+}\right)^{2}}{2 c_{p} T_{w}}
\end{aligned}
$$

A distância adimensional $y_{s}^{+}$representa a localização onde a inclinação da lei logarítmica de parede torna-se constante (vide Fig.3.1). No modelo implementado neste trabalho adotase $y_{s}^{+}=60$. O coeficiente $\alpha$ representa a influência do gradiente de pressão e os coeficientes $\beta$ e $\gamma$ representam os efeitos térmicos.

\subsubsection{Método dos Volumes Finitos}

As equações governantes na seção 3.1.2 e as equações adicionais do modelo de turbulência devem ser integradas e discretizadas nos volumes de controle definidos pela malha computacional. Utiliza-se o Teorema de Gauss para transpor as integrais de volume para integrais de superfície nas faces do volume de controle. Os esquemas de discretização envolvem interpoladores de primeira, segunda ou de alta ordem. É importante escolher esquemas conservativos, estáveis e com precisão adequada. Nas simulações deste presente trabalho é utilizado esquema UPWIND de $2^{a}$ ordem. Este é intrinsecamente conservativo, satisfaz o critério de estabilidade de Scarborough e se adapta em escoamentos tanto difusivos quanto convectivos. Embora os esquemas UPWIND apresentem problema de falsa difusão aqui é utilizado a versão de $2^{a}$ ordem, para não comprometer a precisão numérica.

As equações governantes não podem ser resolvidas diretamente devido às não linearidades dos termos convectivos nas equações de momento e devido ao acoplamento das equações de momento e equação da continuidade (Versteeg e Malalasekera, 2007). As variáveis de velocidade se apresentam tanto nas equações de momento quanto na equação da continuidade. A pressão ocorre nas equações de momento e falta uma equação de transporte para a mesma. No presente trabalho é utilizado o algoritmo SIMPLE (Patankar e Spalding, 1972 apud Versteeg e Malalasekera (2007)). Este método resolve o sistema de equações partindo de estimativas para o campo de pressão. A equação da continuidade é utilizada para corrigir os campos de pressão e de velocidade.

O procedimento iterativo no MVF termina quando as variáveis calculadas convergem e a equação da continuidade é satisfeita. No Fluent@, o resíduo das equações calculadas é 
definido pela equação de conservação em cada célula, conforme a Eq.3.38, em que $\phi$ é uma variável genérica, $a_{P}$ é o coeficiente central, $a_{n b}$ representa os coeficientes das células vizinhas e $b$ é uma contribuição do termo fonte e condição de contorno. A diferença entre os valores definidos no centro da célula e na vizinhança tende a zero à medida que a solução converge. O simulador monitora a somatória dos resíduos normalizada pela somatória $\sum\left|a_{P} \phi_{P}\right|$, considerando todas as células do domínio. O critério de convergência adotado neste trabalho estabelece que os resíduos reduzam abaixo de $10^{-4}$ para as equações da continuidade, do momento e equações adicionais do modelo de turbulência e abaixo de $10^{-7}$ para as equações da energia e equação do modelo de radiação térmica.

$$
a_{P} \phi_{P}=\sum_{n b} a_{n b} \phi_{n b}+b
$$

As condições de contorno nas fronteiras do escoamento podem receber três tipos de tratamento no Método dos Volumes Finitos (Maliska, 2004). Primeiro, pode-se utilizar malha computacional com meios volumes de controle sobre as fronteiras. Esta técnica torna mais complexa a sub-rotina para o processamento numérico devido à existência de volumes inteiros, meios-volumes, quarto de volumes e oitavos de volumes numa malha tridimensional. Além disso, o balanço de conservação nem sempre será atendido nos volumes das fronteiras. Outra forma de tratar as condições de contorno é utilizar malha computacional com volumes fictícios ao longo das fronteiras e fora do domínio do escoamento. A desvantagem é aumentar o tempo de processamento devido ao maior número de incógnitas. O procedimento mais adequado é realizar a integração das equações de conservação nos volumes fronteiriços da mesma forma como é feito nos volumes internos, porém respeitando as condições de contorno na fronteira. Dependendo da propriedade avaliada, a condição de contorno pode ser extrapolada da fronteira para o centro do volume de controle de forma direta ou através de alguma função de interpolação.

\subsection{Modelagem da radiação térmica}

\subsubsection{Introdução}

A radiação pode ser definida como a emissão de radiação eletromagnética devido à agitação molecular e atômica associada à energia interna num corpo (Siegel e Howell, 1992). A radiação térmica engloba aproximadamente o espectro de radiação visível nos comprimentos de onda desde $0,4 \mu \mathrm{m}$ para luz violeta até $0,7 \mu \mathrm{m}$ para luz vermelha e o espectro infravermelho até o comprimento de onda $1.000 \mu \mathrm{m}$. Em problemas envolvendo escoamento a baixas velocidades, como ventilação natural, a radiação térmica não pode ser desprezada (Versteeg e Malalasekera, 2007), pois a contribuição da convecção diminui com a redução da velocidade do escoamento. 
Trocas de calor por radiação ocorrem entre superfícies apresentando temperaturas diferentes. A emissividade, a difusidade e o fator de forma das superfícies são fatores importantes para a radiação. Estes dependem das características superficiais, do tipo de material das paredes e da geometria ou disposição das paredes.

Uma grandeza física básica na modelagem de fenômeno de radiação térmica é a Intensidade de Radiação $I_{\lambda}$, definida como a taxa de energia radiativa por unidade de angulo sólido, unidade de área normal ao feixe radiativo e unidade de comprimento de onda $\lambda$.

Equações analíticas que governam as trocas de calor por radiação podem ser vistas em Hottel e Sarofim (1967) e Modest (2003). A intensidade de radiação pode ser calculada ao longo de feixes de radiação. Há expressões para a troca de calor entre superfícies negras ou cinzentas, difusas e com radiosidade uniforme, e há métodos analíticos para calcular o fator de forma entre duas ou mais superfícies.

A equação de transferência radiativa é deduzida em sua forma completa para meios participativos. A Eq.3.39, obtida em Modest (2003), é denominada Radiative Transport Equation (RTE) na língua inglesa. O termo à esquerda é a taxa de variação da intensidade de radiação por unidade de comprimento do caminho do feixe. O primeiro termo à direita contabiliza o aumento da intensidade pela emissão do meio, o segundo termo contabiliza a redução da intensidade pela absorção do meio e espalhamento para fora do feixe, e o último termo contabiliza a intensidade de outras direções convergidas para dentro do feixe. $\kappa$ é o coeficiente de absorção do meio, função da temperatura, pressão, composição do material e do número de onda da radiação incidente. $\beta$ é o coeficiente de extinção ou de atenuação, definido como a soma dos coeficientes de absorção $\kappa$ e de espalhamento para fora $\sigma_{s}$. $I_{b}$ é a intensidade de um corpo negro, $\Phi$ é função de fase do espalhamento, $\vec{s}$ é vetor direção do feixe, ${ }_{s}$ é vetor direção que aponta para a mesma direção do ângulo sólido $\Omega^{\prime}$, ou seja, na mesma direção do espalhamento, e $\vec{r}$ é vetor posição.

A intensidade é calculada desde sua emissão a partir da parede. A Eq.3.40 fornece a condição de contorno para superfícies sólidas. O termo $\epsilon$ é a emissividade total da parede.

$$
\begin{aligned}
& \frac{d I(\vec{r}, \vec{s})}{d s}=\kappa I_{b}(\vec{r})-\beta I(\vec{r}, \vec{s})+\frac{\sigma_{s}}{4 \pi} \oint_{4 \pi} I\left(\overrightarrow{s^{\prime}}\right) \Phi\left(\overrightarrow{s^{\prime}}, \vec{s}\right) d \Omega^{\prime} \\
& I\left(\overrightarrow{r_{w}}, \vec{s}\right)=\varepsilon I_{b}\left(r_{w}\right)+\frac{(1-\varepsilon)}{2 \pi} \oint_{\vec{n} \cdot \overrightarrow{s^{\prime}}<0} I\left(\overrightarrow{r_{w}}, \overrightarrow{s^{\prime}}\right)\left|\vec{n} \cdot \overrightarrow{s^{\prime}}\right| d \Omega^{\prime}
\end{aligned}
$$

As expressões apresentadas acima são equações diferenciais integrais. A maneira pela qual a RTE e sua condição de contorno são solucionadas caracteriza o modelo numérico de radiação. Existem diversos modelos. No presente trabalho é utilizado o método dos Volumes Finitos de Ordenadas Discretas (Modest (2003)), com denominação Finite Volume Discrete Ordinates Method (FVDOM) na língua inglesa. Este resolve tanto a intensidade de radiação 
emitida pelas paredes quanto a intensidade incorporada ou emitida pelo feixe quando o gás presente no meio participa da radiação.

Nas simulações neste trabalho considera-se meio não participativo ou transparente à radiação, pois as espécies presentes no ar atmosférico limpo não absorvem nem emitem na faixa do comprimento de onda da radiação térmica. Há modelos mais simples que o FVDOM para simular a radiação térmica nesta situação, como o método Parede-Parede ou surfaceto-surface como é denominado na língua inglesa. A preferência pelo FVDOM deve-se ao fato deste adaptar-se em geometrias e malhas com condições de contorno simétricas ou periódicas. Apesar de o FVDOM ser bastante complexo em sua formulação, no presente trabalho o modelo é bastante simplificado zerando-se os parâmetros que definem a participação do meio: coeficientes de absorção e de espalhamento.

\subsubsection{Método dos Volumes Finitos de Ordenadas Discretas}

No método dos Volumes Finitos de Ordenadas Discretas a RTE é resolvida discretamente para um número finito de direções que varrem discretamente o ângulo sólido total de $4 \pi$.

No FVDOM a Eq.3.39 é integrada no volume de controle, utilizando-se o Teorema da Divergência ou Teorema de Gauss, para transformação das integrais de volume em integrais de superfície. A taxa de variação da intensidade torna-se

$$
\int_{V} \frac{\delta I}{\delta s} d V=\int_{A} I \vec{s} \cdot \vec{n} d A
$$

em que dV é o volume do volume de controle e A é a área superficial do volume de controle.

A Fig.3.2 ilustra as faces dos volumes de controle 2D sobre a qual a Eq.3.41 é integrada e também ilustra a discretização do domínio direcional de $4 \pi s r$ em ângulos sólidos discretos.

A Eq.3.42 é a RTE integrada no volume de controle e no domínio do ângulo sólido discreto $\Omega_{i}$.

$$
\int_{\Omega_{i}} \int_{A} I \vec{s} \cdot \vec{n} d A d \Omega=\int_{\Omega_{i}} \int_{V}\left(\kappa I_{b}-\beta I\right) d V d \Omega+\int_{\Omega_{i}} \int_{V} \frac{\sigma_{s}}{4 \pi} \int_{4 \pi} I\left(\overrightarrow{s^{\prime}}\right) \Phi\left(\overrightarrow{s^{\prime}}, \vec{s}\right) d \Omega^{\prime} d V d \Omega
$$

A RTE e a condição de contorno podem ser aproximadas numericamente conforme a Eq.3.43. Na forma mais simples do FVDOM, admite-se que a intensidade de radiação na direção $i$ é constante sobre cada face do volume de controle $A_{k}$ e sobre cada elemento de ângulo sólido $d \Omega$. Os índices subescritos $k$ e $p$ denotam as faces e os centros do volume de controle, respectivamente. $\overrightarrow{s_{i}}$ é vetor direcional cujo módulo é numericamente igual ao ângulo sólido e aponta para a direção do ângulo sólido $\Omega_{i}$. 


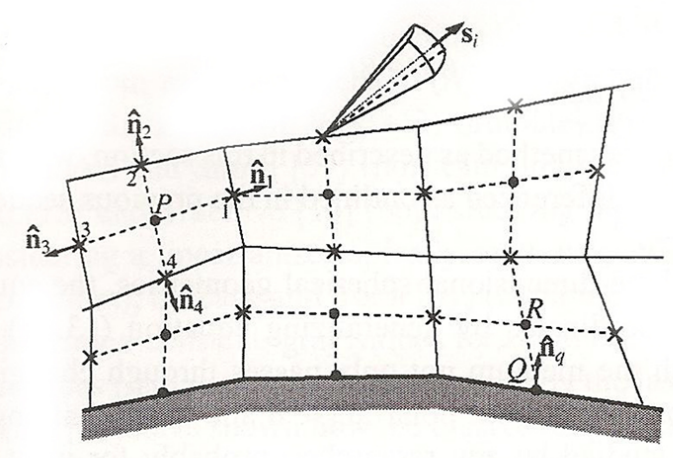

(a)

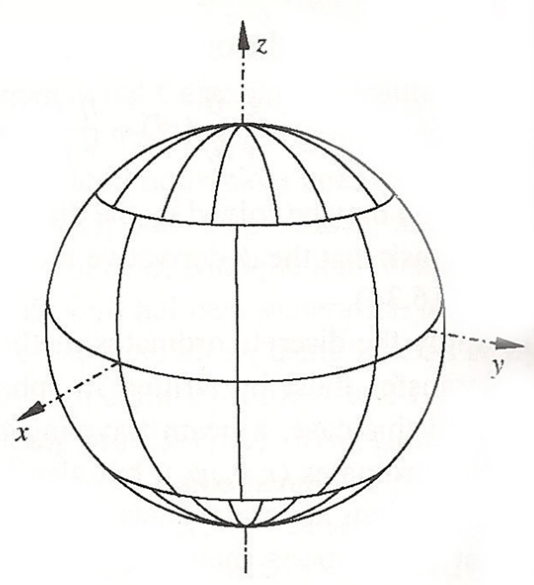

(b)

Figura 3.2: Discretização espacial e direcional para o FVDOM. Volumes finitos (a) e discretização das direções em ângulos sólidos (b) - extraída de Modest (2003).

$$
\sum_{k} I_{k_{i}}\left(\overrightarrow{s_{i}} \cdot \overrightarrow{n_{k}}\right) A_{k}=\beta_{p}\left(S_{p i}-I_{p i}\right) V \Omega_{i}
$$

em que

$$
S_{p i}=\left(1-\omega_{p}\right) I_{b p}+\frac{\omega_{p}}{4 \pi} \sum_{j=1}^{N} I_{p, j} \Phi_{i j}
$$

em que $\omega$ é o coeficiente unificado de espalhamento, definido como $\omega=\frac{\sigma_{s}}{\beta}$.

A integração da RTE no volume de controle requer que o fluxo da intensidade de radiação seja avaliado nas faces do volume de controle. A aproximação mais simples envolve extrapolar a intensidade desde o centro do volume de controle ou desde o vizinho $k$, conforme:

- Radiação incidente $\left(\overrightarrow{s_{i}} \cdot \overrightarrow{n_{k}}<0\right)$, a intensidade na face é aproximada pela intensidade do volume vizinho $\left(I_{k i}\right)$, de onde a radiação vem, conforme

$$
\sum_{k} I_{k i}\left(\overrightarrow{s^{\prime}} \cdot \vec{n}\right) A_{k}=\sum_{k, e} I_{k i}\left|\overrightarrow{s^{\prime}} \cdot \overrightarrow{n_{k}}\right| A_{k}
$$

- Radiação deixando o volume de controle $\left(\overrightarrow{s_{i}} \cdot \overrightarrow{n_{k}}>0\right)$, a intensidade na face é aproximada pela intensidade armazenada no centro do volume de controle $\left(I_{p i}\right)$, conforme 


$$
\sum_{k} I_{k i}\left(\overrightarrow{s^{\prime}} \cdot \vec{n}\right) A_{k}=\sum_{k, s} I_{p i}\left|\overrightarrow{s^{\prime}} \cdot \overrightarrow{n_{k}}\right| A_{k}
$$

Desta forma, a expressão que relaciona a intensidade de radiação na direção $i$ e ponto $p$ e seus vizinhos é

$$
I_{p i}=\frac{\beta_{p} S_{p i} V \Omega_{i}+\sum_{k, e} I_{k i}\left|\overrightarrow{s_{i}} \cdot \overrightarrow{n_{k}}\right| A_{k}}{\beta_{p} V \Omega_{i}+\sum_{k, s}\left(\overrightarrow{s_{i}} \cdot \overrightarrow{n_{k}} A_{k}\right)}
$$

em que os índices subescritos e e $s$ denotam radiação que entra ou sai através da face, respectivamente.

A condição de contorno pode ser aproximada discretamente conforme a Eq.3.48. A equação Eq.3.40 é integrada para todas as direções deixando a superfície, segundo $\vec{n} . \vec{s}>0$, e admite-se que a intensidade e a emissividade são constantes, tirando-as para fora da integral.

$$
I_{q} \sum_{i, s} \overrightarrow{s_{i}} \cdot \overrightarrow{n_{q}} A_{Q}=\varepsilon_{q} I_{b q} \sum_{i, s} \overrightarrow{s_{i}} \overrightarrow{n_{q}} A_{Q}+\left(1-\varepsilon_{q}\right) \sum_{i, e} I_{q e}\left|\overrightarrow{s_{i}} \cdot \overrightarrow{n_{q}}\right| A_{Q}
$$

ou ainda

$$
I_{q}=\varepsilon_{q} I_{b q}+\frac{\left(1-\varepsilon_{q}\right) \sum_{i, e} I_{q e}\left|\overrightarrow{s_{i}} \cdot \overrightarrow{n_{q}}\right|}{\sum_{i, s}\left(\overrightarrow{s_{i}} \cdot \overrightarrow{n_{q}}\right)}
$$

Os índices subescritos $q$ e $Q$ denotam a face do volume de controle adjacente à parede, conforme a Fig.3.2.

Vê-se que o problema de radiação no FVDOM é iterativo, pois a condição de contorno $I_{q}$ depende das intensidades de radiação $I_{q e}$ dos volumes internos (R na Fig.3.2). A solução da intensidade parte da superfície, pela condição de contorno, e progride para as células interiores. No presente trabalho, apenas a condição de contorno contribui para a intensidade da radiação, uma vez que o meio não participa e os coeficientes de absorção e de espalhamento são zerados. Conhecendo-se a intensidade em todas as direções, o fluxo de radiação $q_{\text {rad }}$ nos volumes de controle junto às paredes poderá ser obtido por integração.

No presente trabalho o FVDOM é utilizado de forma desacoplada à solução da energia. As equações da energia e da radiação são resolvidas separadamente. Nos volumes de controle junto às paredes, o fluxo de energia obtido pelo modelo de radiação é contabilizado no termo fonte $S_{E}$ da Eq.3.10. A Eq.3.50 expressa o termo fonte obtido a partir do fluxo de energia devido à radiação $q_{\text {rad }}$. $\Delta V$ é o volume do volume de controle, $\vec{n}$ representa vetor normal à superfície do volume de controle e $d A$ representa área infinitesimal do volume de controle. 


$$
S_{\text {rad }}=-\frac{1}{\Delta V} \int_{A} q_{\text {rad }} \cdot \vec{n} d A
$$

\subsection{Simulador do corpo humano}

No presente trabalho é utilizado o Modelo de Sistema Térmico do Corpo Humano (MSTCH) desenvolvido por Ferreira (2001). O modelo está escrito em linguagem $\mathrm{C}++$. O modelo MSTCH é integrado à ferramenta de CFD através da transferência de informações via arquivo.

O MSTCH modela a interação entre o sistema termorregulador, o sistema passivo e o meio ambiente. O sistema termorregulador do corpo humano é responsável pela manutenção da temperatura corporal dentro de limites adequados. Este controle é feito através do mecanismo vasomotor, da produção de suor e dos tremores ou calafrios. Estes são controlados pelo sistema nervoso central do corpo humano, que deve responder contra perturbações térmicos internas, como variação no nível de atividade física com consequente aumento de metabolismo, ou perturbações advindas do meio ambiente como variações na temperatura, velocidade e umidade do ar. O mecanismo vasomotor consiste na variação do fluxo de sangue para a extensa rede de vasos presente na pele. Em geral, o sangue com temperatura próxima de $37^{\circ}$, é mais quente do que a pele, que ainda é isolada pela camada de gordura. A vasocontrição é um mecanismo de controle da temperatura corporal bastante eficiente. A produção de suor promove a perda de calor pela evaporação na superfície da pele, portanto constitui-se num mecanismo de defesa ao calor. Os tremores ou calafrios são provocados pelo aumento da tensão dos músculos esqueléticos com consequente aumento da geração de calor no organismo. Este mecanismo é responsável pela defesa contra o frio.

O sistema passivo envolve os processos de transferência de calor que ocorrem no interior do corpo humano. Compreende os processos de condução e convecção de calor interior do corpo humano bem como a transferência de calor entre o corpo e o ambiente através de condução, convecção, radiação térmica, evaporação e respiração.

\subsubsection{Geometria e anatomia}

O modelo geométrico utilizado pelo MSTCH é representado na Fig.(3.3). O corpo humano é dividido em 15 segmentos cilíndricos de seção elíptica, representando a cabeça, o pescoço, o tronco, os braços, os antebraços, as mãos, as coxas, as pernas e os pés. As seções elípticas permitem melhorar a representabilidade do corpo humano. A Tab.(3.1) detalha os parâmetros do modelo geométrico. $L$ é o comprimento de cada segmento cilíndrico, a é o semi-eixo maior da seção elíptica e $b$ é o semi-eixo menor. $A$ é a área de cada segmento. A área total do modelo geométrico é igual a $1,8 \mathrm{~m}^{2}$ e a sua altura é igual a $1,77 \mathrm{~m}$

São consideradas camadas concêntricas de tecidos nos segmentos do modelo geométrico. 

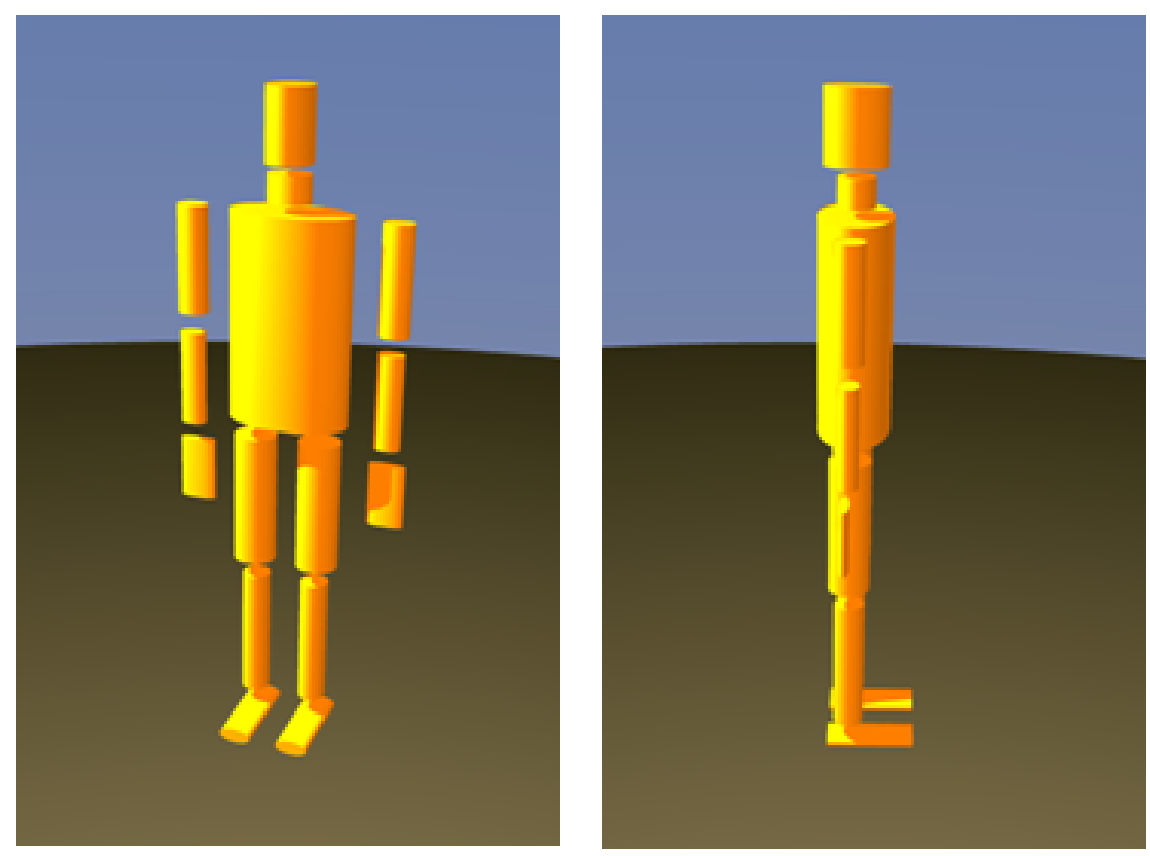

Figura 3.3: Representação geométrica utilizada no MSTCH.

Tabela 3.1: Parâmetros do modelo geométrico.

\begin{tabular}{|c|c|c|c|c|}
\hline Elementos & $A_{s}\left(m^{2}\right)$ & $\mathrm{L}(m)$ & $2 \mathrm{a}(m)$ & $2 \mathrm{~b}(m)$ \\
\hline Cabeça & 0,1135 & 0,20 & 0,131 & 0,173 \\
\hline Pescoço & 0,0294 & 0,08 & 0,128 & 0,105 \\
\hline Tronco & 0,5985 & 0,60 & 0,357 & 0,207 \\
\hline Braço & (2x) 0,1662 & 0,31 & 0,081 & 0,090 \\
\hline Antebraço & (2x) 0,1202 & 0,28 & 0,079 & 0,057 \\
\hline Mão & (2x) 0,0900 & 0,19 & 0,109 & 0,031 \\
\hline Coxa & $(2 x) 0,3402$ & 0,44 & 0,119 & 0,127 \\
\hline Perna & (2x) 0,2160 & 0,40 & 0,083 & 0,089 \\
\hline Pé & (2x) 0,1260 & 0,26 & 0,102 & 0,047 \\
\hline
\end{tabular}

Os tecidos são a pele, a gordura, o músculo, o osso, o cérebro, as vísceras, o pulmão e o coração. Cada segmento do corpo humano é representado por distribuição de camadas e proporções distintos. A representação de cada segmento pode ser vista em Ferreira (2001). Para cada tipo de tecido o MSTCH utiliza as propriedades massa específica, calor específico e condutividade térmica. Também são utilizados valores para parâmetros fisiológicos como metabolismo basal e perfusão basal para cada tipo de tecido. Os valores basais correspondem à situação de baixa atividade física. Para refinar a avaliação são utilizadas vazões de sangue basal diferentes para a pele nos diferentes segmentos.

\subsubsection{Modelo matemático}

O MSTCH resolve a equação da condução de calor, dada pela Eq.(3.51), nos tecidos no interior de cada segmento, nas três dimensões. A variação da energia é calculada pelo termo de transporte por difusão segundo a lei de Fourier para condução de calor e pela geração de 
energia interna $M$, que serve como termo fonte para incluir outros processos de geração ou perda de energia. A equação diferencial é resolvida numericamente pelo MVF.

$$
\rho c \frac{\partial T}{\partial t}=\nabla(k \nabla T)+M
$$

À Eq.(3.51) deve-se adicionar um termo de energia devido à perfusão de sangue, dos pequenos vasos, nos tecidos. A relação (3.52) descreve este termo. A transferência de energia depende da diferença entre as temperaturas do tecido $T$ e do sangue arterial $T_{a r, i}$ e da taxa de perfusão do sangue $\omega_{b l}$. O termo de perfusão é obtido pelo modelo de circulação de Pennes (Ferreira, 2001). O índice subescrito $b l$ indica que a propriedade é avaliada no fluido sangue, o índice subescrito ar indica sangue arterial e o índice $i$ indica que a propriedade é avaliada em cada segmento do manequim.

$$
\omega_{b l} \cdot \rho_{b l} \cdot c_{b l} \cdot\left(T_{a r, i}-T\right)
$$

Os grandes vasos sanguíneos são modelados por dois reservatórios de sangue paralelos, um venoso e o outro arterial, em cada segmento, com exceção do tronco. Há troca de calor contra-corrente entre os dois reservatórios. As Eqs.(3.53) e (3.54) são EDO's que representam o balanço de energia nos reservatórios arterial e venoso, respectivamente. O primeiro termo à direita, em ambas as equações, representa o termo de transporte por advecção. $W_{a r, i n}$ e $W_{v e, i n}$ são as vazões de sangue que entram nos reservatórios arterial e venoso, respectivamente. O segundo termo à direita descreve a troca de calor contra-corrente. Os coeficientes de transferência de calor $H_{a v}$ foram estimados a partir de fatores de forma para condução bidimensional entre dois cilindros imersos em um meio infinito (DeWitt e Incropera, 1996) apud Ferreira (2001). Na Eq.(3.54) o último termo contabiliza o transporte de energia, pela perfusão de sangue, para o reservatório venoso. Para o tronco há uma equação diferencial semelhante à Eq.(3.54), mas com $H_{a v}=0$. O índice "i" indica que a temperatura ou o coeficiente de troca de calor são avaliados em cada segmento do manequim.

$$
\begin{array}{r}
m_{a r, i} \cdot c_{b l} \frac{\partial T_{a r, i}(t)}{\partial t}=\rho_{b l} \cdot c_{b l} \cdot W_{a r, i n}\left(T_{a r, i n}-T_{a r, i}\right)+H_{a v, i}\left(T_{v e, i}-T_{a r, i}\right) \\
m_{v e, i} \cdot c_{b l} \frac{\partial T_{v e, i}(t)}{\partial t}=\rho_{b l} \cdot c_{b l} \cdot W_{v e, i n}\left(T_{v e, i n}-\right. \\
\left.+\int_{v e, i}\right)+H_{a v, i}\left(T_{a r, i}-T_{v e, i}\right)+ \\
+\rho_{b l} \cdot \omega_{b l}\left(T-T_{v e, i}\right) d V
\end{array}
$$

A transferência de calor com o ambiente é descrita pelos processos de convecção, radiação 
transpiração e respiração. A Eq.(3.56) calcula as perdas da calor devido à convecção $C$ e radiação térmica $R$ em função da resistência térmica da roupa $R_{c l}$, da relação entre superfície com roupa e superfície nua $f_{c l}$, temperatura superficial da pele $T_{s}$, temperatura operativa $T_{o}$ e coeficiente combinado de transferência de calor $h$. O coeficiente combinado é obtido a partir dos coeficientes de radiação térmica $h_{r}$ e de convecção $h_{c}$, mostrados na Tab.(3.2). Estes foram obtidos experimentalmente em de Dear et al. (1997).

$$
C+R=\frac{T_{p e l e}-T_{o}}{R_{c l}+\frac{1}{f_{c l} \cdot h}}
$$

Nas simulações integradas neste trabalho os fluxos de calor $C$ e $R$ calculados pelo MSTCH são utilizados somente quando os respectivos fluxos de calor fornecidos pelo simulador de CFD é relaxado. O fator de relaxação $\alpha$ pondera o fluxo de calor combinado conforme a expressão:

$$
C+R=(1-\alpha)(C+R)_{M S T C H}+\alpha(C+R)_{C F D}
$$

As perdas de energia pelo processo de evaporação são calculados conforme a Eq.(3.57). A perda de calor depende da fração de superfície molhada $w$, da umidade relativa do ar $\phi_{a}$, da pressão parcial do vapor d'água $P_{w, a}$ e da pressão de saturação do ar à temperatura da pele $P_{w, s}$. Também é incluído a resistência térmica $R_{e, c l}$ imposta pelas roupas além do fator de área vestida $f_{c l}$. O coeficiente de transferência de calor por evaporação $h_{e}$ também é condição de contorno. Este é obtido a partir do coeficiente convectivo, valendo-se de uma analogia. Os valores utilizados no MSTCH encontram-se na Tab.(3.2).

$$
E=w \frac{P_{w, s}-\phi_{a} P_{w, a}}{R_{e, c l}+\frac{1}{f_{c l} \cdot h_{e}}}
$$

As perdas de calor na respiração são calculadas a partir de modelo proposto por Fanger (1972). A Eq.(3.58) é utilizada para calcular a perda de calor no processo da respiração. O primeiro termo à direita representa a perda de calor latente, onde $\lambda$ é a entalpia de vaporização da água a $34^{\circ} \mathrm{C}$ e à pressão ambiente, $\omega_{e x}$ é a umidade absoluta do ar expirado e $\omega_{a}$ a umidade absoluta do ar inspirado. O segundo termo representa a perda de calor sensível, onde $T_{e x}$ é a temperatura do ar expirado e $T_{a}$ a temperatura do ar inspirado. O MSTCH utiliza equações de Fanger (1972) para calcular $\omega_{e x}-\omega_{a}, T_{e x}$ e a vazão mássica $\dot{m}$. $c_{a}$ é o calor específico do ar inspirado. No MSTCH, $45 \%$ da perda calculada pela respiração é distribuída para os músculos da cabeça, 25\% para os músculos do pescoço e $30 \%$ para o pulmão. Isto é realizado adicionando-se os valores ao termo fonte na Eq.(3.51) para os segmentos da cabeça, pescoço e tronco. 
Tabela 3.2: Coeficientes de transferência de calor utilizados no MSTCH.

\begin{tabular}{lccc}
\hline Elementos & $\begin{array}{c}h_{r} \\
\left(W m^{-2} K^{-1}\right)\end{array}$ & $\begin{array}{c}h_{c} \\
\left(W m^{-2} K^{-1}\right)\end{array}$ & $\begin{array}{c}h_{e} \\
\left(\mathrm{Wm}^{-2} \mathrm{~Pa}^{-1}\right)\end{array}$ \\
\hline \hline Cabeça & 4,1 & 3,6 & 5,9 \\
Pescoço & 4,1 & 3,6 & 5,9 \\
Tronco & 4,4 & 3,2 & 5,3 \\
Braço & 5,2 & 2,9 & 4,8 \\
Antebraço & 4,9 & 3,7 & 6,1 \\
Mão & 4,1 & 4,1 & 6,8 \\
Coxa & 4,3 & 4,1 & 6,8 \\
Perna & 5,3 & 4,1 & 6,8 \\
Pé & 3,9 & 5,1 & 8,4 \\
\hline
\end{tabular}

$$
Q_{R}=\dot{m} \cdot \lambda\left(\omega_{e x}-\omega_{a}\right)+\dot{m} \cdot c_{a}\left(T_{e x}-T_{a}\right)
$$

A termorregulação é modelada por equações empíricas. O MSTCH utiliza a Eq.3.59 proposta por Savage e Brengelmann (1996) apud Ferreira (2001) para calcular a variação da perfusão na pele $\Delta \omega_{\text {pele }}$, a Eq.3.60 proposta por Nadel et al. (1971) apud Ferreira (2001) para calcular a transferência de calor por evaporação do suor $E_{\text {suor }}$ e a Eq.3.61 proposta por Gordon et al. (1976) apud Ferreira (2001) para calcular o calor gerado pelos calafrios $M_{\text {tremor }}$. As equações utilizam variáveis obtidas no interior e na superfície do corpo humano. $K_{1}$ até $K_{7}$ são constantes, $T_{h}$ é a temperatura do hipotálamo, $T_{p e l e}$ é a temperatura da pele, $A_{S}$ é a área superficial do modelo geométrico e $\Delta Q$ é a diferença entre o calor perdido na superfície e o valor correspondente à condição de neutralidade térmica. Os subíndices $i$ e $o$ denotam os segmentos do manequim e valor de referência, respectivamente.

$$
\begin{gathered}
\Delta \omega_{\text {pele }}=K_{1}\left(T_{h}-T_{h, o}\right)+K_{2}\left(T_{\text {pele }}-T_{\text {pele }, o}\right) \\
E_{\text {suor }, i}=\left[K_{3}\left(T_{h}-T_{h, o}\right)+K_{4}\left(T_{\text {pele }}-T_{\text {pele }, o}\right)\right] e^{\frac{T_{p e l e, ~}-T_{\text {pele }, o}}{10}} \\
M_{\text {tremor }} A_{S}=K_{5}\left(T_{h}-T_{h, o}\right)+K_{6}\left(T_{\text {pele }}-T_{\text {pele }, o}\right)+K_{7} \Delta Q
\end{gathered}
$$

As equações para variação da perfusão e para a transpiração na pele são condições de contorno para a solução do balanço térmico no corpo humano. O calor gerado pelos calafrios é incluído como termo fonte na Eq.(3.51) do balanço térmico. 
No presente trabalho, o MSTCH utiliza os fluxos de calor por convecção e radiação obtidos na simulação de CFD. Estas são condições de contorno para a simulação do corpo humano do MSTCH. O MSTCH, por sua vez, calcula as temperaturas superficiais do manequim e as fornece, como condição de contorno, para a simulação de CFD. 


\section{Capítulo 4}

\section{Simulações}

Neste capítulo são apresentadas as simulações numéricas desenvolvidas neste trabalho. Primeiro, é apresentado um estudo de validação de geometria computacional a partir de comparação entre resultados numéricos com resultados experimentais da literatura. Em seguida, são apresentadas as simulações com integração de ferramenta de CFD com MSTCH.

\subsection{Validação geométrica}

Foram avaliadas duas geometrias de manequim computacional para estudo de influência geométrica. A Fig.4.1 mostra o manequim real utilizado nos experimentos da literatura (de Dear et al. (1997)) e os dois manequins computacionais.

O manequim simplificado foi desenvolvido com a ferramenta CAD SolidWorks $₫$. Este manequim apresenta os segmentos do corpo em forma cilíndrica com base elíptica, conforme os parâmetros do modelo geométrico do MSTCH apresentados na Tab.3.1. O manequim complexo apresenta formas mais fiéis ao corpo humano. Esta última geometria foi desenvolvida em Ramsis@. A Tab.4.1 mostra a área superficial dos segmentos e a área total de cada manequim.

A altura dos manequins computacionais foi estimada a partir de informações do manequim real e equações empíricas relacionando altura com o peso e a área superficial do corpo. O manequim real utilizado em de Dear et al. (1997) apresenta 1,471 $\mathrm{m}^{2}$. O índice de massa corporal IMC para uma mulher comum segundo a NHANES II (National Health and Nutrition Examination Survey) é igual a $22,45 \mathrm{~kg} / \mathrm{m}^{2}$. A área DuBois $A D=0.20247 *$ massa $^{0.425} *$ altura $^{0.725}$ correlaciona a área superficial do manequim com a massa corpórea e altura. Após procedimento iterativo obteve-se $1,52 \mathrm{~m}$ de altura para os manequins. Ainda, a postura dos manequins computacionais e a inclinação dos membros inferiores e superiores imitam o manequim real, a fim de minimizar os erros de perdas de calor por radiação térmica devido aos fatores de forma.

Os ensaios experimentais foram conduzidos em túnel de vento com $30 \mathrm{~m}$ de comprimento e 1,5m de altura. Nas simulações numéricas, o domínio computacional é reduzido, com o 
Tabela 4.1: Segmentos dos manequins e áreas superficiais.

\begin{tabular}{lccccc}
\hline $\begin{array}{l}\text { Segmentos } \\
\text { do manequim }\end{array}$ & $\begin{array}{c}\text { experimental } \\
{\left[\mathrm{m}^{2}\right]}\end{array}$ & $\begin{array}{c}\text { geometria complexa } \\
{\left[\mathrm{m}^{2}\right]}\end{array}$ & $\begin{array}{c}\text { geometria simplificada } \\
{\left[\mathrm{m}^{2}\right]}\end{array}$ & var. \\
\hline \hline pés & 0,042 & 0,065 & $155 \%$ & 0,044 & $105 \%$ \\
canelas & 0,089 & 0,095 & $107 \%$ & 0,087 & $98 \%$ \\
coxas & 0,162 & 0,146 & $90 \%$ & 0,156 & $96 \%$ \\
pélvis & 0,182 & 0,156 & $86 \%$ & 0,132 & $73 \%$ \\
cabeça & 0,100 & 0,113 & $113 \%$ & 0,120 & $120 \%$ \\
mãos & 0,037 & 0,035 & $95 \%$ & 0,037 & $100 \%$ \\
antebraço & 0,052 & 0,043 & $83 \%$ & 0,052 & $100 \%$ \\
braço & 0,073 & 0,048 & $66 \%$ & 0,078 & $107 \%$ \\
peito & 0,144 & 0,141 & $98 \%$ & 0,159 & $110 \%$ \\
costas & 0,133 & 0,106 & $80 \%$ & 0,159 & $120 \%$ \\
\hline total & 1,471 & 1,377 & $94 \%$ & 1,479 & $101 \%$ \\
\hline
\end{tabular}

manequim a $1,225 \mathrm{~m}$ da fronteira de insuflamento de ar e a $4 m$ da fronteira de exaustão, para reduzir o tempo de processamento. A velocidade do ar insuflado e as temperaturas das paredes do túnel e das superfícies do manequim são controladas. A Fig.A.1 no apêndice A esquematiza o experimento.

Primeiro foi gerada uma malha para a geometria simplificada com aproximadamente 2,5 milhões de elementos e com espessura das camadas de prisma de aproximadamente 30 milímetros. Esta malha não foi suficiente para as simulações com insuflamento do ar acima de $3 \mathrm{~m} / \mathrm{s}$ devido às limitações para o tratamento de parede aprimorado $y^{+}<5$. Por este motivo, a malha para a geometria simplificada foi substituída por uma nova malha com 3,8 milhões de elementos, mais refinada que a primeira. Também foi gerada uma malha com 4,6 milhões de elementos para a geometria complexa, já com os parâmetros da malha refinada. As malhas são não-estruturadas e apresentam elementos tetraédricos com camadas de elementos prismáticos junto às superfícies do manequim, visando uma melhor solução dentro da camada limite. A Fig.4.2 mostra a malha volumétrica com seus elementos de

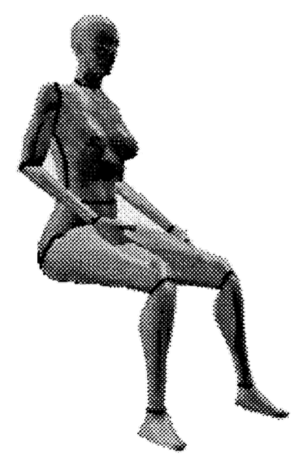

(a)

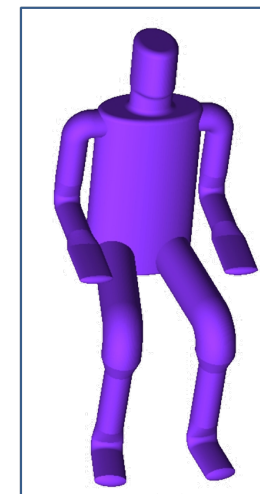

(b)

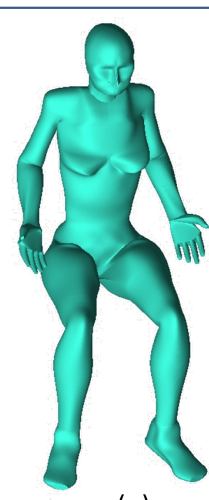

(c)

Figura 4.1: Manequim real (a), manequim computacional simplificado (b) e manequim computacional complexo $(\mathrm{c})$. 
prisma na geometria complexa.

A Tab.4.2 mostra os parâmetros utilizados para obter as camadas de prisma. Junto ao peito e à pélvis a malha apresenta cinco camadas de prismas e nos demais segmentos apresenta quatro camadas. A lei de crescimento das camadas de prisma é exponencial. As camadas de prismas apresentam aproximadamente 15 milímetros de espessura para diminuir o $y^{+}$nas superfícies do manequim.

As condições de contorno na simulação representam o experimento em de Dear et al. (1997). Na seção de entrada a velocidade do escoamento é prescrita. O ar insuflado recebe um tratamento de contorno para velocidade admitida (velocity inlet) na fronteira a montante. Esta condição prescreve velocidade constante e permite que a pressão total do escoamento seja determinada a partir da solução interna. Para uma completa definição da condição de contorno, a turbulência também deve ser informada. A intensidade de turbulência foi prescrita desde 4,1\% até 8,4\% dependendo da velocidade do ar insuflado, conforme os experimentos em de Dear et al.. A escala de comprimento foi prescrita em $0,5 \mathrm{~m}$. Os ensaios experimentais foram conduzidos com um cilindro de $0,5 \mathrm{~m}$ de largura a montante do

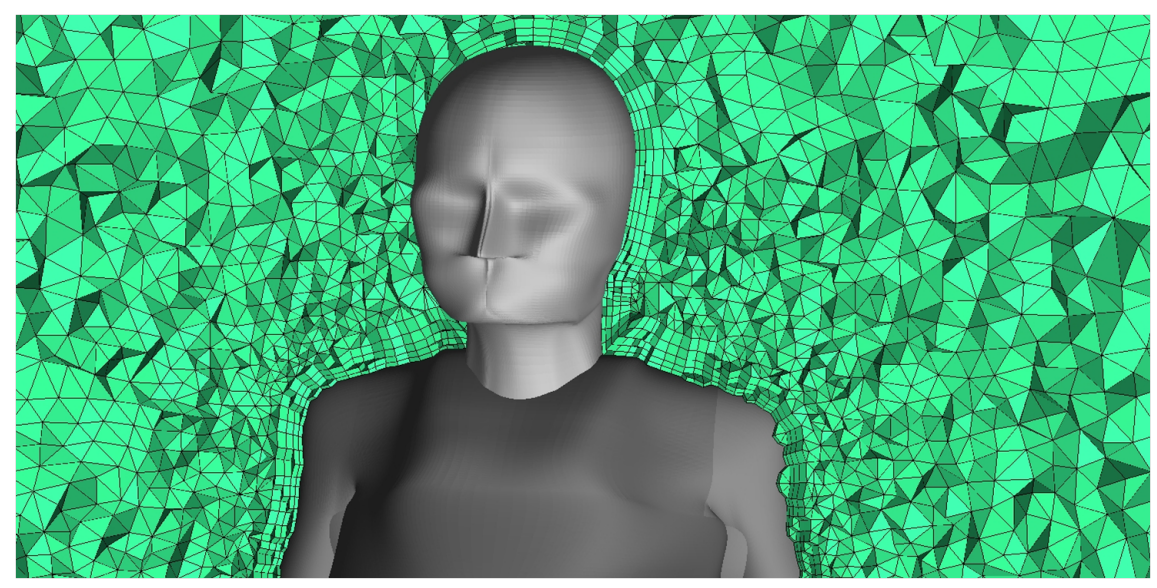

Figura 4.2: Malha volumétrica próxima ao manequim.

Tabela 4.2: Parâmetros das camadas de prisma das malhas computacionais - altura e número de elementos.

\begin{tabular}{lcc}
\hline segmentos & \multicolumn{2}{c}{ parâmetros da malha } \\
do manequim & altura $(\mathrm{mm})$ & $\mathrm{n}^{\circ}$ camadas \\
\hline \hline cabeça & 15 & 4 \\
peito & 15 & 5 \\
pélvis & 15 & 5 \\
costas & 15 & 4 \\
braços & 15 & 4 \\
antebraços & 15 & 4 \\
mãos & 15 & 4 \\
coxas & 15 & 4 \\
canelas & 15 & 4 \\
pés & 15 & 4 \\
\hline
\end{tabular}




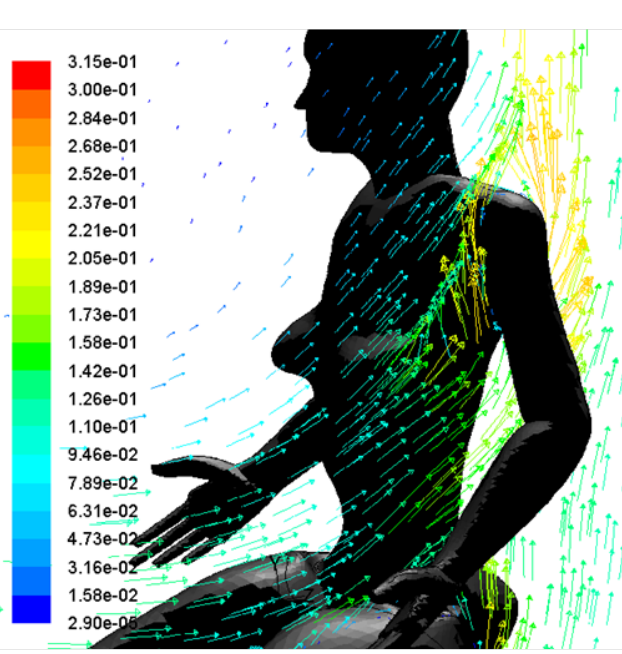

(a)

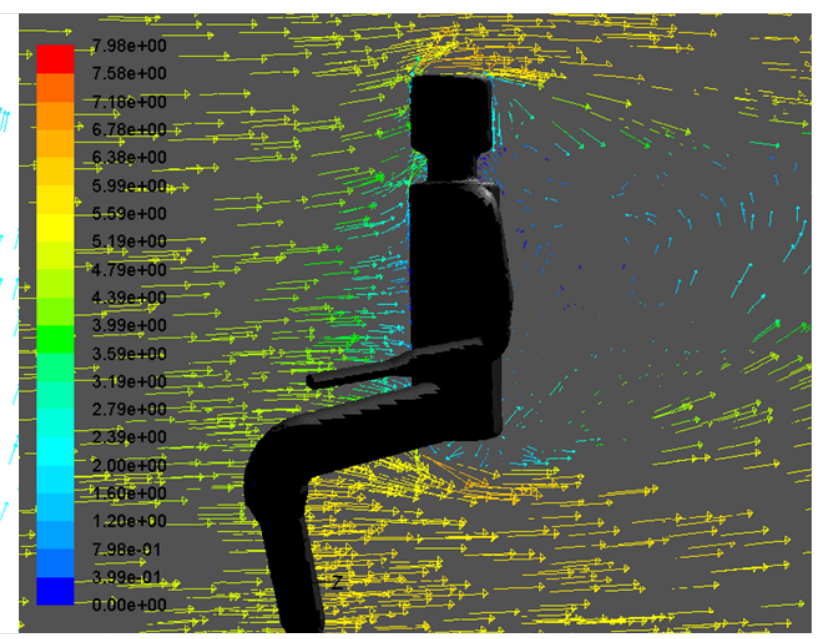

(b)

Figura 4.3: Pluma térmica em torno do manequim complexo: insuflamento de ar a $0,05 \mathrm{~m} / \mathrm{s}$.

escoamento para gerar turbilhões de larga escala.

$\mathrm{Na}$ fronteira a jusante o escoamento recebe tratamento de contorno de fluxo em saída (outflow condition). Esta condição é adequada quando a velocidade e a pressão não são conhecidas no início do processo iterativo. Toda a solução é extrapolada do interior do escoamento. Para evitar escoamento reverso o domínio computacional foi desenhado com maior extensão a jusante do escoamento: o manequim está posicionado a um metro da fronteira a montante e três metros da fronteira a jusante.

A temperatura do manequim é prescrita em $34^{\circ} \mathrm{C}$ e a temperatura das paredes são prescritas em $22^{\circ} \mathrm{C}$. As superfícies são prescritas com emissividade igual a 0,95 para a radiação.

A turbulência é tratada com modelo k- $\epsilon$ RNG de duas equações. O tratamento de parede é realizado com modelo aprimorado (enhanced wall treatment). A radiação térmica é tratada pelo modelo dos feixes discretos (discrete ordinates). São desconsiderados o fator de espalhamento e o coeficiente de absorção na equação de transporte radiativa RTE uma vez que o meio é não-participante.

Foram simuladas sete condições de insuflamento: velocidade de insuflamento do ar de $0,05 \mathrm{~m} / \mathrm{s}$ para convecção natural e $0,2 \mathrm{~m} / \mathrm{s}, 0,5 \mathrm{~m} / \mathrm{s}, 1,2 \mathrm{~m} / \mathrm{s}, 2,0 \mathrm{~m} / \mathrm{s}, 3,0 \mathrm{~m} / \mathrm{s}$, e $5,0 \mathrm{~m} / \mathrm{s}$ para convecção forçada. O critério de parada nas simulações foi resíduo nas equações: $10^{-4}$ para as equações de momento, da continuidade, de $\mathrm{k}$ e de $\epsilon$; e $10^{-7}$ para as equações da energia e equação da transferência radiativa.

A Fig.4.3 mostra os vetores do escoamento em plano de corte próximo ao manequim complexo com velocidade de insuflamento do ar a $0,05 \mathrm{~m} / \mathrm{s}$ e manequim simplificado com velocidade de insuflamento do ar a $5 \mathrm{~m} / \mathrm{s}$. Pode-se observar a formação de pluma térmica ao redor do ombro/cabeça. Este fenômeno é esperado nas menores velocidades, em situações com escoamento natural. Para contabilizar este fenômeno teve que se considerar a variação da massa específica no termo de empuxo na equação de momento.

A Fig.4.4 mostra o mapa do fluxo de calor total - composto pelo fluxo de calor por 

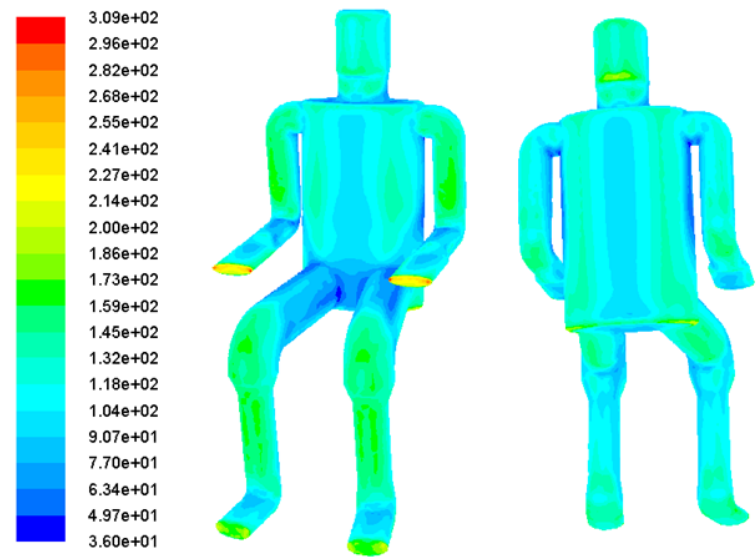

(a)
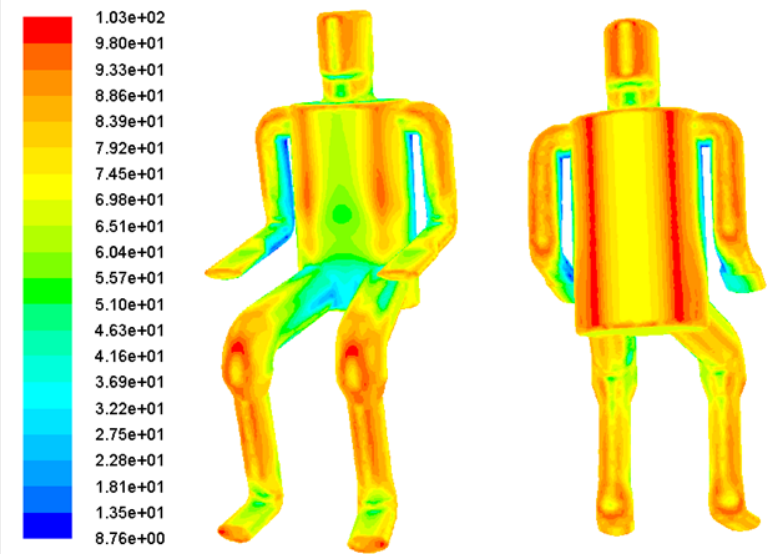

(b)

Figura 4.4: Perdas de calor nas superfícies do manequim para escoamento quase estagnado (insuflamento a $0,05 \mathrm{~m} / \mathrm{s}$ ). Perdas de calor total $\left(W / m^{2}\right)$ (a) e perdas de calor por radiação térmica $\left(W / m^{2}\right)(\mathrm{b})$.

convecção mais o fluxo de calor devido à radiação térmica - e o mapa do fluxo de calor por radiação térmica somente. $\mathrm{O}$ manequim a $34^{\circ} \mathrm{C}$ perde calor por convecção para o escoamento de ar mais frio e perde calor por radiação para as paredes a $22^{\circ} \mathrm{C}$.

A convecção é mais intensa nas extremidades da mão e a radiação térmica é menos intensa na região pélvica e nas regiões entre os braços e o tronco. A disposição dos segmentos do manequim é preponderante para os fatores de forma. Há faixas verticais no tronco do manequim que concentram a perda de calor por radiação. Provavelmente, isto é devido ao fator de forma para as paredes laterais do domínio.

A Tab.4.3 compara os coeficientes experimentais e numéricos de radiação térmica $h_{r}$ e de convecção natural $h_{c}$ obtidos no ensaio experimental em de Dear et al. e simulação numérica, para velocidade de escoamento abaixo de $0,1 \mathrm{~m} / \mathrm{s}$ (convecção natural). No pósprocessamento do CFD, os coeficientes de convecção e de radiação térmica são obtidos pela divisão dos respectivos fluxos de calor através da pele do manequim com a diferença de temperatura entre a pele e uma temperatura de referência aqui definida como $22^{\circ} \mathrm{C}$, igual a temperatura das paredes e do ar insuflado. Os fluxos de calor e a temperatura da pele do manequim são avaliados nas faces dos elementos de malha adjacentes às paredes.

As simulações numéricas superestimaram as perdas por radiação térmica. Considerando os resultados médios para o corpo inteiro, a geometria complexa superestima em $12 \%$ o coeficiente de radiação e a geometria simplificada superestima em $33 \%$ o mesmo coeficiente. Isto indica que a disposição espacial e a proporção de áreas superficiais dos membros do manequim interferem no cálculo da radiação térmica. As geometrias apresentam diferenças sutis de postura. Os antebraços do manequim complexo estão mais estendidos para baixo e estão mais próximos das coxas. Também há uma desproporção entre as áreas por segmento do manequim. Por exemplo, os pés e coxas do manequim complexo são maiores, mas os braços e costas são menores. Ademais, a geometria complexa apresenta formas irregulares. 
A simulação da convecção teve melhor desempenho para ambas as geometrias. Considerando os resultados médios para o corpo inteiro, tanto a geometria complexa quanto a simplificada superestiram a convecção natural em 5\%. O pior resultado nas mãos do manequim complexo deve-se a superestimação da perda por convecção nas superfícies arredondadas de menores raios, como nos dedos das mãos, conforme Fig.4.5. Isto pode ser devido à limitação do modelo de tratamento de parede. Um mapa do $y^{+}$para ambas as geometrias será mostrado mais a seguir.

Tabela 4.3: Coeficientes de transferência de calor por radiação $h_{r}$ e por convecção natural $h_{c}$ para velocidade de escoamento abaixo de $0,1 \mathrm{~m} / \mathrm{s} .\left(^{*}\right)$ coeficiente experimental.

\begin{tabular}{lcccccc}
\hline Segmento & \multicolumn{2}{c}{$h_{r}\left(W m^{-2} K^{-1}\right)$} & \multicolumn{3}{c}{$h_{c}\left(W m^{-2} K^{-1}\right)$} \\
& de Dear* & $\begin{array}{c}\text { CFD } \\
\text { complexa }\end{array}$ & $\begin{array}{c}\text { CFD } \\
\text { simples }\end{array}$ & de Dear* & $\begin{array}{c}\text { CFD } \\
\text { complexa }\end{array}$ & $\begin{array}{c}\text { CFD } \\
\text { simples }\end{array}$ \\
\hline \hline pé (esq. e dir.) & 4,2 & 5,61 & 6,54 & 4,2 & 3,93 & 3,89 \\
canela (esq. e dir.) & 5,4 & 5,31 & 6,76 & 4,0 & 3,62 & 3,69 \\
coxa (esq. e dir.) & 4,6 & 4,78 & 5,67 & 3,7 & 3,29 & 3,24 \\
pélvis & 4,8 & 4,82 & 6,06 & 2,8 & 2,92 & 3,36 \\
cabeça & 3,9 & 5,48 & 6,36 & 3,7 & 3,03 & 3,28 \\
mão (esq. e dir.) & 3,9 & 4,43 & 5,12 & 4,5 & 6,45 & 4,47 \\
antebraço (esq. e dir.) & 5,2 & 4,75 & 5,15 & 3,8 & 3,95 & 3,95 \\
braço (esq. e dir.) & 4,8 & 5,08 & 5,98 & 3,4 & 3,54 & 3,95 \\
peito & 3,4 & 5,03 & 5,74 & 3,0 & 3,13 & 3,20 \\
costas & 4,6 & 5,04 & 6,28 & 2,6 & 2,43 & 2,51 \\
todo o corpo & 4,5 & 5,04 & 5,98 & 3,3 & 3,47 & 3,45 \\
\hline
\end{tabular}

Tabela 4.4: Variação percentual dos coeficientes de transferência de calor por radiação $h_{r}$ e por convecção natural $h_{c}$ em relação aos resultados experimentais.

\begin{tabular}{|c|c|c|c|c|}
\hline Segmento & $\begin{array}{l}\text { var. perce } \\
\text { geometria } \\
\text { complexa }\end{array}$ & $\begin{array}{c}\text { tual de } h_{r} \\
\text { geometria } \\
\text { simples }\end{array}$ & $\begin{array}{l}\text { var. perce } \\
\text { geometria } \\
\text { complexa }\end{array}$ & $\begin{array}{c}\text { tual de } h_{c} \\
\text { geometria } \\
\text { simples }\end{array}$ \\
\hline pé (esq. e dir.) & $134 \%$ & $156 \%$ & $94 \%$ & $93 \%$ \\
\hline canela (esq. e dir.) & $98 \%$ & $125 \%$ & $91 \%$ & $92 \%$ \\
\hline coxa (esq. e dir.) & $104 \%$ & $123 \%$ & $89 \%$ & $88 \%$ \\
\hline pélvis & $100 \%$ & $126 \%$ & $104 \%$ & $120 \%$ \\
\hline cabeça & $141 \%$ & $163 \%$ & $82 \%$ & $89 \%$ \\
\hline mão (esq. e dir.) & $114 \%$ & $131 \%$ & $143 \%$ & $99 \%$ \\
\hline antebraço (esq. e dir.) & $91 \%$ & $99 \%$ & $104 \%$ & $104 \%$ \\
\hline braço (esq. e dir.) & $106 \%$ & $125 \%$ & $104 \%$ & $116 \%$ \\
\hline peito & $148 \%$ & $169 \%$ & $104 \%$ & $107 \%$ \\
\hline costas & $110 \%$ & $137 \%$ & $93 \%$ & $97 \%$ \\
\hline todo o corpo & $112 \%$ & $133 \%$ & $105 \%$ & $105 \%$ \\
\hline
\end{tabular}

A Fig.4.6 e a Fig.4.7 mostram o perfil do escoamento ao longo do domínio computacional. Quando o ar é insuflado a $0,05 \mathrm{~m} / \mathrm{s}$ forma-se uma zona de recirculação a montante 


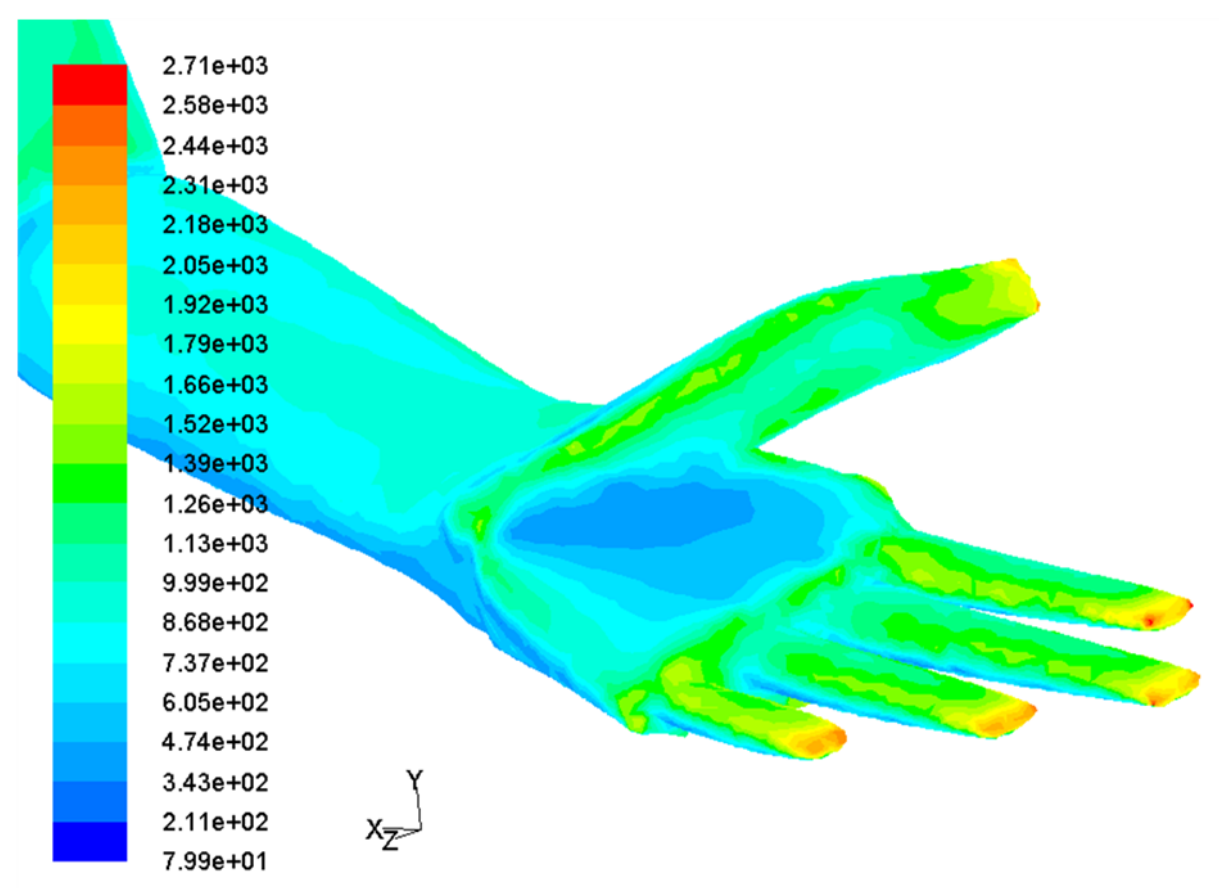

Figura 4.5: Perdas de calor total $\left(W / m^{2}\right)$ na mão do manequim complexo em simulação do escoamento a $5 \mathrm{~m} / \mathrm{s}$.

do manequim e a pluma térmica é perceptível em torno do tronco do manequim. A partir de $0,5 \mathrm{~m} / \mathrm{s}$ a um descolamento do escoamento na região das costas do manequim.

A Fig.4.8 mostra mapas de fluxo de calor total - convecção mais radiação térmica - no manequim simplificado. Nas simulações com velocidade do ar acima de $0,5 \mathrm{~m} / \mathrm{s}$ é possível observar a queda da perda de calor na região posterior do manequim, devido ao descolamento do escoamento.

A Fig.4.9 mostra o contorno de $y^{+}$nos manequins simplificado e complexo para a situação com insuflamento do ar a $5 \mathrm{~m} / \mathrm{s}$. Os menores valores de $y^{+}$concentram-se na região posterior dos manequins, como costas e região posterior das canelas, onde as velocidades do escoamento são menores devido à recirculação provocada pelo desprendimento da camada limite. O $y^{+}$ também é menor numa estreita faixa vertical na região frontal e central do tronco, devido à estagnação do escoamento em bordo de ataque. Em regiões com raios de curvatura menores o $y^{+}$tende a ser maior. Este efeito ocorre mais no manequim complexo devido ao maior número de irregularidades das superfícies.

A Tab.4.5 mostra os valores médios do $y^{+}$nos segmentos do manequim complexo e simplificado para velocidades do ar iguais a 0,05 e $5 \mathrm{~m} / \mathrm{s}$. Todas as simulações apresentam valores médios de $y^{+}$nos segmentos que atendem ao requisito do tratamento de parede do modelo de turbulência.

As Fig.4.10, 4.11 e 4.12 mostram os resultados experimental e numérico da convecção como função da velocidade do ar. As curvas de regressão obtidas experimentalmente representam uma média dos valores obtidos considerando-se oito direções do escoamento em torno do manequim. O apêndice A explica os experimentos em de Dear et al. (1997). Estas 


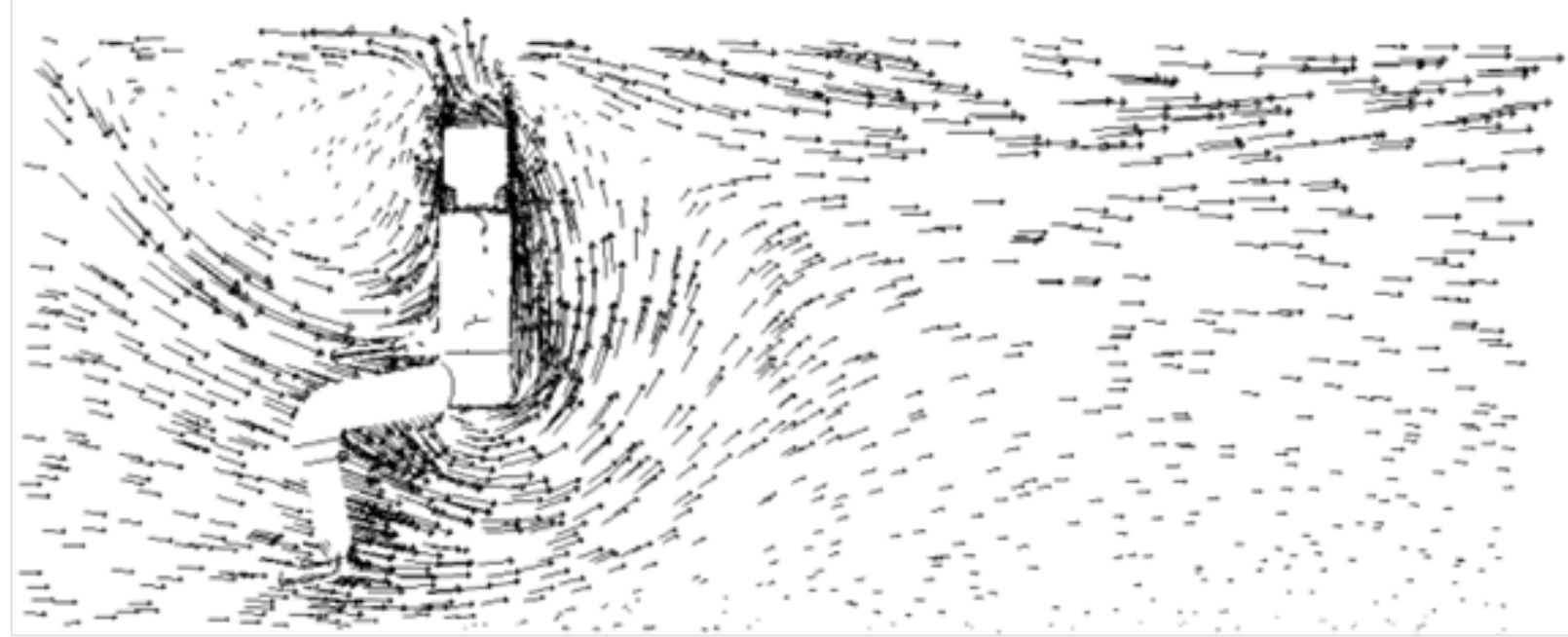

a) Insuflamento a $0,05 \mathrm{~m} / \mathrm{s}$

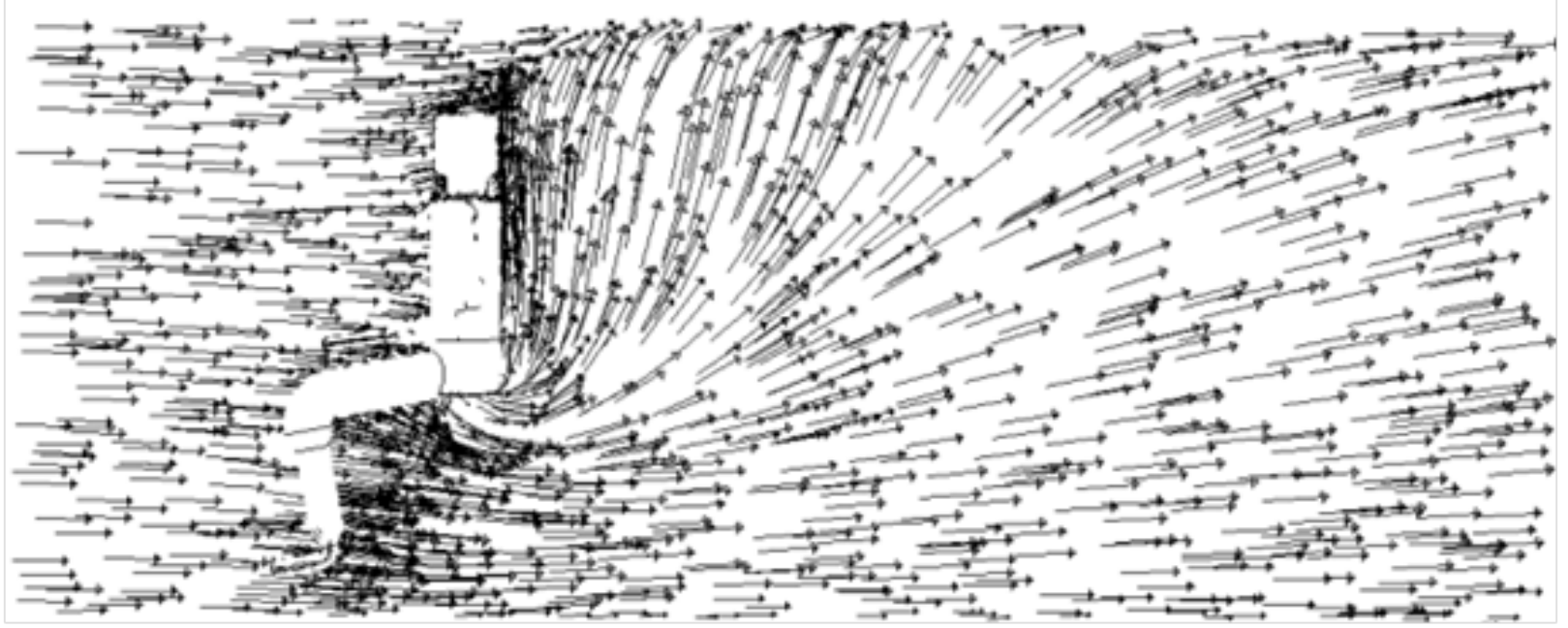

b) Insuflamento a $0,2 \mathrm{~m} / \mathrm{s}$

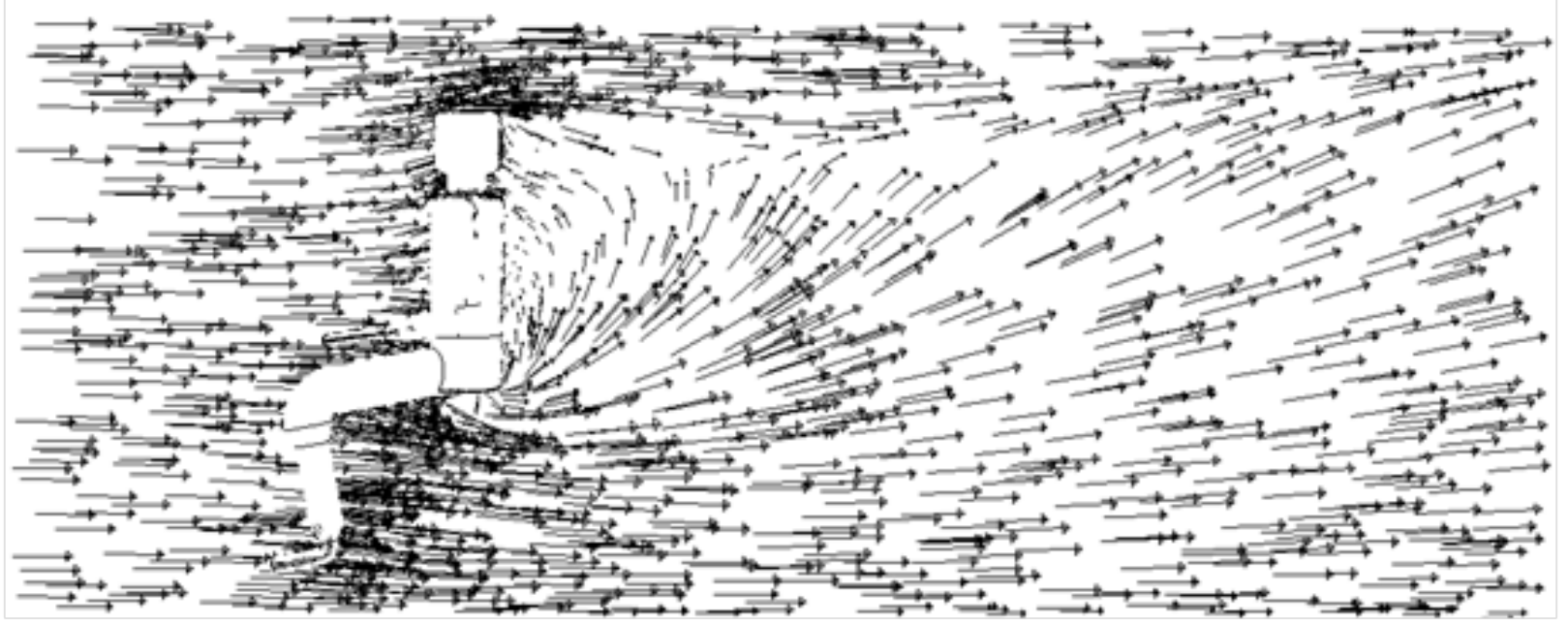

c) Insuflamento a $0,5 \mathrm{~m} / \mathrm{s}$

Figura 4.6: Vetores de velocidade do escoamento em plano de corte longitudinal. (a) insuflamento a $0,05 \mathrm{~m} / \mathrm{s}$, (b) insuflamento a $0,2 \mathrm{~m} / \mathrm{s}$ e (c) insuflamento a $0,5 \mathrm{~m} / \mathrm{s}$. 


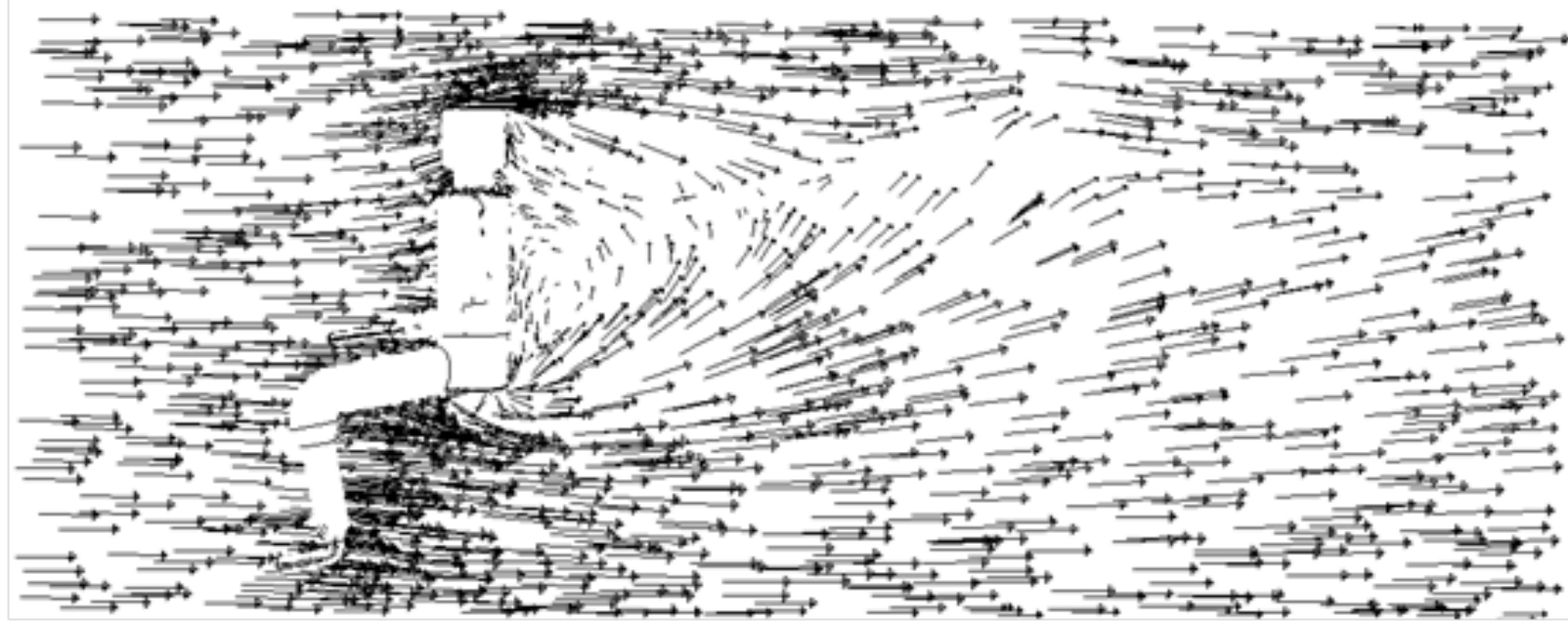

a) Insuflamento a $0,8 \mathrm{~m} / \mathrm{s}$

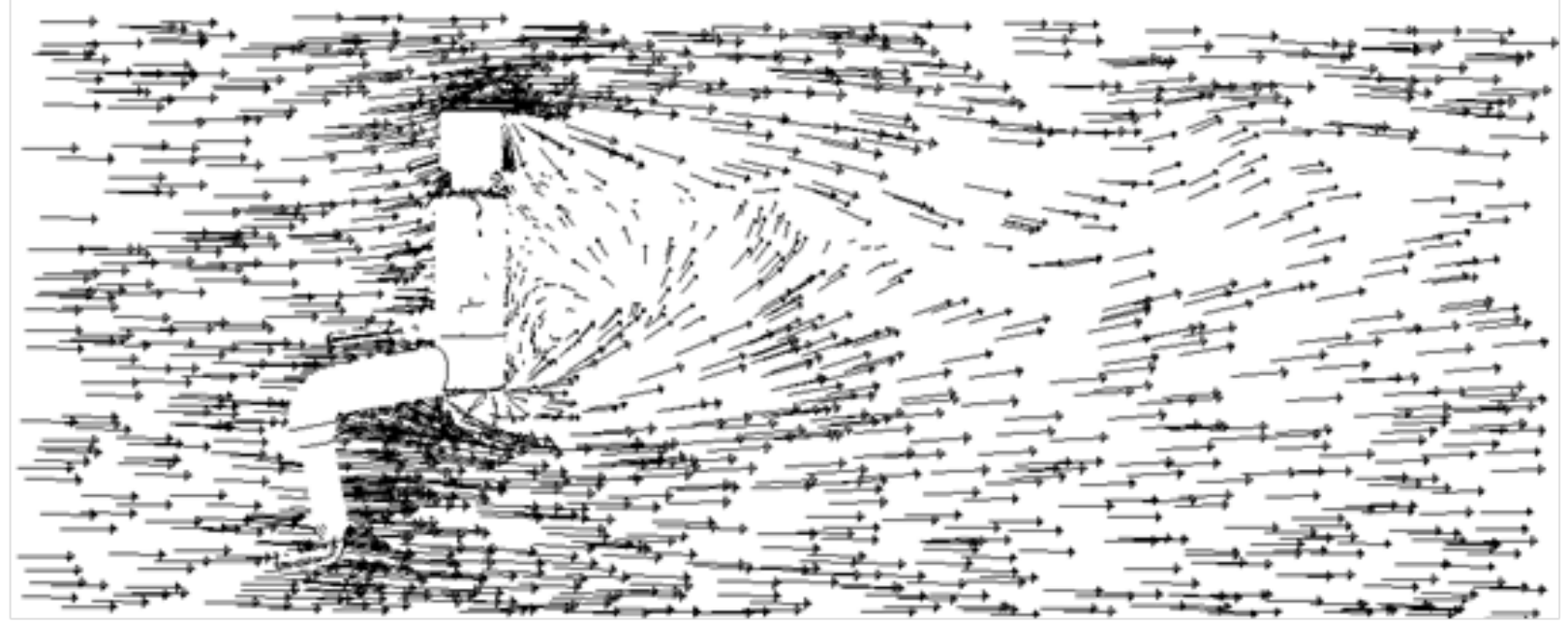

b) Insuflamento a $3 \mathrm{~m} / \mathrm{s}$

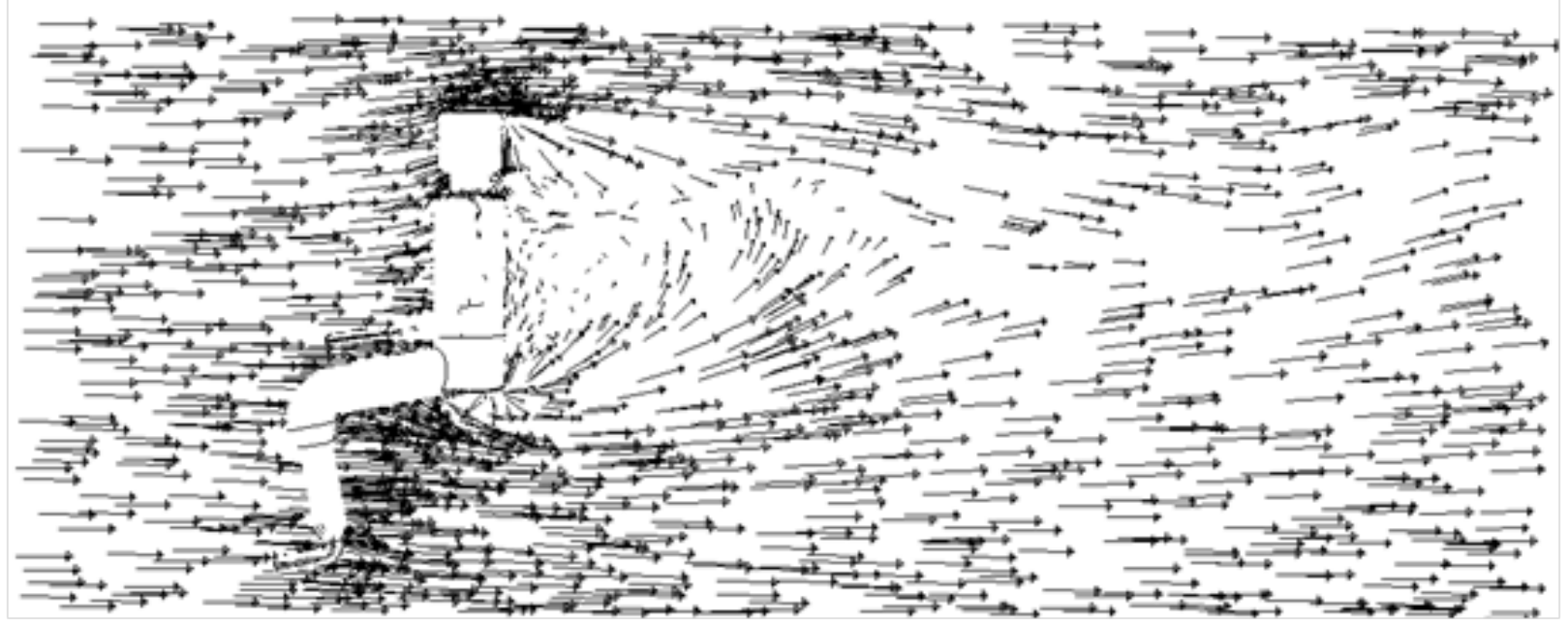

c) Insuflamento a $5 \mathrm{~m} / \mathrm{s}$

Figura 4.7: Vetores de velocidade do escoamento em plano de corte longitudinal. (a) insuflamento a $0,8 \mathrm{~m} / \mathrm{s}$, (b) insuflamento a $3 \mathrm{~m} / \mathrm{s}$ e (c) insuflamento a $5 \mathrm{~m} / \mathrm{s}$ 


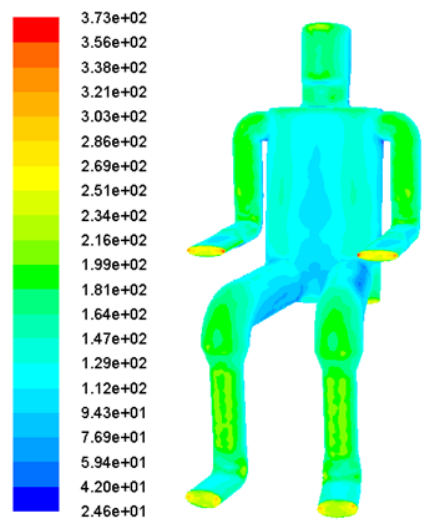

(a)

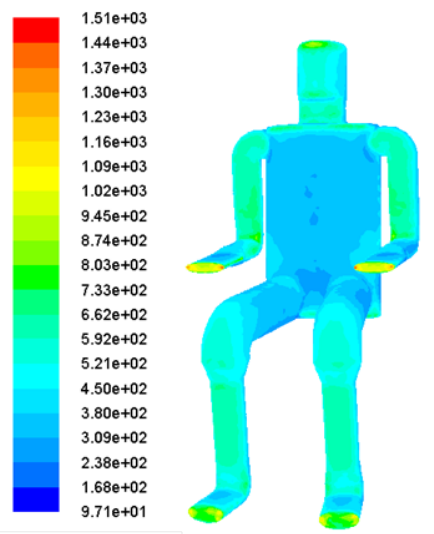

(c)
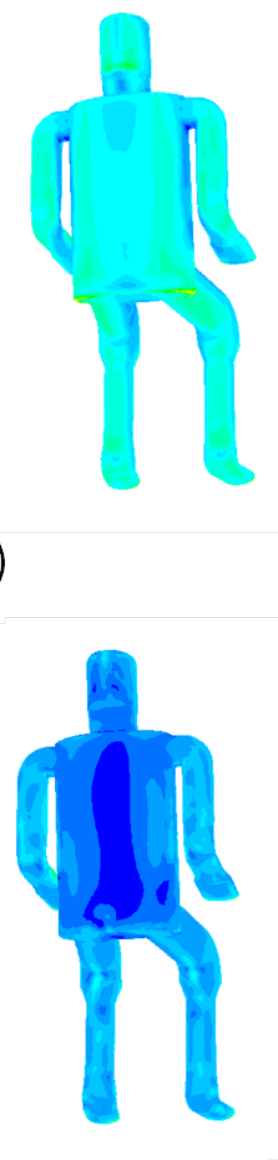

)

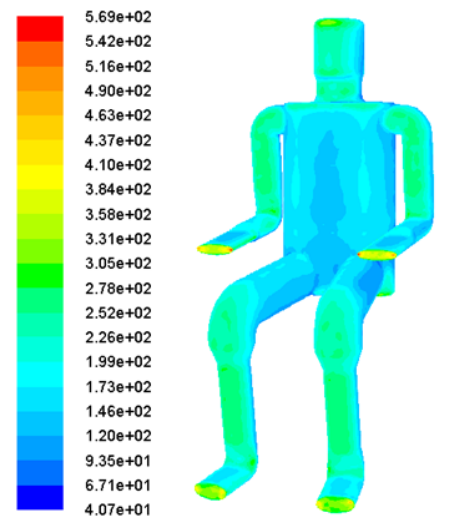

(b)

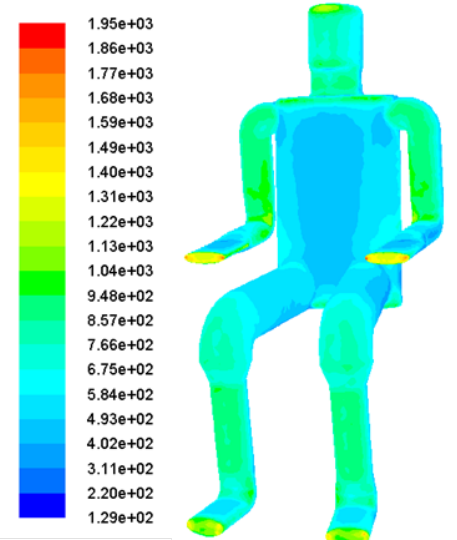

(d)
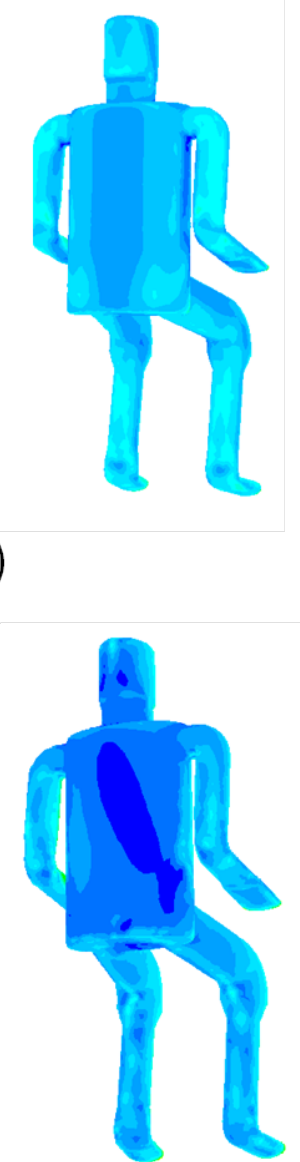

Figura 4.8: Mapa de fluxo de calor total no manequim simplificado $\left(W / m^{2}\right)$. Simulação com insuflamento a $0,05 \mathrm{~m} / \mathrm{s}$ (a), insuflamento a $0,5 \mathrm{~m} / \mathrm{s}$ (b), insuflamento a $3 \mathrm{~m} / \mathrm{s}$ (c) e insuflamento a $5 \mathrm{~m} / \mathrm{s}(\mathrm{d})$.

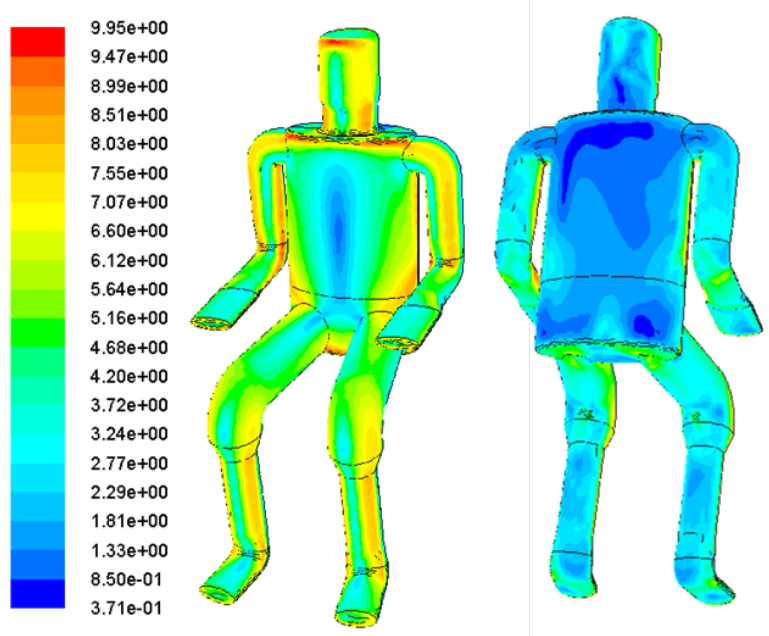

(a)

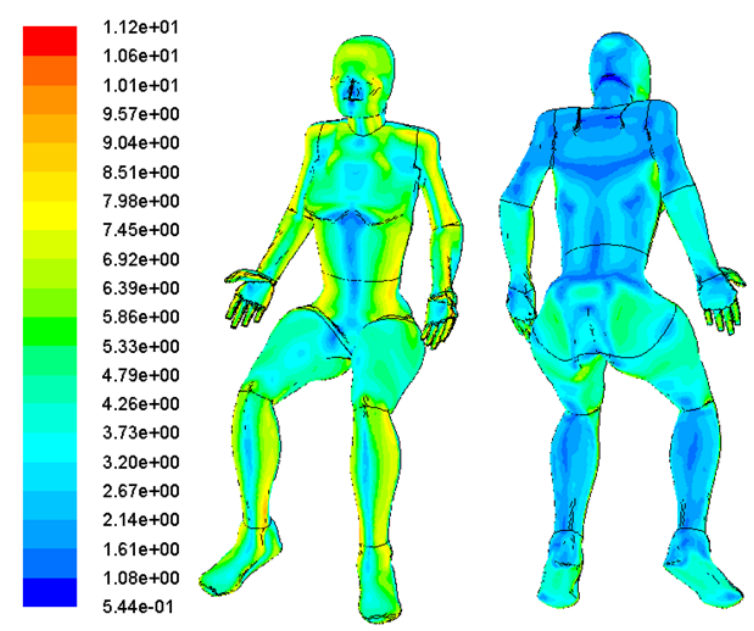

(b)

Figura 4.9: Contorno de $y^{+}$no manequim simplificado (a) e complexo (b) para velocidade do escoamento igual a $5 \mathrm{~m} / \mathrm{s}$. 
Tabela 4.5: Valor médio do $y^{+}$ponderado pela área nos segmentos.

\begin{tabular}{lcccc}
\hline segmentos & \multicolumn{2}{c}{ malha complexa } & \multicolumn{2}{c}{ malha simplificada } \\
do manequim & $0,05 \mathrm{~m} / \mathrm{s}$ & $5 \mathrm{~m} / \mathrm{s}$ & $0,05 \mathrm{~m} / \mathrm{s}$ & $5 \mathrm{~m} / \mathrm{s}$ \\
\hline \hline cabeça & 0,39 & 4,19 & 0.37 & 4.46 \\
peito & 0,40 & 4,77 & 0.43 & 4.76 \\
pélvis & 0,39 & 3,83 & 0.35 & 3.37 \\
costas & 0,47 & 2,51 & 0.45 & 2.02 \\
braço & 0,41 & 4,00 & 0.39 & 4.54 \\
antebraço & 0,39 & 4,85 & 0.36 & 4.62 \\
mão & 0,35 & 5,80 & 0.27 & 3.82 \\
coxa & 0,35 & 4,31 & 0.33 & 4.52 \\
canela & 0,35 & 4,47 & 0.35 & 4.64 \\
pé & 0,29 & 4,41 & 0.26 & 4.17 \\
\hline
\end{tabular}

curvas de regressão estão escritas matematicamente na Tab.A.1. Já os valores experimentais registrados por um " $\mathrm{x}$ " foram medidos com o escoamento defronte para a face do manequim, tal como nas simulações numéricas deste trabalho.

Os gráficos das Fig.4.10 a 4.12 mostram que os resultados numéricos correspondem aos resultados experimentais para as velocidades do escoamento mais baixas, de zero a 1,2m/s. Exceção é feita para as mãos do manequim complexo, onde a perda de calor por convecção é superestimada nas superfícies arredondadas de menor raio, como dedos. Na cabeça os resultados numéricos são menores por que no experimento foi utilizada uma peruca no manequim, o que justifica menores perdas de calor por convecção na cabeça do manequim real em virtude do efeito resistivo. Nas costas os resultados de convecção são baixo possivelmente devido ao descolamento do escoamento, especialmente nas maiores velocidades.

\subsubsection{Conclusões}

Neste capítulo foram realizadas simulações do escoamento e da transferência de calor em manequim no interior de um túnel de vento. Os resultados do fluxo de calor nas superfícies do manequim foram comparados com resultados experimentais da literatura. O objetivo deste estudo é validar a simulação numérica do escoamento de baixa velocidade sobre manequins, visando avaliações de ambientes térmicos ou estudo de conforto térmico com ferramentas numéricas.

As simulações apresentaram qualidade de malha coerente com os requisitos do tratamento de parede aprimorado, ou seja, $y^{+}<5$ (Fluent Inc. (2006)). Os valores médios do $y^{+}$nos segmentos dos manequins atendem ao requisito do modelo de tratamento de parede do modelo de turbulência, exceto na mão do manequim complexo no escoamento mais crítico, com velocidade de insuflamento do ar igual a $5 \mathrm{~m} / \mathrm{s}$, conforme Tab.4.5. Considerando valores pontuais, apenas as simulações com velocidade de $3 \mathrm{~m} / \mathrm{s}$ e $5 \mathrm{~m} / \mathrm{s}$ apresentam regiões com $y^{+}$ superior a cinco, mesmo assim sem ultrapassar 11,2, como mostra a Fig.4.9.

A modelagem da pluma térmica a partir do modelo de Boussinesq atendeu as expecta- 

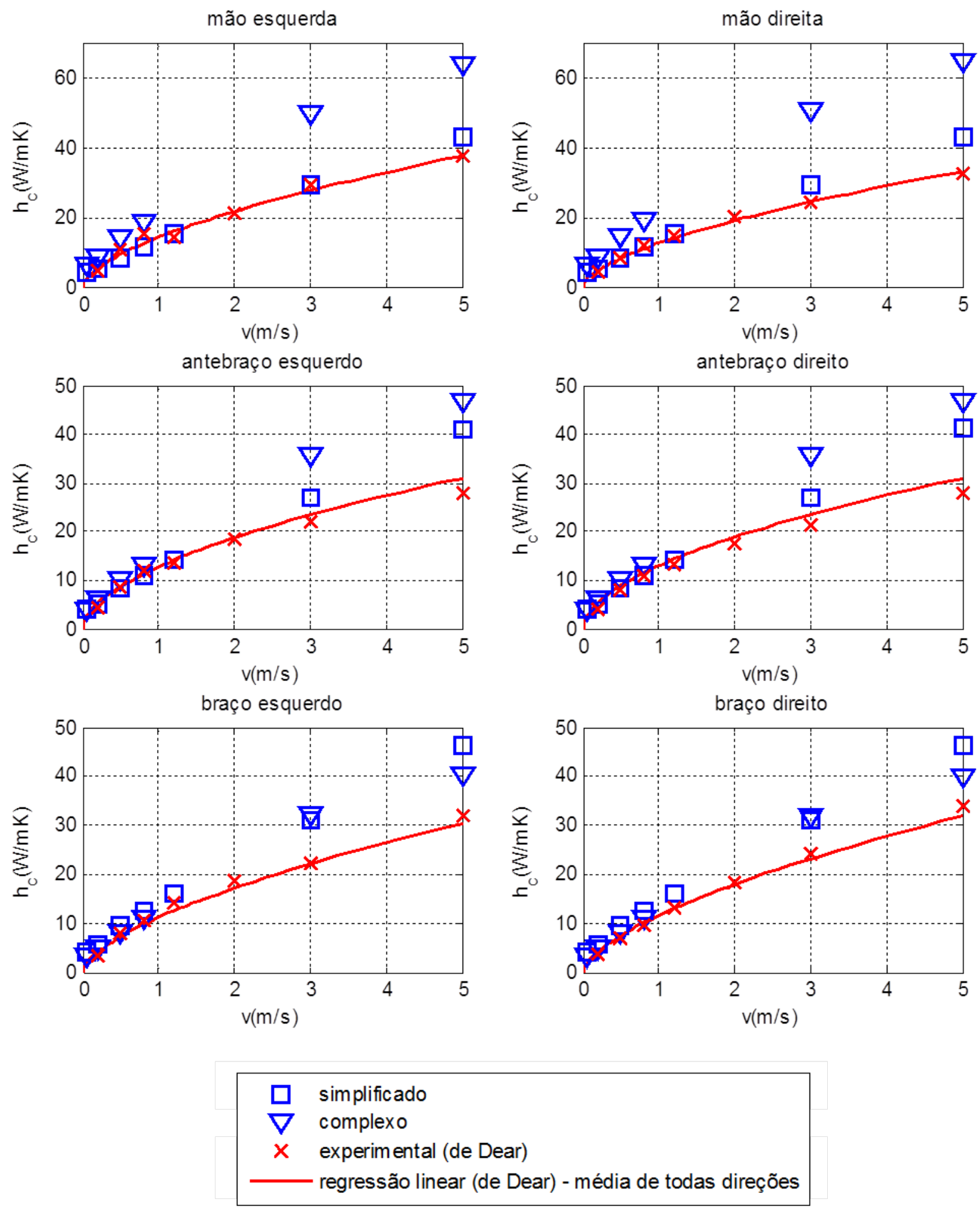

Figura 4.10: Comparação dos resultados do coeficiente de convecção: Membros superiores 

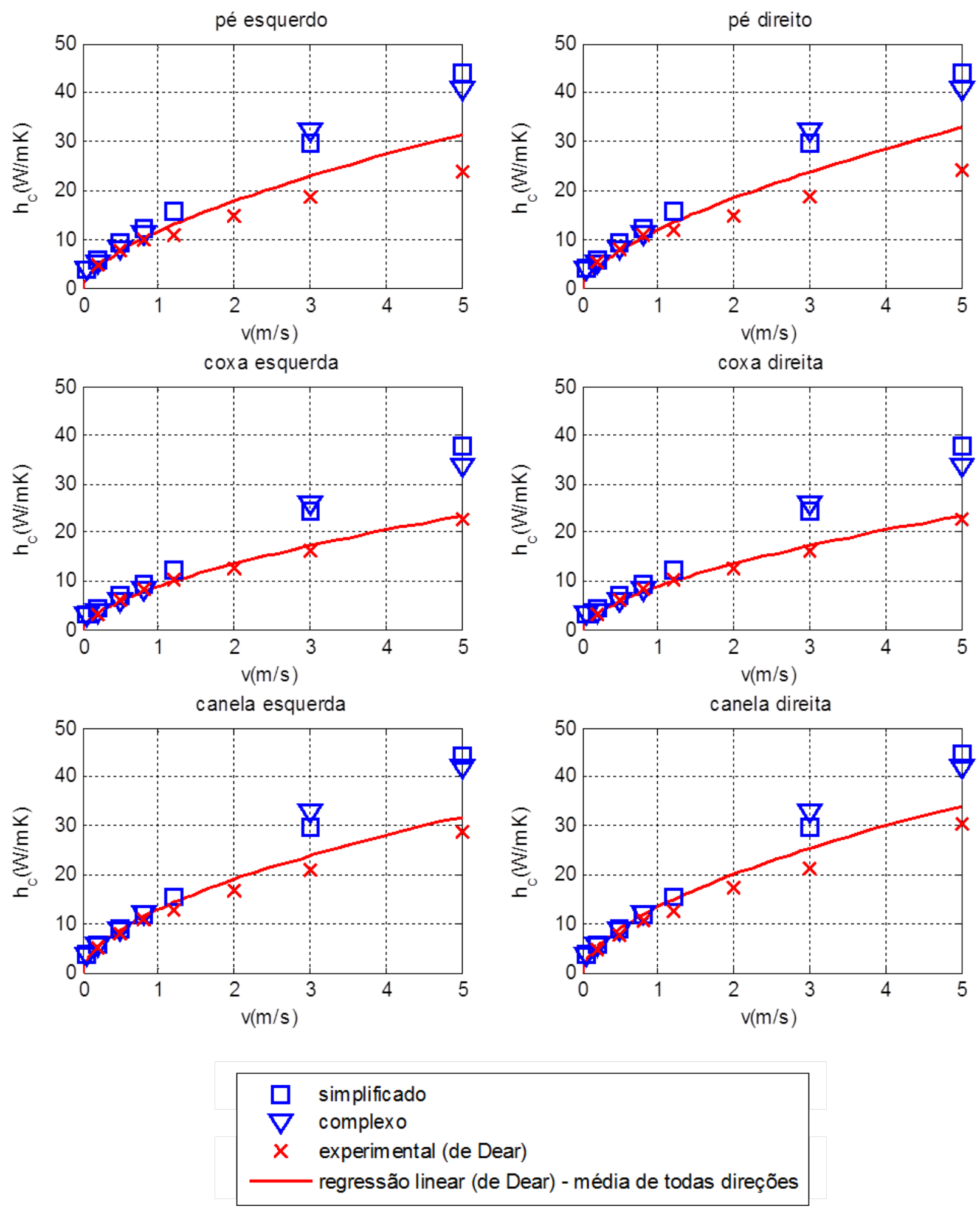

Figura 4.11: Comparação dos resultados do coeficiente de convecção: Membros inferiores 

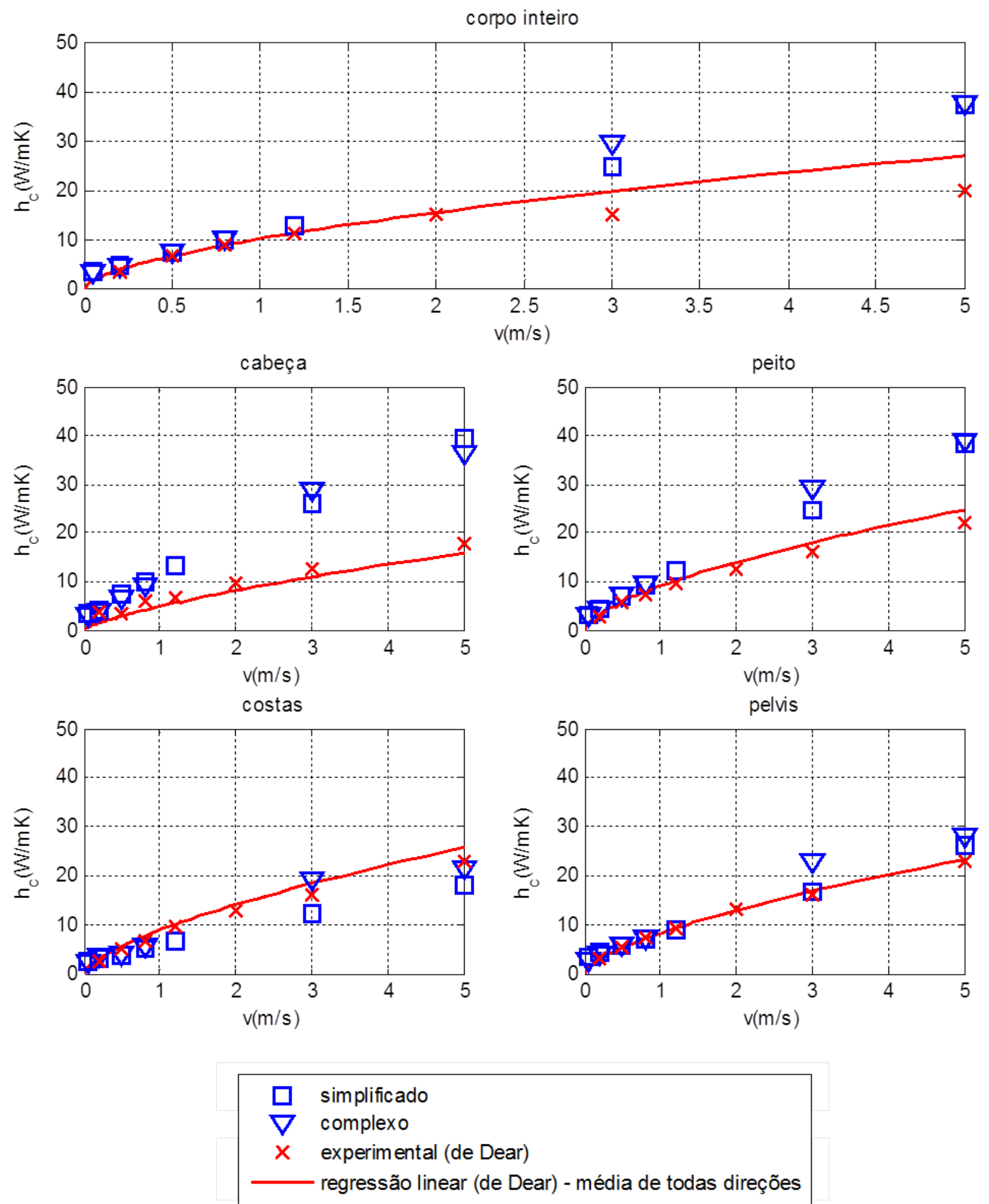

Figura 4.12: Comparação dos resultados do coeficiente de convecção: cabeça, peito, costas, pélvis e média no corpo inteiro 
tivas. Na simulação de escoamento natural - velocidade do ar menor que $0,1 \mathrm{~m} / \mathrm{s}$ - ocorreu a formação de uma pluma térmica no entorno do manequim, conforme a Fig.4.3.

Nos resultados experimentais a participação da radiação térmica sobre a perda de calor total é igual a 58\%. Nas simulações numéricas deste trabalho a participação da radiação é igual a $53 \%$ com o manequim complexo e $63 \%$ com o manequim simplificado, conforme os valores apresentados na Tab.4.3. Os valores são coerentes com a literatura (Murakami et al., 2000). Esperava-se participação da radiação superior a $50 \%$ devido a grande proximidade com as paredes que apresentam temperatura $12^{\circ} \mathrm{C}$ abaixo da temperatura do manequim.

Simulações do manequim simplificado com malha grosseira e refinada revelam que a qualidade da malha não interferiu nos resultados numéricos de radiação térmica. Ao que tudo indica, os fatores de forma das superfícies do manequim diferem porque dependem da postura do manequim (inclinação dos membros inferiores e superiores), da distância entre os segmentos do corpo e da proporção entre as áreas superficiais do manequim (Sorensen e Voigt, 2003). A Tab.4.1 mostra que o manequim simplificado apresenta maior área e o manequim complexo apresenta menor área. Portanto, os resultados alcançados são satisfatórios.

A comparação das perdas de calor por convecção mostra que os resultados numéricos são coerentes com os resultados experimentais até aproximadamente 1,2m/s, o que engloba os escoamentos típicos de conforto térmico. A superestimativa da perda de calor por convecção em regiões irregulares com raios de curvaturas menores pode ser provocada por incapacidade do tratamento de parede do modelo de turbulência. Da mesma forma, a previsão do descolamento do escoamento nas regiões posteriores do manequim depende do desempenho do tratamento de parede.

Para melhorar a avaliação da convecção nas regiões posteriores ao sentido do escoamento é necessário adotar ferramentas numéricas capazes de prever corretamente o descolamento do escoamento, em situações de desprendimento da camada limite quando há gradiente adverso de pressão, notadamente para situações de convecção forçada. Ademais, é necessário um estudo de dependência de malha com técnica de malha adaptativa para detectar a influência do $y^{+}$e do modelo de tratamento de parede sobre os resultados de perda de calor nas superfícies defrontes ao escoamento e com raios de curvaturas menores, onde as velocidades do escoamento podem ser maiores.

A geometria simplificada deve ser suficiente para estudos de avaliação de ambiente térmico e de conforto térmico face aos resultados com velocidade do ar inferior a $1 \mathrm{~m} / \mathrm{s}$. Uma manequim simplificado exige menor controle da malha devido ao menor número e grau das irregularidades da geometria. O detalhamento dos dedos e demais superfícies do corpo humano pode incorrer em erros numéricos quando a geometria simplificada oferece valores mais próximos dos resultados experimentais. Mesmo para velocidades maiores que $1 \mathrm{~m} / \mathrm{s}$ o custo computacional e de tempo pode justificar a utilização de manequins simplificados. 


\subsection{Simulações integradas}

As simulações integradas consistem da simulação do ambiente térmico com ferramenta de CFD e simulação do sistema térmico do corpo humano com outra ferramenta numérica, de forma integrada. Foram realizadas duas baterias de simulações. Com as simulações prelimin̄ares a metodologia de integração proposta foi implementada e os problemas de estabilidade e divergência numérica puderam ser diagnosticados.

\subsubsection{Geometria e malha}

A geometria do manequim na posição sentada foi desenhada em ambiente Solid Worksß. O manequim é dividido em 15 segmentos cilíndricos de seção elíptica, com dimensões similares aos parâmetros definidos na Tab.3.1.

O manequim é inserido no interior de uma pequena sala com $2 \mathrm{~m}$ de largura por $2 \mathrm{~m}$ de comprimento e $2,7 \mathrm{~m}$ de altura. O insuflamento do ar é realizado numa zona retangular com $0,7 \mathrm{~m}$ de largura por $1 \mathrm{~m}$ de comprimento logo abaixo do manequim. O manequim está flutuando com seus pés a aproximadamente $200 \mathrm{~mm}$ do piso. A Fig.4.13 mostra a geometria utilizada na simulação de CFD. O manequim está posicionado um pouco à direita da sala para que a assimetria do escoamento e da transferência de calor possam ser mais bem analisadas.

Uma malha computacional foi gerada em ambiente Icemß. A malha é não-estruturada com elementos tetraédricos. Há três camadas de elementos prismáticos ao longo dos segmentos do manequim para melhorar a precisão dos resultados na camada limite. A Fig.4.14 mostra a malha volumétrica no domínio do escoamento - elementos tetraédricos e camada de prismas - e a malha superficial no manequim.

Ao todo, a malha conta com aproximadamente 1,2 milhões de elementos. Destes, apro-

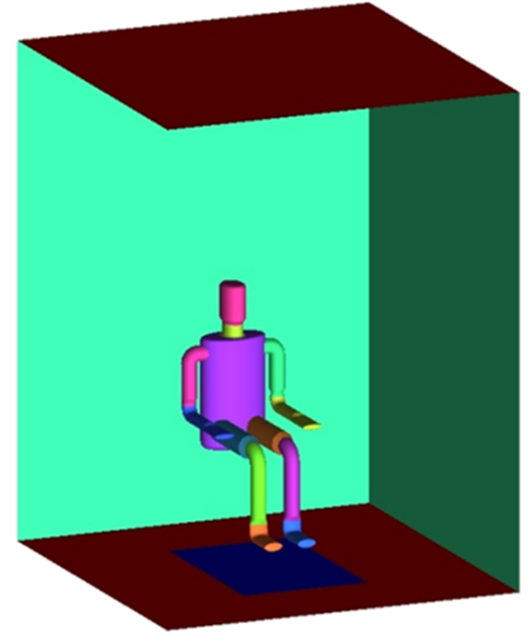

(a)

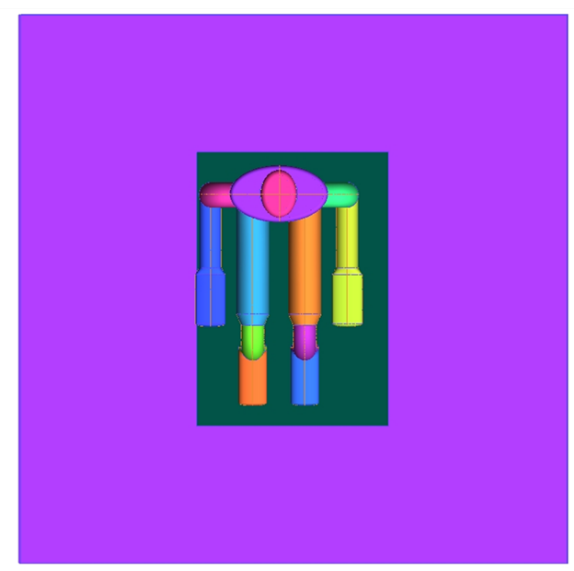

(b)

Figura 4.13: Manequim cilíndrico no interior de sala com insuflamento de ar inferior. Vista isométrica (a) e vista superior (b). 


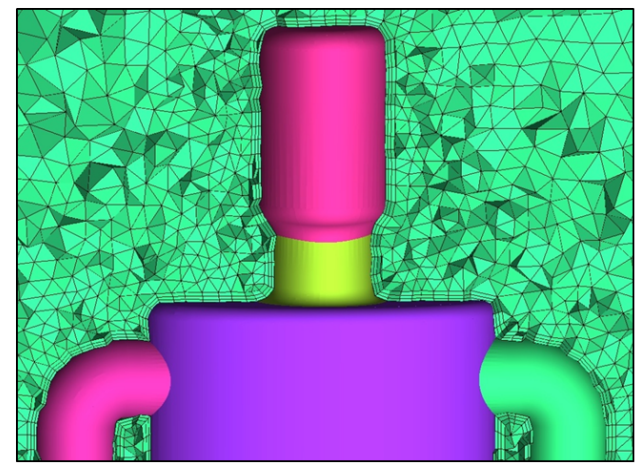

(a)

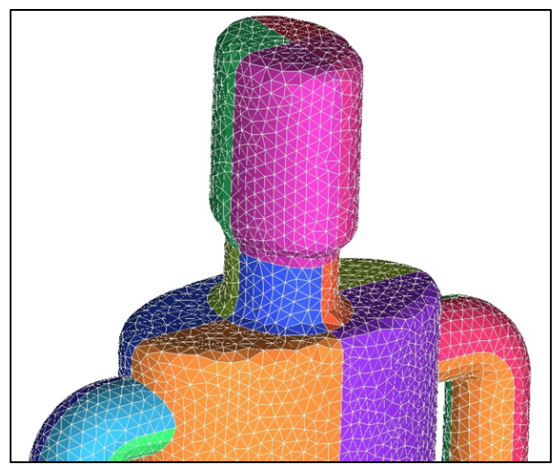

(b)

Figura 4.14: Malha computacional para a simulação integrada preliminar. Malha volumétrica no domínio do escoamento (a) e malha superficial no manequim (b).

ximadamente 22 mil são elementos de superfície no manequim e 67 mil são elementos da camada de prismas. Os elementos de superfícies no manequim e nas paredes medem aproximadamente $15 \mathrm{~mm}$ e $80 \mathrm{~mm}$, respectivamente. Os elementos nas seções de insuflamento e exaustão do ar medem $40 \mathrm{~mm}$ e $50 \mathrm{~mm}$, respectivamente. As três camadas de prismas têm altura igual a aproximadamente $10 \mathrm{~mm}$. O elemento mais próximo às superfícies mede $2,75 \mathrm{~mm}$. A lei de crescimento das camadas é exponencial. O valor médio do $y^{+}$nas superfícies do manequim como um todo é igual a 2,4 e o valor médio nos segmentos não ultrapassa quatro.

A malha foi gerada com os segmentos do manequim discretizados em quatro quadrantes cada um, como mostra a Fig.4.14. Isto foi feito para discretizar a solução do MSTCH. Além disso, melhora-se a previsão das assimetrias do escoamento.

\subsubsection{Metodologia numérica para integração}

A metodologia desenvolvida para a integração da simulação do ambiente térmico (CFD) com a simulação do modelo do sistema térmico do corpo humano (MSTCH) é resumida no fluxograma da Fig.4.15. Vale ressaltar que neste trabalho o termo iteração remete à solução iterativa das equações resolvidas no simulador de CFD e MSTCH, enquanto interação é a simulação consecutiva de ambos os simuladores. O termo integração significa o processo global.

Inicialmente, são definidas condições de contorno preliminares no simulador de CFD, baseadas nas condições térmicas do ambiente em avaliação. O simulador de CFD executa algumas iterações buscando-se o regime permanente para as condições impostas. A partir desta pré-solução é iniciado o processo interativo entre o simulador de CFD e o simulador do MSTCH. A solução do escoamento obtido na simulação de CFD alimenta o simulador do MSTCH. Este, por sua vez, recalcula novas condições nas superfícies do manequim. As soluções são retroalimentadas até que o resíduo entre a última solução e a solução posterior atinja um mínimo estabelecido. 


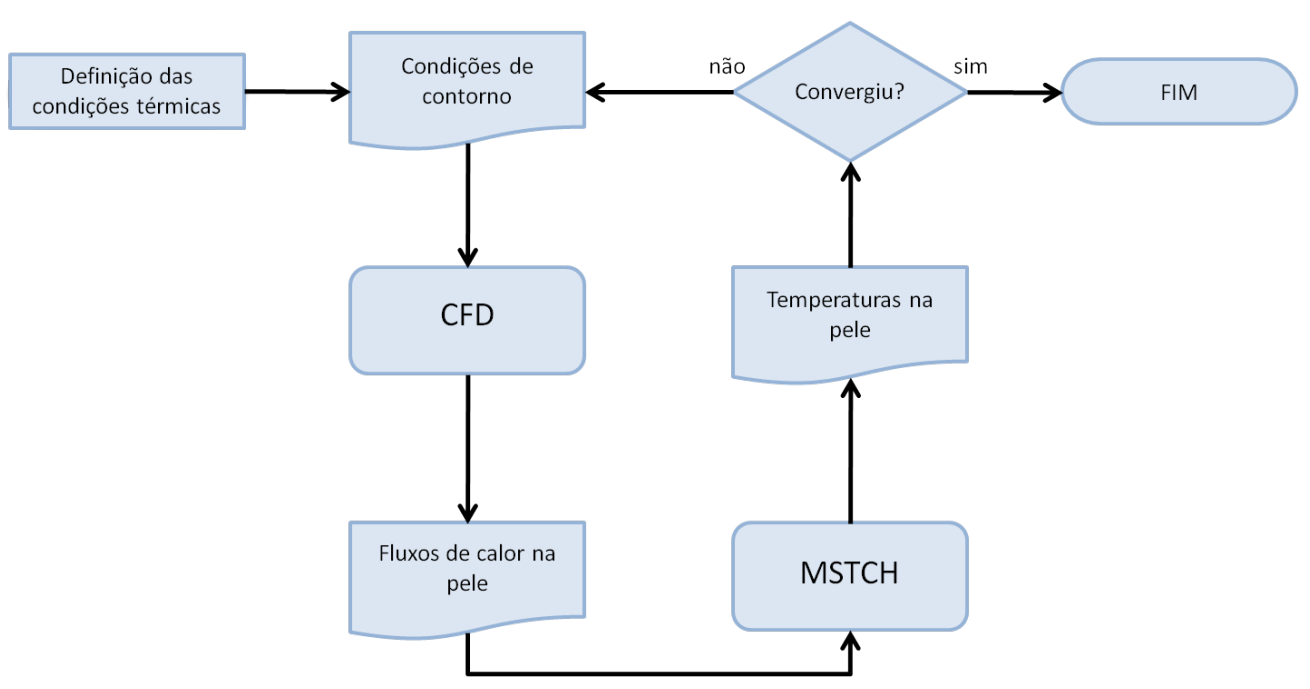

Figura 4.15: Metodologia de integração numérica.

Neste trabalho, as variáveis retroalimentadas são a temperatura superficial do manequim, calculado pelo MSTCH, e os fluxos de calor através do manequim, calculados no Fluent@. A interação é realizada por transferência via arquivo a partir de um script em ambiente LINUX, apresentado no apêndice B.

\subsubsection{Condições de contorno}

As condições de contorno para a simulação de CFD representam o escoamento natural em manequim no interior de uma sala. O escoamento entra pelo piso da sala e sai pelo teto. Na seção de insuflamento do ar é prescrita velocidade constante igual a $0,5 \mathrm{~m} / \mathrm{s}$, com direção normal à superfície. No teto é prescrita pressão atmosférica. Para o tratamento da turbulência são definidas a intensidade de turbulência e a escala de comprimento da turbulência na seção de insuflamento do ar.

O fluido ar é modelado com viscosidade cinemática $\mu=1,7894 E^{-5} \mathrm{~kg} / \mathrm{ms}$, calor específico $c=1006,43 \mathrm{~J} / \mathrm{kgK}$, condutividade térmica $k=0,0242 \mathrm{~W} / \mathrm{mK}$, massa específica constante $\rho=1,12 \mathrm{~kg} / \mathrm{m}^{3}$ e coeficiente de expansão térmica $\beta=0,0033$ para contabilizar variação de $\rho$ no termo de empuxo na equação de momento.

A temperatura inicial das superfícies do manequim é prescrita em $34^{\circ} \mathrm{C}$. Esta condição de contorno é adaptativa durante o processo interativo. O MSTCH recalcula as temperaturas em cada segmento do manequim conforme os fluxos de calor fornecidos pelo Fluent@. Para o modelo de radiação são prescritas as emissividades das superfícies e são desconsiderados os coeficientes de absorção e de espalhamento - meio não participante. A temperatura das paredes em volta do manequim é constante.

A lista a seguir sumariza as condições de contorno adotadas no simulador Fluent@.

- insuflamento: velocidade prescrita em $0,05 \mathrm{~m} / \mathrm{s}$ e temperatura prescrita em $24^{\circ} \mathrm{C}$

- teto: exaustão à pressão atmosférica. 
- paredes laterais: temperatura prescrita em $24^{\circ} \mathrm{C}$.

- manequim: condição de contorno adaptativa

- radiação: $\epsilon=0,95$

- fluido: $\mu=1,7894 E^{-5} \mathrm{~kg} / \mathrm{ms}, c=1006,43 \mathrm{~J} / \mathrm{kgK}, \rho=1,12 \mathrm{~kg} / \mathrm{m}^{3}$ e $\beta=0,0033$

- turbulência: intensidade de turbulência igual a $5 \%$ e escala de comprimento da turbulência igual a $0,25 m$

Os parâmetros fisiológicos e propriedades térmicas definidos para o MSTCH estão apresentados na seção 3.3. O perfil de temperatura inicial correspondente à condição de neutralidade térmica é definido para temperatura operativa igual a $30^{\circ} \mathrm{C}$, umidade relativa do ar de $50 \%$, velocidade do ar inferior a $0,15 \mathrm{~m} / \mathrm{s}$ e condições de metabolismo basal. O manequim é considerado nu.

\subsubsection{Simulações e resultados}

As simulações de CFD procederam com modelo de turbulência k- $\epsilon$ RNG e tratamento de parede aprimorado (enhanced wall treatment). A radiação foi modelada com modelo dos feixes discretos - discrete ordinates (DO) - para meio não participante. O ar é modelado pelo modelo de Boussinesq. Esta aproximação considera massa específica constante apenas nos termos de empuxo (buoyancy term) nas equações de momento. Isto permite prever a pluma térmica formada acima do manequim a um custo computacional mais baixo em comparação aos modelos para escoamento compressível.

As simulações preliminares mostraram que ocorrem problemas de instabilidade e divergência numérica em alguns dos segmentos do manequim durante o processo interativo. Para contornar o problema foram incluídos fatores de relaxação $\alpha$ na condição de contorno

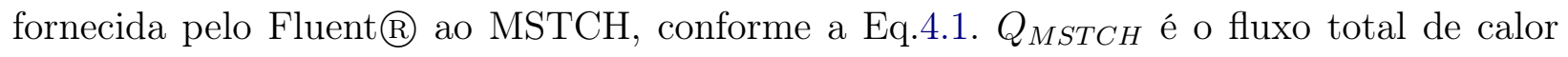
utilizado pelo MSTCH, $Q_{\text {neutro }}$ é o fluxo total com neutralidade térmica pois não confere variação da temperatura do segmento do manequim e $Q_{C F D}$ é o fluxo total de calor calculado pelo simulador de CFD.

$$
Q_{M S T C H}=(1-\alpha) Q_{\text {neutro }}+\alpha Q_{C F D}
$$

Foram realizadas duas baterias de simulação. Na primeira bateria foram realizadas cinco integrações sucessivas, cada qual com os fatores de relaxação 0,2, 0, 4, 0,6, 0, 8 e 1, 0. Em cada integração foram executados 10 passos interativos, cada um com vinte iterações das equações de Navier-Stokes e duas iterações da equação de transporte radiativa no simulador Fluent@. O processo iterativo no MSTCH desenvolvia-se até atingir o regime permanente para as condições impostas. 
Os resultados de temperatura média da pele em função do número de interações para cada segmento estão apresentados nas Fig.4.16 a 4.19. Observam-se problemas de divergência nas Fig.4.18 e 4.19, à medida que a relaxação é reduzida (fator tendendo a 1,0). A partir de um determinado momento a solução torna-se oscilatória e começa a divergir. Os elementos críticos são os pés a partir do fator de relaxação 0,6 .

Uma segunda bateria de simulação foi realizada para investigar a instabilidade da metodologia desenvolvida, agora com trinta iterações das equações governantes do escoamento e dez iterações da equação de radiação em cada acesso no simulador Fluent@. Além disso, partiu-se de um fator de relaxação menor com incrementos de 0,1 até atingir 1,0. A Fig.4.20 mostra que a solução final ainda instabiliza, agora a partir do fator de relaxação 0, 9 .

Para verificar a influência da integração dos modelos de CFD com MSTCH foram comparados os valores de perda de calor e temperatura antes e após a integração. Na pré-solução de CFD o manequim todo dissipa $69,59 \mathrm{~W} / \mathrm{m}^{2}$ e após a integração o manequim todo dissipa $557 \mathrm{~W} / \mathrm{m}^{2}$. Cerca de $80 \%$ da perda de calor é devido à radiação térmica. Considerando-se os valores por segmentos, as maiores diferenças entre os valores iniciais e finais se verificam nos membros inferiores e superiores. Nos pés, o fluxo de calor total - convecção mais radiação reduziu de $80,2 W / m^{2}$ para $22,3 W / m^{2}$.

Após a integração, as temperaturas dos segmentos do manequim aproximaram-se da temperatura ambiente. A Fig.4.22 mostra os contornos de temperatura no manequim. Os pés apresentam as menores temperaturas e a cabeça, pescoço e tronco apresentam as maiores temperaturas. A diferença de temperatura entre os dois pés deve-se a disposição assimétrica do insuflamento do ar abaixo do manequim.

\section{Instabilidade numérica}

Uma análise detalhada do processo interativo revela que as oscilações da temperatura ocorrem em torno da temperatura operativa do ambiente $T_{o p}$. A temperatura operativa é a temperatura de um meio imaginário que confere mesma quantidade de troca de calor por conveç̧ão e radiação que o meio real (Stancato, 2009). A temperatura operativa é função da temperatura do ar ambiente e da temperatura das paredes no entorno, podendo ser definida como uma média ponderada entre a temperatura do ar e temperatura média radiante.

$\mathrm{Na}$ condição simulada neste trabalho as temperaturas do manequim partem a $34^{\circ} \mathrm{C}$, portanto $10^{\circ} \mathrm{C}$ acima da temperatura das paredes e do ar insuflado. Vale ressaltar que a temperatura do ar próximo depende da localização de cada manequim. A medida que o ar sobe para o teto sua temperatura aumenta.

As temperaturas nos pés partem de $34^{\circ} \mathrm{C}$ e tendem para um valor próximo da $T_{o p} \mathrm{em}$ virtude da baixa vazão de sangue e sua proximidade com a superfície que insufla o ar a temperatura mais baixa. Consequentemente, na temperatura final dos pés o fluxo de calor é quase nulo.

Supõe-se que a instabilização numérica ocorre quando o fluxo de calor obtido pelo si- 


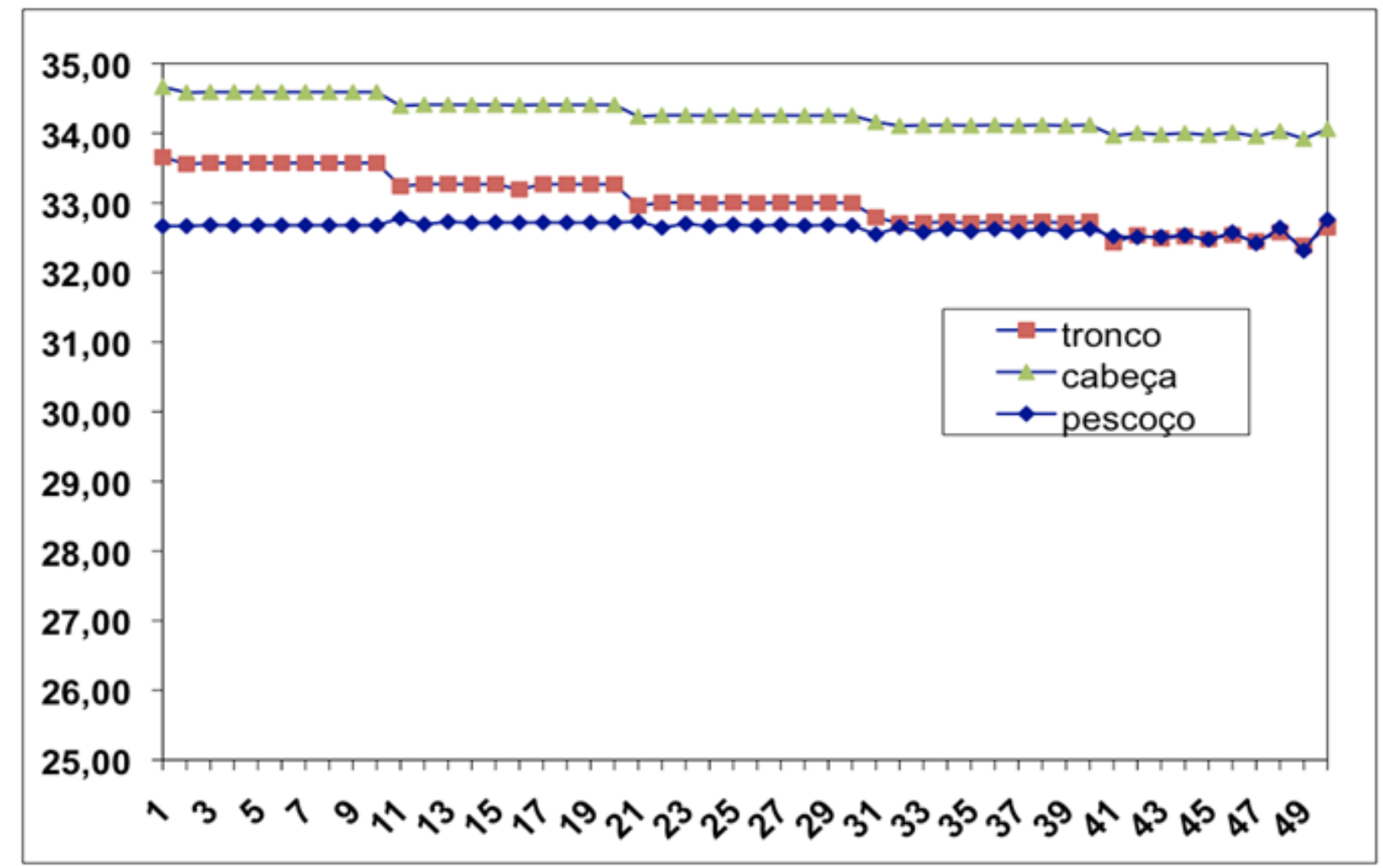

(a)

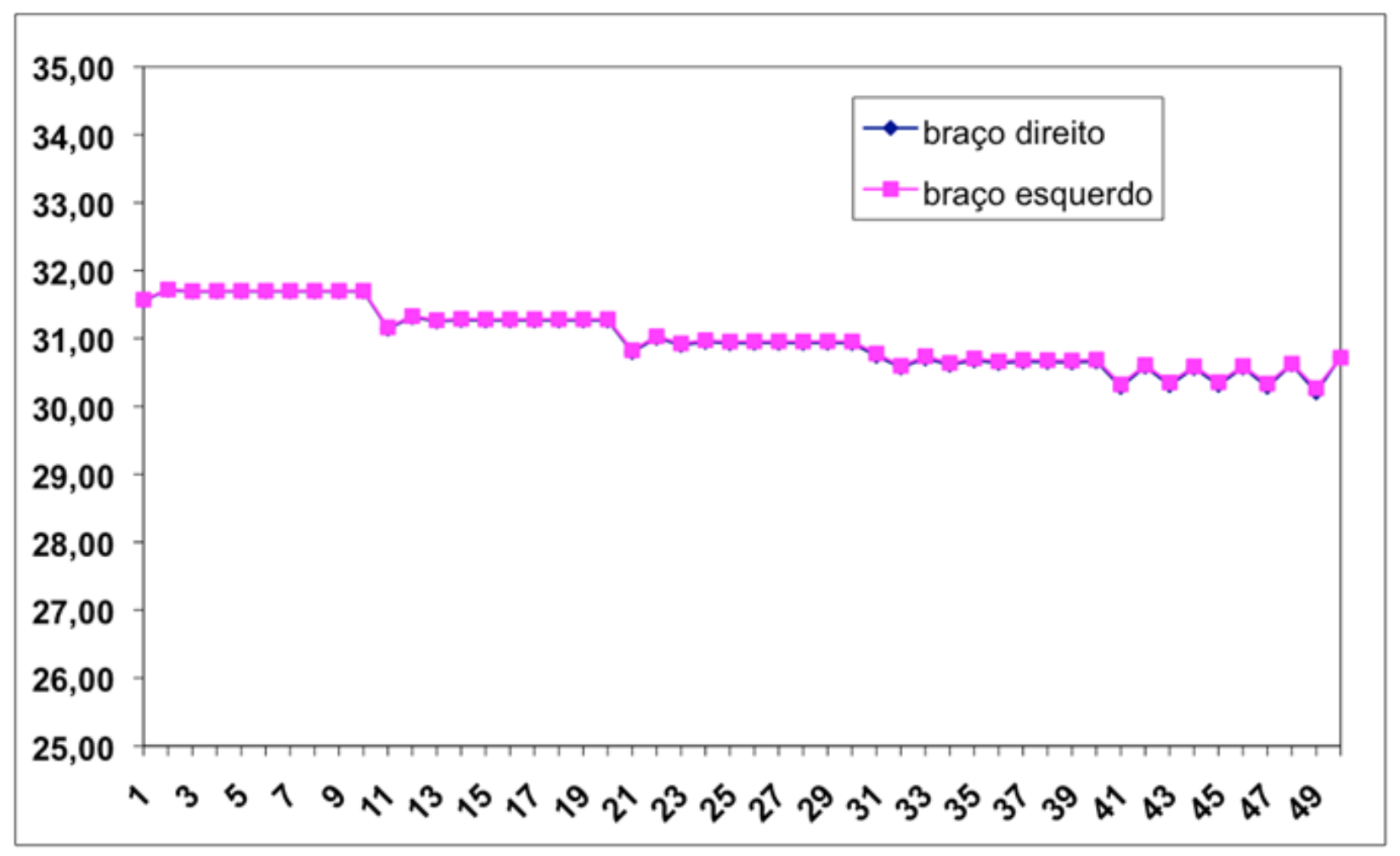

\section{(b)}

Figura 4.16: Temperatura média da superfície da pele $\left({ }^{\circ} \mathrm{C}\right)$ em função do número da interação. Tronco, cabeça e pescoço (a) e braços (b). 


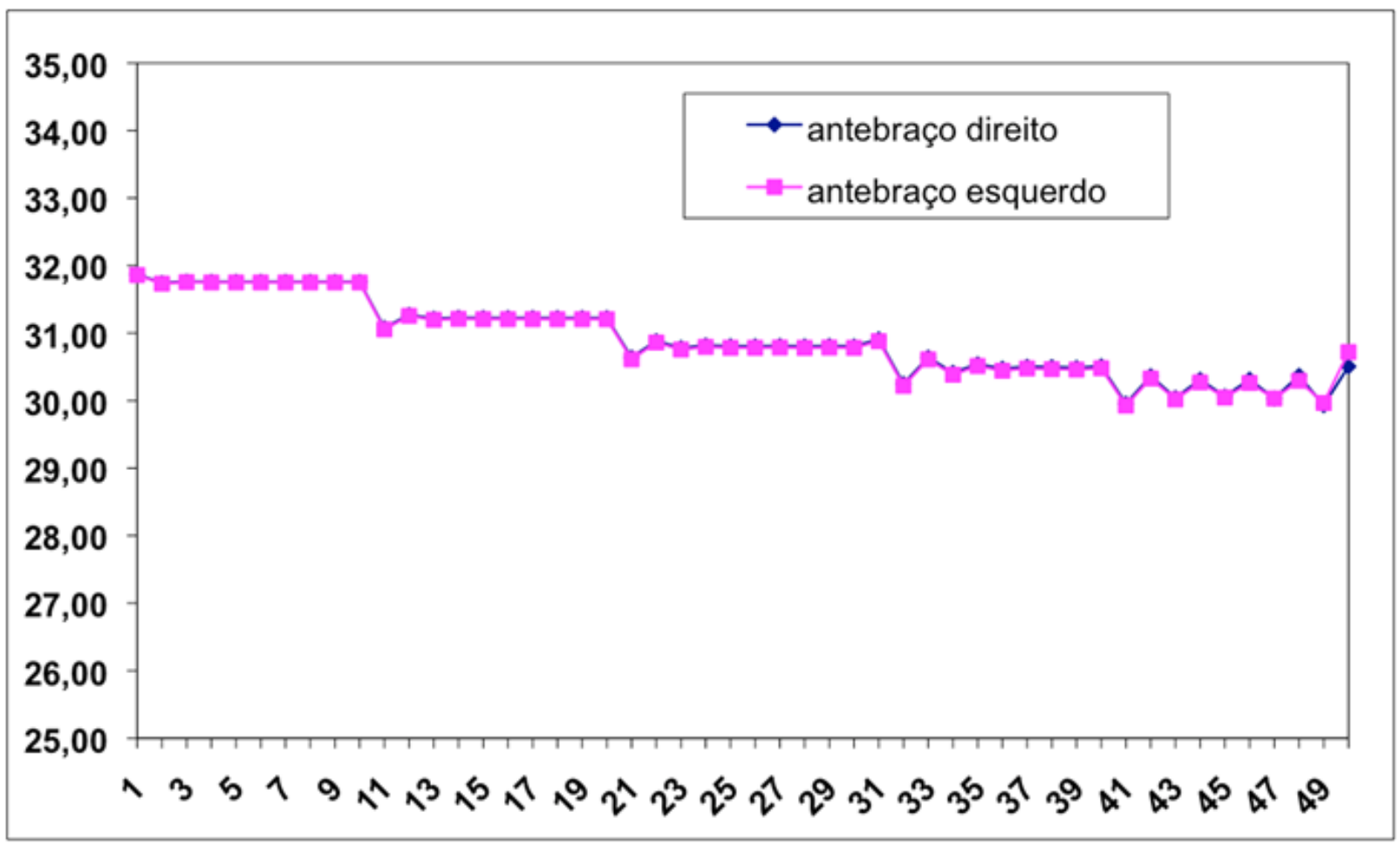

(a)

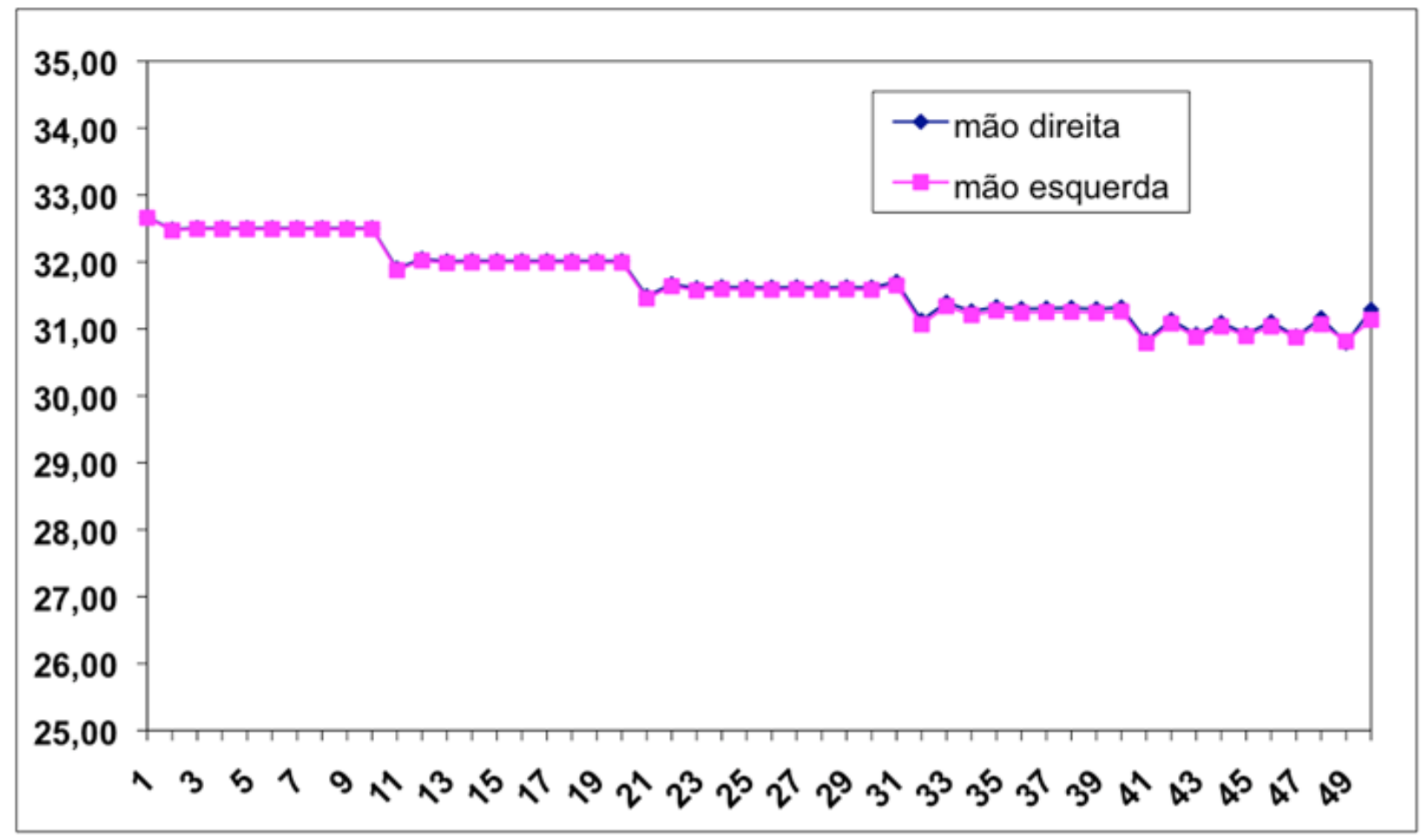

(b)

Figura 4.17: Temperatura média da superfície da pele $\left({ }^{\circ} \mathrm{C}\right)$ em função do número da interação. Antebraços (a) e mãos (b). 

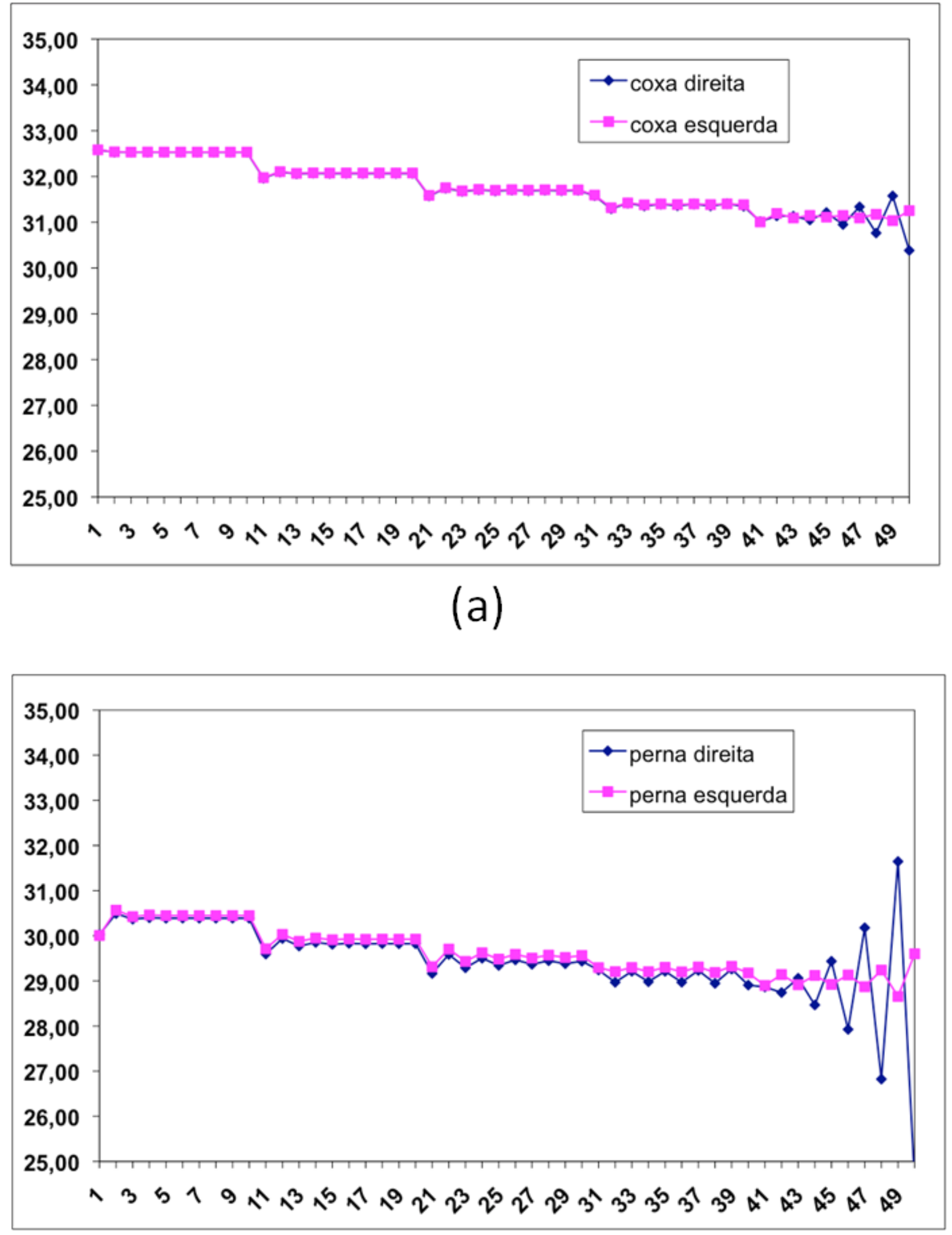

(b)

Figura 4.18: Temperatura média da superfície da pele $\left({ }^{\circ} \mathrm{C}\right)$ em função do número da interação. Coxas (a) e pernas (b). 


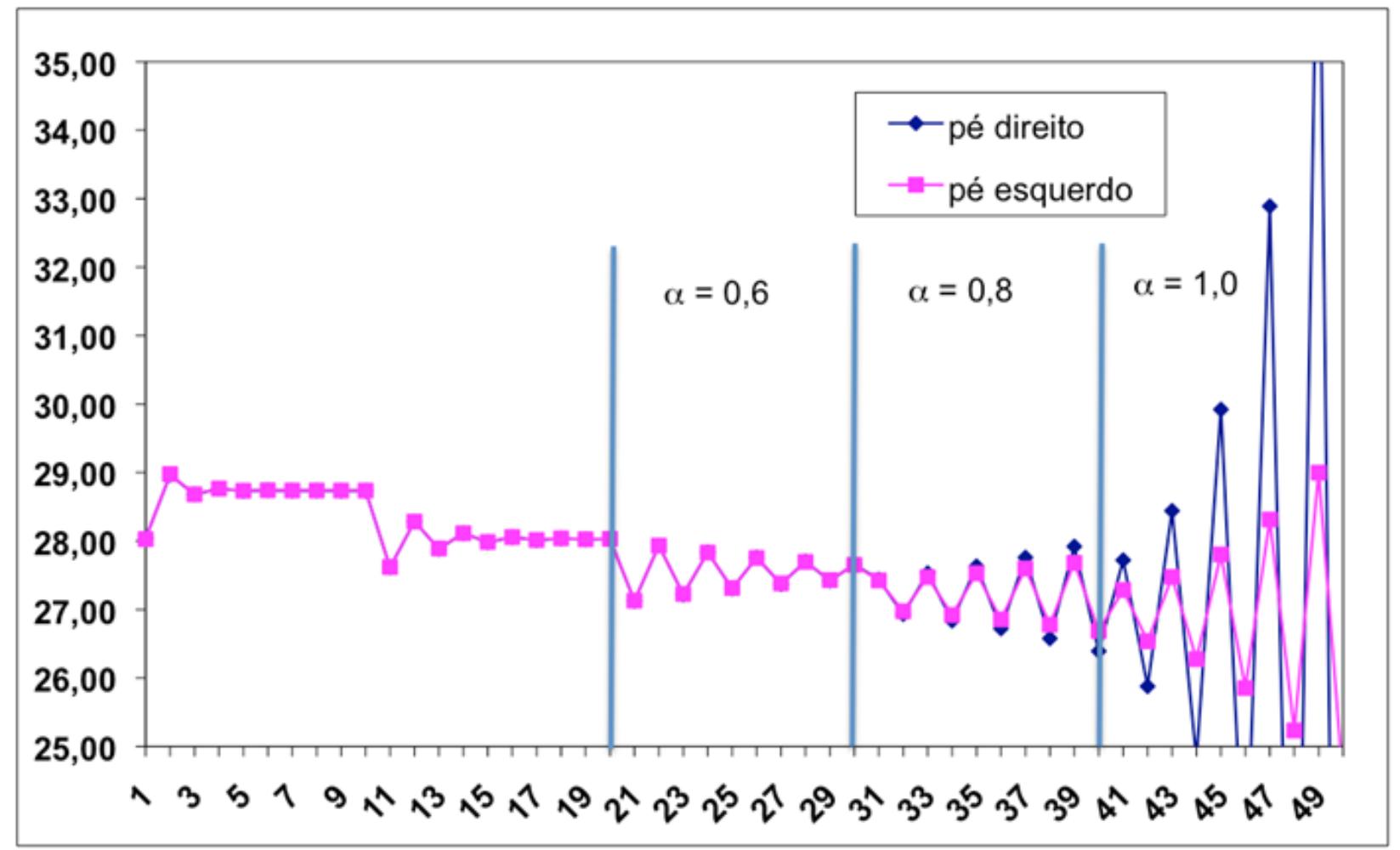

Figura 4.19: Temperatura média da superfície da pele dos pés $\left({ }^{\circ} \mathrm{C}\right)$ em função do número da interação.

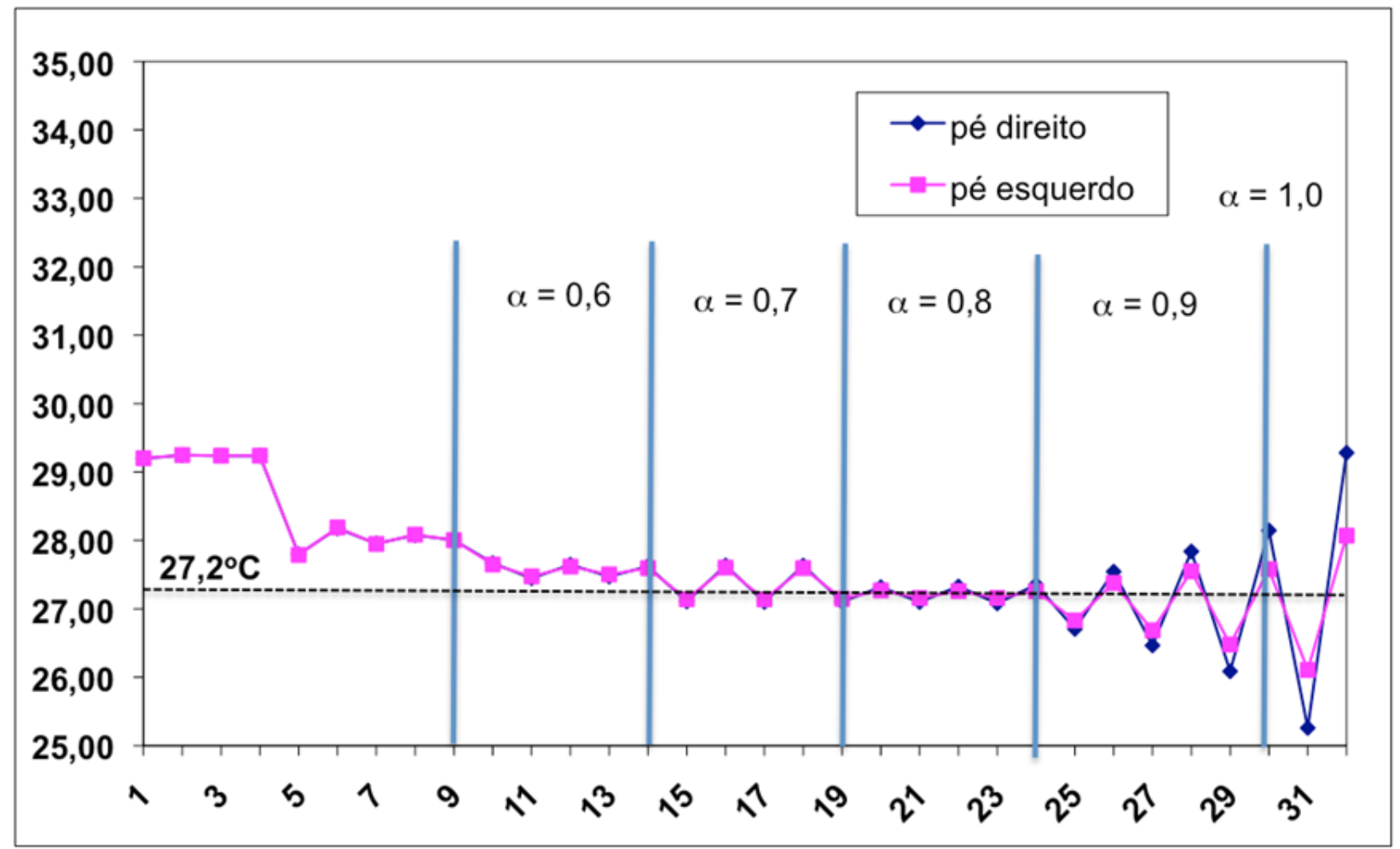

Figura 4.20: Temperatura média da superfície da pele dos pés $\left({ }^{\circ} \mathrm{C}\right)$ em função do número da interação. Segunda simulação - menor incremento do fator de relaxação e maior número de iterações da radiação no Fluent. 


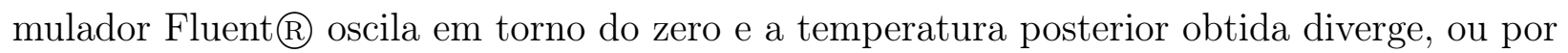
superestimativa do fluxo de calor obtido no Fluent $(\mathbb{R}$ ou superestimativa da temperatura obtida no MSTCH.

A Fig.4.21 esquematiza o mecanismo que leva à instabilização numérica numa condição onde a temperatura inicial do segmento do manequim é superior à temperatura operativa do ambiente. Estão indicados seis passes de interações consecutivos. As temperaturas são calculadas pelo MSTCH e os fluxos de fluxo de calor são calculados pelo Fluent .

Na primeira interação representada na Fig.4.21 a temperatura $T_{1}$ está acima da temperatura operativa e o fluxo de calor $Q_{1}$ é positivo, orientado do manequim para o ambiente. A simulação procede com $T_{2}$ e $Q_{2}$ e depois $T_{3}$ e $Q_{3}$. Neste exemplo, $T_{3}$ está muito próximo da temperatura operativa e o fluxo $Q_{3}$ obtido no Fluent@ leva o MSTCH a calcular nova temperatura $T_{4}$ que transpõe a temperatura operativa em $\Delta T_{4}$. Neste momento tem início a instabilização numérica.

No exemplo da Fig.4.21 o fluxo de calor obtido em passo de interação seguinte é negativo, agora orientado do ambiente para o manequim, devido $T_{4}<T_{o p}$. A temperatura $T_{5}$ transpõe novamente a $T_{o p}$ agora numa distância maior $\Delta T_{5}$, e assim sucessivamente.

\subsubsection{Modificação no procedimento interativo}

Nas simulações integradas neste trabalho as condições iniciais de temperatura $\left(34^{\circ}\right.$ nas superfícies do manequim) estão afastadas da solução exata. Nos primeiros passos de interação a integração progride sem apresentar problemas com instabilidade numérica. A instabilidade incorre apenas depois que a solução se aproxima da solução buscada. O fluxo de calor e a temperatura tornam-se oscilatórios. O MSTCH responde com saltos de temperatura cada vez maiores e a solução instabiliza.

Para corrigir a instabilidade numérica é necessário adotar algum mecanismo que se an-

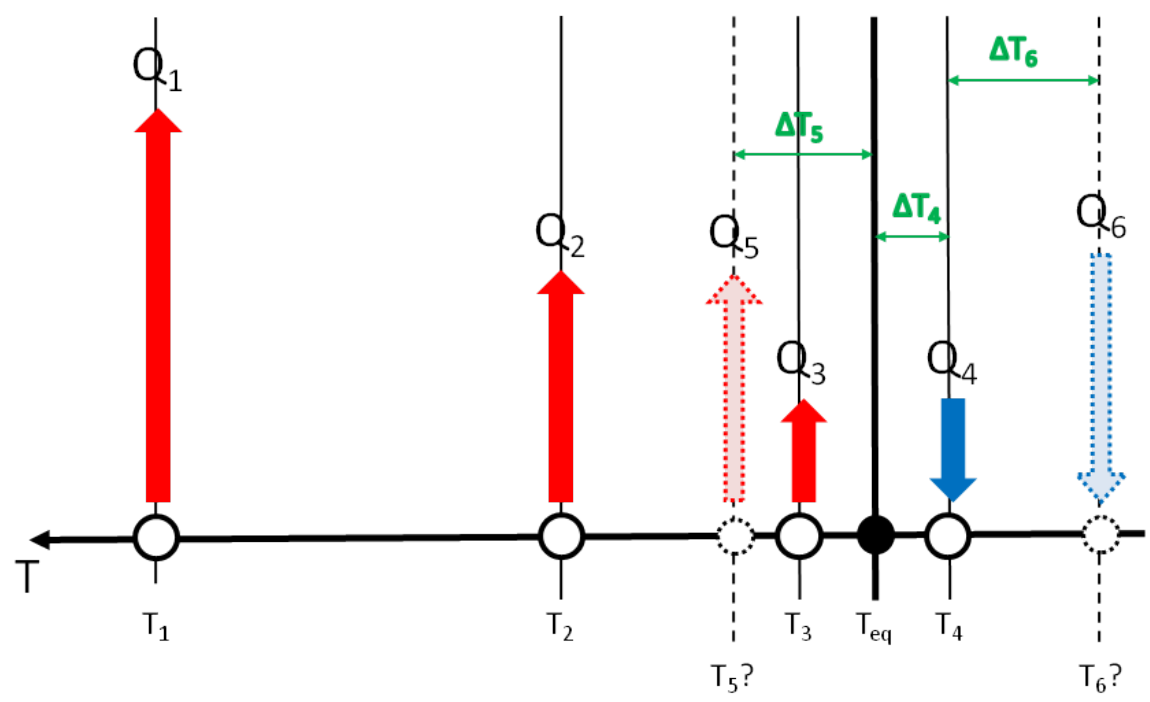

Figura 4.21: Mecanismo de instabilização numérica. 

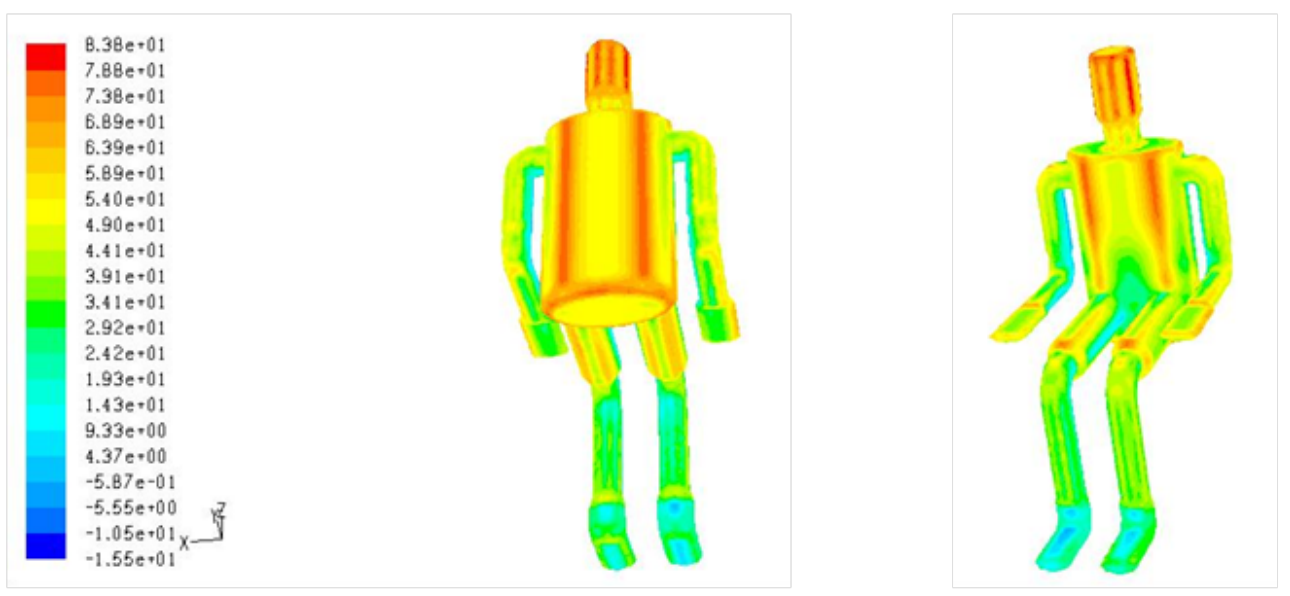

(a)
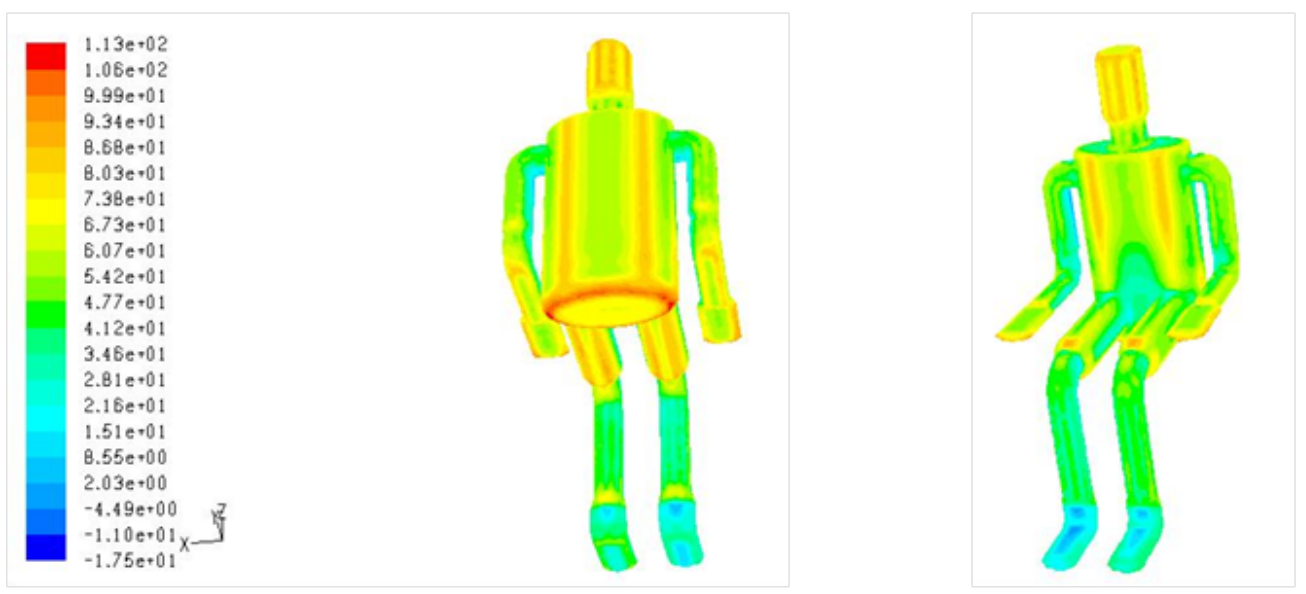

(b)
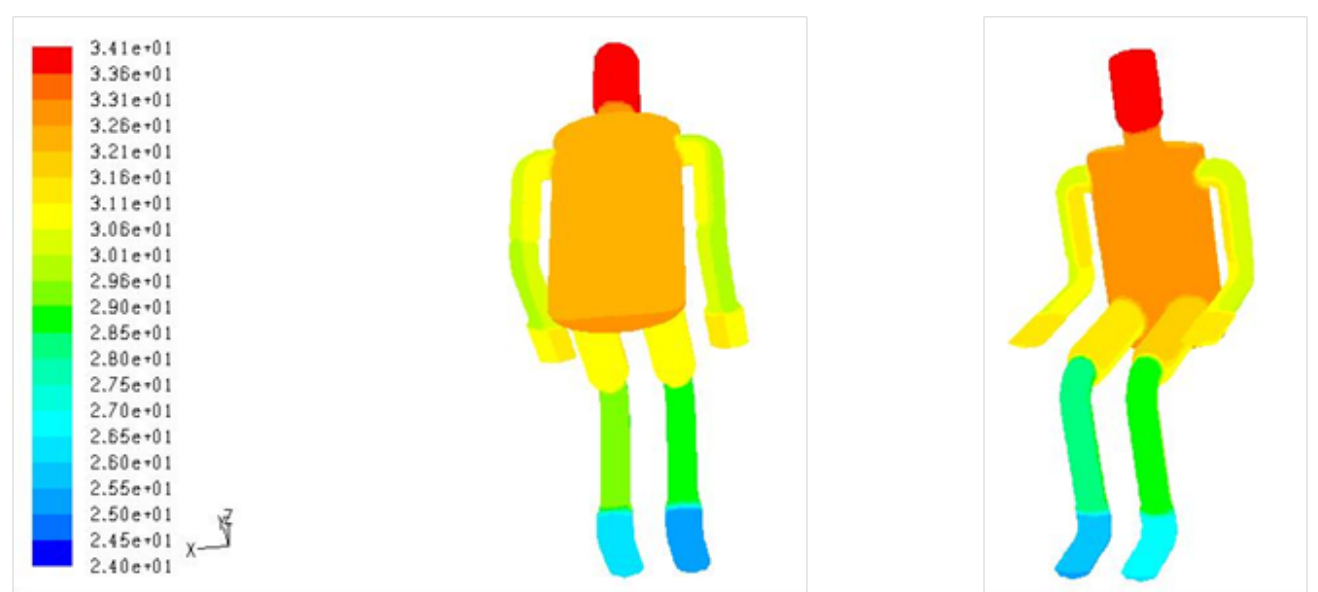

(c)

Figura 4.22: Resultados da segunda bateria. Mapa de fluxo de calor por radiação (a), mapa de fluxo de calor total (a) e contorno de temperatura (c). 


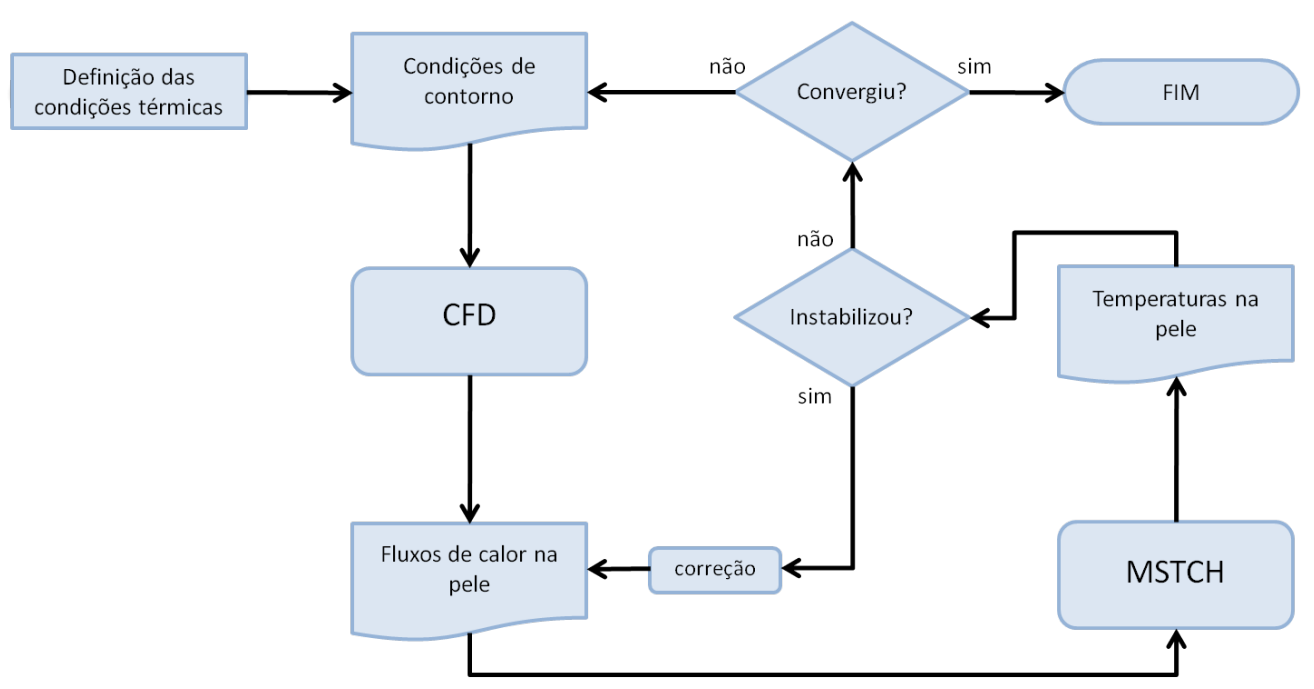

Figura 4.23: Temperatura média da superfície da pele $\left({ }^{\circ} \mathrm{C}\right)$ das mãos, obtido em simulação integrada com modificação no procedimento interativo

teceda ao mecanismo da instabilização ilustrado na Fig.4.21. Uma alternativa é detectar a instabilidade no seu início e relaxar o fluxo de calor fornecido pelo simulador de CFD, para evitar a instabilização da temperatura.

A proposta foi testada numa simulação de mock-up aeronáutico realizada no LETE ( Laboratory of Environment and Thermal Engineering) da Escola Politécnica da USP. Foi implementada uma sub-rotina no MSTCH que verifica se a amplitude da temperatura aumentou nos últimos três passos de interação, de forma separada para cada segmento do manequim. Os últimos valores de temperatura e fluxo de calor são armazenados num arquivo para histórico. O MSTCH recalcula o fluxo de calor quando o salto de temperatura nos últimos dois passos de interação ultrapassa o salto de temperatura nos dois passos de tempo anteriores. Na proposta implementada, o fluxo de calor é calculado como a média dos últimos três fluxos de calor armazenados.

O fluxograma da Fig.4.23 substitui o fluxograma da Fig.4.15. Agora, a metodologia de integração primeiro verifica se há instabilidade no processo interativo antes de verificar se a simulação convergiu. Quando a instabilidade é detectada a condição de contorno de fluxo de calor é corrigida, recalculada como a média dos últimos três fluxos de calor fornecidos pelo simulador de CFD.

Os resultados obtidos com modificação no procedimento interativo foram satisfatórios. A Fig.4.24 mostra os resultados de temperatura para as mãos de manequim sentado. Os resultados com metodologia sem modificações divergiram nos pés e principalmente nas mãos.

\subsubsection{Conclusões}

Neste capítulo foi testada uma metodologia de integração envolvendo simulador de CFD e MSTCH para simular o ambiente térmico e também as trocas térmicas no interior do corpo humano, respectivamente. O CFD e o MSTCH interagem através da troca de informações e 
são executados alternadamente. O simulador de CFD calcula os fluxos de calor nas superfícies do manequim e a MSTCH calcula as temperaturas. Neste trabalho, a transferência de arquivo foi realizada via arquivo a partir de um script em LINUX. Para avaliar a viabilidade desta integração foram discutidas a geometria do manequim, a malha e o desempenho da metodologia de integração proposta.

O manequim virtual da simulação de CFD é fiel à geometria implementada no MSTCH. Ambos apresentam área superficial de $1,8 \mathrm{~m}^{2}$ e são representados por segmentos cilíndricos de base elíptica. As dimensões são similares. O manequim do presente estudo é discretizado em 15 segmentos: cabeça, pescoço, tronco, braços, antebraços, mãos, coxas, canelas e pés. Cada segmento ainda foi subdividido em quatro quadrantes para explorar as assimetrias do ambiente térmico na simulação de CFD. O manequim foi posicionado um pouco à direita da sala para testar a capacidade da metodologia, que pode ser comprovada com os resultados de temperatura. A temperatura dos pés esquerdo e direito convergiram para valores diferentes após a integração.

A malha utilizada é não-estruturada com elementos tetraédricos e apresenta camada de prismas ao longo das superfícies do manequim. A malha computacional atende o requisito do tratamento de parede aprimorado, ou seja $y^{+}<5$. Isto deve garantir que existam elementos de malha dentro da região viscosa da camada limite, permitindo que o escoamento possa ser calculado conforme o modelo de duas camadas.

A solução segundo a metodologia de integração proposta tende à instabilidade numérica em alguns segmentos do corpo humano. Pensa-se que os segmentos mais suscetíveis à instabilização são aqueles com menor geração de energia interna ou metabolismo. Nestes tipos de segmentos, a temperatura superficial tende para a temperatura ambiente, condição que confere fluxo de calor quase nulo entre pele e ambiente. Depois que a solução tende para a temperatura buscada a solução pode oscilar e divergir.

Para evitar a instabilidade numérica pode-se adotar relaxação numérica nos fluxos de

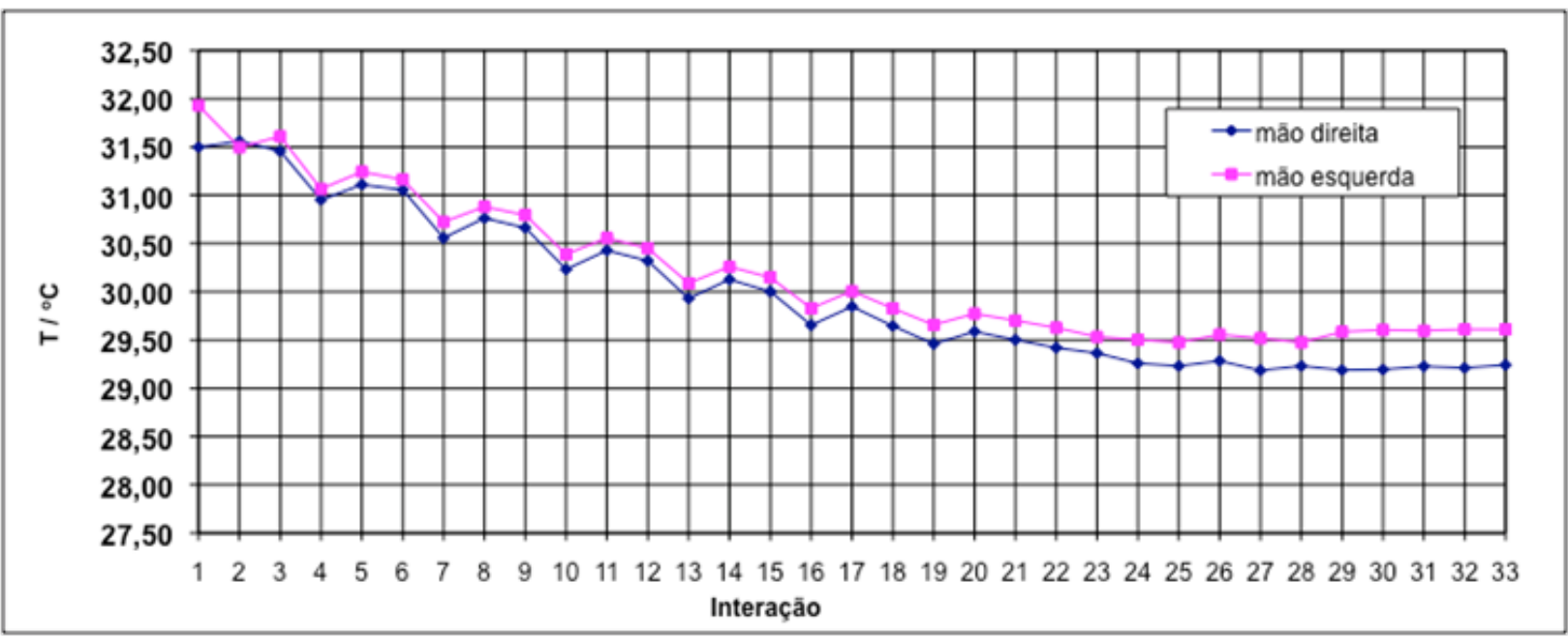

Figura 4.24: Temperatura média da superfície da pele $\left({ }^{\circ} \mathrm{C}\right)$ dos pés, obtido em simulação integrada com modificação no procedimento interativo 
calor para frear a instabilização da temperatura. Isto funciona, porém exige manipulação constante da solução durante o processo interativo. É desejável que a solução final seja obtida na menor relaxação possível. Foi implementada uma modificação no MSTCH que incorre numa relaxação automática quando a divergência no resultado da temperatura é detectada. A nova proposta foi bem sucedida em uma nova integração. Em segmentos suscetíveis à instabilidade a solução da temperatura passou a convergir sem intervenções manuais.

Espera-se que a simulação de manequins computacionais com vestimenta melhore a estabilidade do método de integração sem a necessidade de modificações para controlar a estabilidade. A resistência térmica da roupa funciona como uma relaxação natural do fluxo de calor. 


\section{Capítulo 5}

\section{Conclusão}

Os resultados alcançados mostram que a integração de CFD com modelo térmico do corpo humano é viável com as ferramentas disponíveis. A simulação de CFD do ambiente térmico em simulador comercial foi integrada à simulação do sistema térmico do corpo humano realizada em código acadêmico. Na metodologia proposta, os simuladores obtêm os fluxos de calor e as temperaturas separadamente e retroalimentam as informações via arquivo em ambiente LINUX. Foram discutidos o detalhamento da geometria para o manequim numérico, a qualidade da malha, a viabilidade do modelo de turbulência e de tratamento de parede aplicados, a modelagem da pluma térmica, a modelagem da radiação térmica e o desempenho da integração numérica no que tange aspectos de estabilidade numérica e coerência dos resultados.

A literatura aponta que o modelo de turbulência $k-\epsilon$ está entre os mais utilizados para simulação de escoamento ao redor do corpo humano (Gao e Niu, 2005). Os modelos $k-\epsilon$ padrão e RNG $k-\epsilon$ são suficientes quando a ênfase é dada ao campo do escoamento, portanto são suficientes para uma análise qualitativa do escoamento médio. A boa aceitação destes modelos deve-se aos bons resultados e ao baixo custo computacional. Deve-se ressaltar, os modelos $k-\epsilon$ padrão e RNG $k-\epsilon$ apresentam dificuldades em situações especiais como conveç̧ão natural e grande gradiente de temperatura (Zhai et al. (2007)).

Aqui foi utilizado o modelo de turbulência RNG $k-\epsilon$. Este modelo incorpora avanços ao $k-\epsilon$ padrão que aumenta sua aplicabilidade para um maior número de classes de escoamento.

A característica crítica da malha é a discretização junto às paredes do manequim, onde são obtidos os fluxos de calor, portanto deve-se resolver mais corretamente o escoamento no interior da camada limite. O modelo de turbulência $k-\epsilon$ foi desenvolvido para escoamento turbulento, portanto não é adequado na sub-camada viscosa junto às superfícies do manequim. O tratamento de parede aprimorado introduz o modelo de 2-camadas que modifica a formulação da viscosidade turbulenta em $k-\epsilon$ quando o volume de controle encontra-se na subcamada viscosa. O tratamento de parede aprimorada requer malha refinada nas regiões junto às paredes, com $y<5$.

Escoamentos típicos em problemas de conforto térmico apresentam baixas velocidades e 
são suscetíveis à formação de pluma térmica. O desempenho do modelo de Boussinesq foi satisfatório na modelagem do fenômeno. As Fig.4.3 e 4.6 mostram que há formação de pluma térmica nas simulações com menores velocidades do ar. O modelo Boussinesq incorpora baixo custo computacional que não requer modelo para gás incompressível.

A radiação térmica é preponderante nos problemas de conforto térmico. Murakami et al. (2000) mostram que a transferência de calor por radiação pode corresponder a mais de $35 \%$ do total de calor perdido por um manequim. Aqui é utilizado o Método dos Volumes Finitos de Ordenadas Discretas (FVDOM). Este modelo é utilizado devido sua capacidade em modelar domínios computacionais com condições de contorno periódicas e simétricas. Contudo, podem-se utilizar modelos mais simples voltados para modelagem de meios transparentes à radiação térmica, como surface to surface. Os resultados de radiação térmica alcançados neste trabalho são satisfatórios se consideradas as desigualdades de posturas e dimensões superficiais dos manequins.

O estudo de validação geométrica de manequins na seção 4.1 mostram que uma geometria simplificada com segmentos cilíndricos é suficiente para calcular as perdas de calor nas superfícies do manequim. Nas situações com ventilação natural ou pouco forçada (de 0 a $1 \mathrm{~m} / \mathrm{s}$ ) os resultados numéricos de perdas por convecção de ambas as geometrias - complexa e simplificada - são coerentes com os dados experimentais. O erro aumenta com a velocidade do escoamento. Manequins complexos com maior nível de detalhamento geométrico podem incorrer em erros numéricos quando com uma geometria simplificada se obtém resultados mais próximos dos dados experimentais. Uma geometria simplificada exige menor controle doa malha em regiões com superfícies irregulares e reduz o custo computacional.

Nas simulações integradas, o procedimento interativo apresentou problemas de estabilidade numérica em alguns segmentos do corpo humano. O mecanismo que leva a instabilização pode ser compreendido. Os segmentos mais suscetíveis são aqueles com menor metabolismo e vazão de sangue, como pés e mãos. Os resultados de temperatura mostram que as oscilações ocorrem em torno da solução buscada e o fluxo de calor oscila em torno do zero. Para corrigir a instabilidade foi proposta uma modificação no MSTCH que antecede a divergência na solução da temperatura. A relaxação no fluxo de calor fornecida pelo simulador de CFD evita a instabilização numérica na metodologia de integração proposta. Por este motivo, espera-se menores problemas com estabilidade numéricas em simulações em que houver resistência térmica adicional para modelar a vestimenta e cabelos.

Os resultados de temperatura após a simulação integrada são condizentes com a realidade. As temperaturas finais nos pés e nas mãos são menores que a média total para o corpo inteiro. Além disso, cada pé convergiu para temperaturas diferentes, devido ao posicionamento assimétrico do manequim. É evidente que a metodologia de integração é satisfatória. 


\subsection{Sugestões para trabalhos futuros}

Os próximos estudos envolvendo simulação numérica do escoamento em manequins devem utilizar técnicas de malha adaptativa segundo o $y^{+}$, para uniformizar a qualidade da malha em toda superfície do manequim. Além disso, as dimensões superficiais dos segmentos do corpo humano e sua disposição espacial devem ser rigorosamente controladas para minimizar os erros da simulação da radiação térmica.

Para avaliar o desempenho dos modelos de tratamento de parede e modelo de pluma térmica é necessário utilizar experimentos com técnicas avançadas de visualização da velocidade, como PIV. Os modelos de tratamento de parede devem ser testados nos bordos a montante do escoamento onde ocorre separação da camada limite e no escoamento a jusante onde ocorre descolamento do escoamento devido ao gradiente adverso de pressão. Uma sugestão é comparar os perfis do escoamento em função da velocidade do ar para conhecer os momentos corretos e localização do descolamento da velocidade e também formação da pluma térmica.

Os próximos trabalhos com integração das simulações de CFD e do MSTCH podem incorporar a resistência térmica adicional das roupas e cabelos do manequim, a equação de transporte da umidade do ar e o insuflamento de ar através da respiração. É importante dividir os segmentos do manequim em quatro quadrantes para simular ambientes com assimetrias térmicas.

Para tornar a metodologia de integração mais completa pode-se incorporar um modelo subjetivo de sensação térmica para construir cartas de conforto automaticamente a partir das simulações, tornando a ferramenta apta para avaliações de conforto térmico também. 


\section{Apêndice A}

\section{Avaliação experimental dos coeficientes de transferência de calor}

Na literatura há estudos que avaliam experimentalmente os coeficientes de transferência de calor entre o corpo humano e o ambiente. Nishi e Gagge (1970) propõem uma metodologia baseada na analogia entre a transferência de calor e a transferência de massa. Segundo os autores, a metodologia permite avaliar os coeficientes de convecção mesmo para atividades dinâmicas, tais como corrida e ciclismo. Ichihara et al. (1995), de Dear et al. (1997) e Yang et al. (2009) utilizaram manequins térmicos para estimar os coeficientes de transferência de calor. Nestes trabalhos, as equações de correlação são válidas para velocidades do escoamento desde 0, 05 até 1, $4 \mathrm{~m} / \mathrm{s}$ (até $5 \mathrm{~m} / \mathrm{s}$ em de Dear et al. (1997)). Kurazumi et al. (2008) testaram várias posturas de manequins: ereto, sentado, pernas cruzadas e supino, com a intenção de estudar a convecção natural e a influência da temperatura ambiente $\left(26^{\circ} \mathrm{C}\right.$ a $16^{\circ} \mathrm{C}$ ) sobre a transferência de calor.

O estudo de validação geométrica da seção 4.1 compara resultados de simulação numérica com resultados experimentais em de Dear et al. (1997), a partir da avaliação dos coeficientes de transferência de calor. O estudo experimental utiliza um manequim com temperatura controlada e exposto a várias velocidades de escoamento em um túnel de vento. São avaliados os coeficientes de radiação, de convecção natural e de convecção forçada para velocidades desde $0,05 \mathrm{~m} / \mathrm{s}$ até $5 \mathrm{~m} / \mathrm{s}$.

Os experimentos foram conduzidos em túnel de vento com aproximadamente $16 \mathrm{~m}$ de comprimento desde a seção de insuflamento do ar até a seção de teste. O manequim utilizado é feminino, com $1,5 \mathrm{~m}$ de altura e $1,471 \mathrm{~m}^{2}$ de área superficial. O manequim está sentado e conta com 16 segmentos independentes: cabeça, peito, costas, pélvis, braços, antebraços, mãos, coxas, pernas e pés. A Fig.A.1 mostra o esquema experimental.

A taxa de calor perdida pelo manequim é estimada pela potência elétrica fornecida para manter o manequim à temperatura constante. O controle de temperatura é realizado a partir de uma malha de termopares nas superfícies do manequim.

Os ensaios foram conduzidos com oito velocidades de escoamento: $0,05 \mathrm{~m} / \mathrm{s}$ para avaliar 


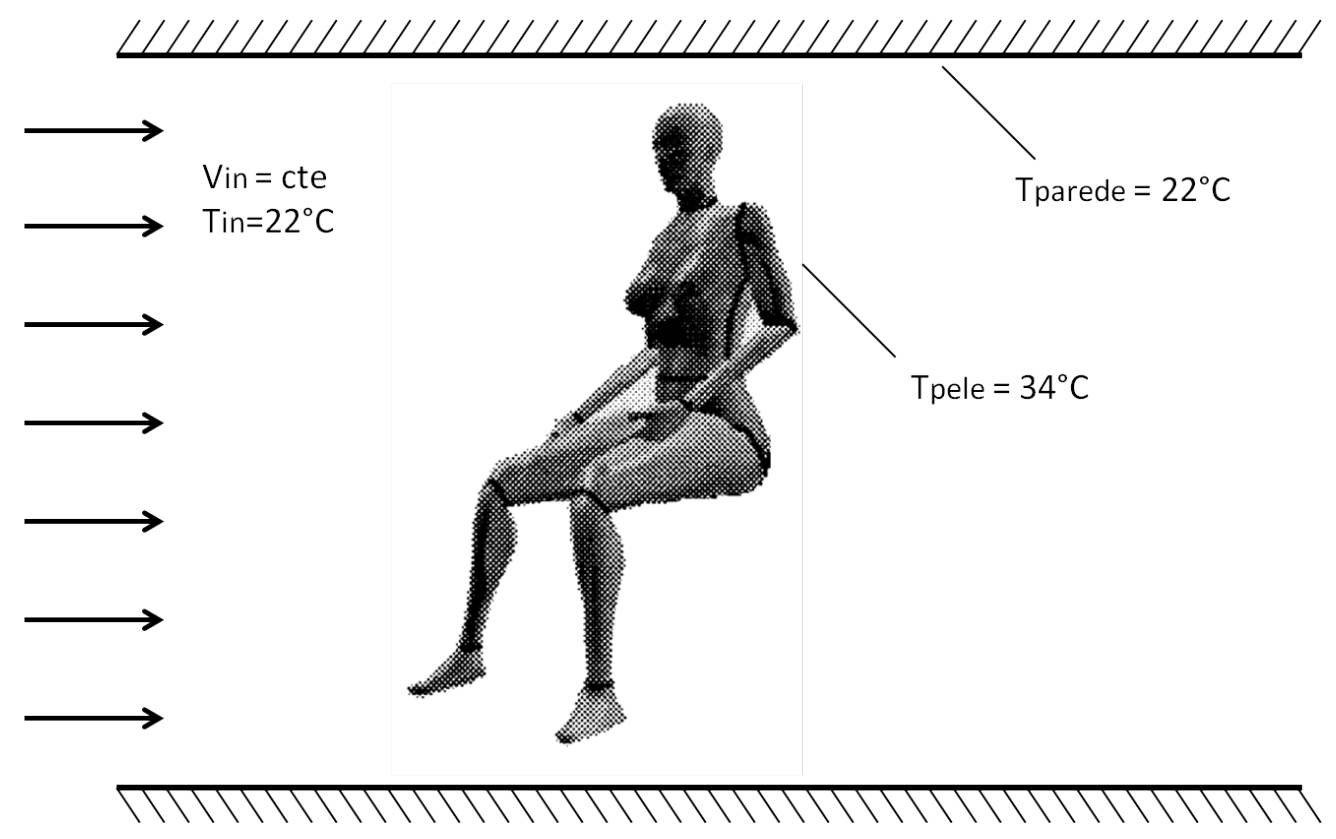

Figura A.1: Esquemático experimental (de Dear et al.)

a convecção natural e $0,2 \mathrm{~m} / \mathrm{s}, 0,5 \mathrm{~m} / \mathrm{s}, 0,8 \mathrm{~m} / \mathrm{s}, 1,2 \mathrm{~m} / \mathrm{s}, 2,0 \mathrm{~m} / \mathrm{s}, 3,0 \mathrm{~m} / \mathrm{s}$ e $5,0 \mathrm{~m} / \mathrm{s}$ para avaliar a convecção forçada. A temperatura do escoamento na seção de insuflamento é constante, igual a $22^{\circ} \mathrm{C}$, e a temperatura do manequim é constante e igual a $34^{\circ} \mathrm{C}$.

A Tab.A.1 mostra as equações de correlação para os coeficientes de convecção forçada em função da velocidade de escoamento.

Tabela A.1: Constantes A e b das equações de regressão $h_{c}=A v^{b}$ para o coeficiente de convecção forçada em função da velocidade do escoamento (de Dear et al., 1997).

\begin{tabular}{lcclcc}
\hline Segmento & $\mathrm{A}$ & $\mathrm{b}$ & Segmento & $\mathrm{A}$ & $\mathrm{b}$ \\
\hline \hline pé esq. & 12,8 & 0,66 & pé dir. & 13,0 & 0,54 \\
canela esq. & 12,9 & 0,56 & canela dir. & 13,4 & 0,58 \\
coxa esq. & 8,9 & 0,60 & coxa dir. & 8,9 & 0,60 \\
pélvis & 8,2 & 0,65 & & & \\
cabeça & 4,9 & 0,73 & & & \\
mão esq. & 14,3 & 0,60 & mão dir. & 12,6 & 0,60 \\
antebraço esq. & 11,6 & 0,62 & antebraço dir. & 11,9 & 0,63 \\
braço esq. & 11,2 & 0,62 & braço dir. & 11,6 & 0,66 \\
peito & 9,1 & 0,59 & & & \\
costas & 8,9 & 0,63 & & & \\
\hline
\end{tabular}




\section{Apêndice B}

\section{Script}

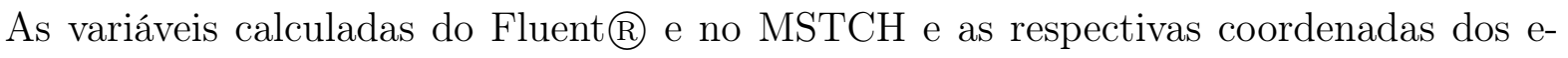
lementos de malha são armazenadas em arquivo de texto conforme o formato apresentado abaixo. Da simulação de CFD escreve-se o arquivo profi lee.txt contendo fluxos de calor e da simulação do MSTCH escreve-se o arquivo profiles.txt contendo temperaturas calculadas pelo MSTCH. As informações são escritas para cada uma das 15x4=60 zonas em ordem alfabética pelo nome. Esta formatação permite ao Fluent@ receber as novas condições de contorno em cada elemento de malha nas superfícies do manequim. Vale ressaltar que o MSTCH utiliza os fluxos médios em cada uma das zonas do manequim e devolve uma temperatura uniforme para cada uma das zonas, daí a importância em se discretizar a malha em zonas circulares, pela maior facilidade de implementar este tipo de discretização no simulador do MSTCH.

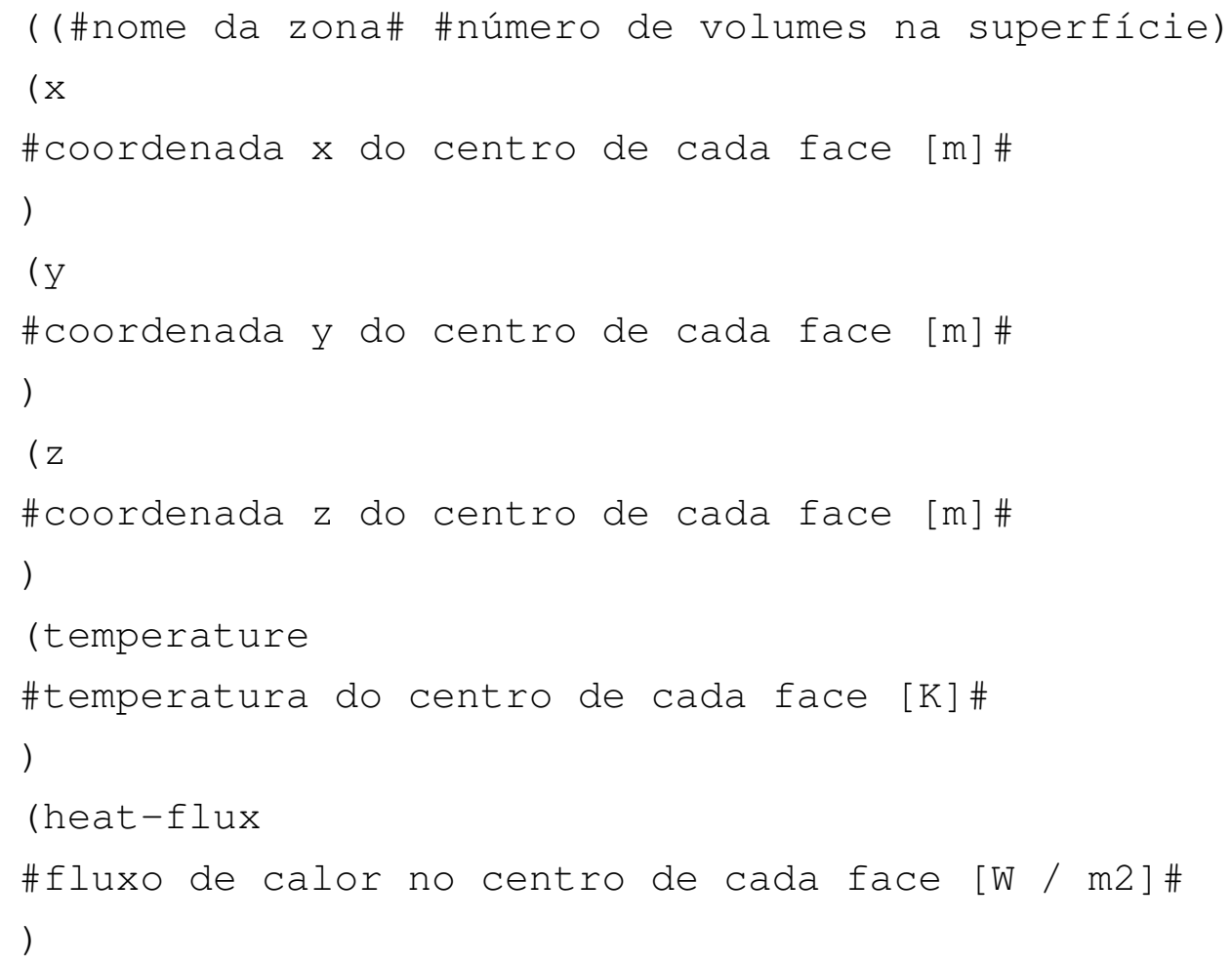


O script desenvolvido para LINUX procede a interação entre os simuladores de CFD e

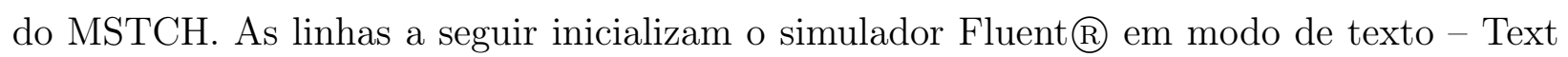
User Interface (TUI).

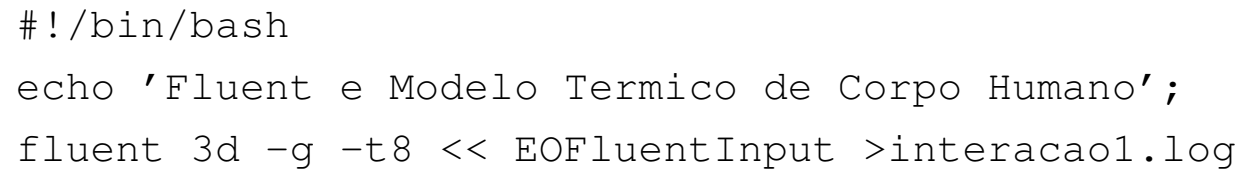

Os próximos comandos servem para acessar a malha computacional malha_1200k . cas, acessar as condições de contorno preliminares FluentMSTCHv3_e.prof e executar 20 iterações dentro do simulador de CFD. O arquivo com as condições de contorno contém as temperaturas nas superfícies do manequim. Ao final do processo iterativo é escrito o arquivo FluentMSTCHv3_s.prof com as temperaturas e os fluxos de calor calculados e a primeira simulação no Fluent@ é abandonada.

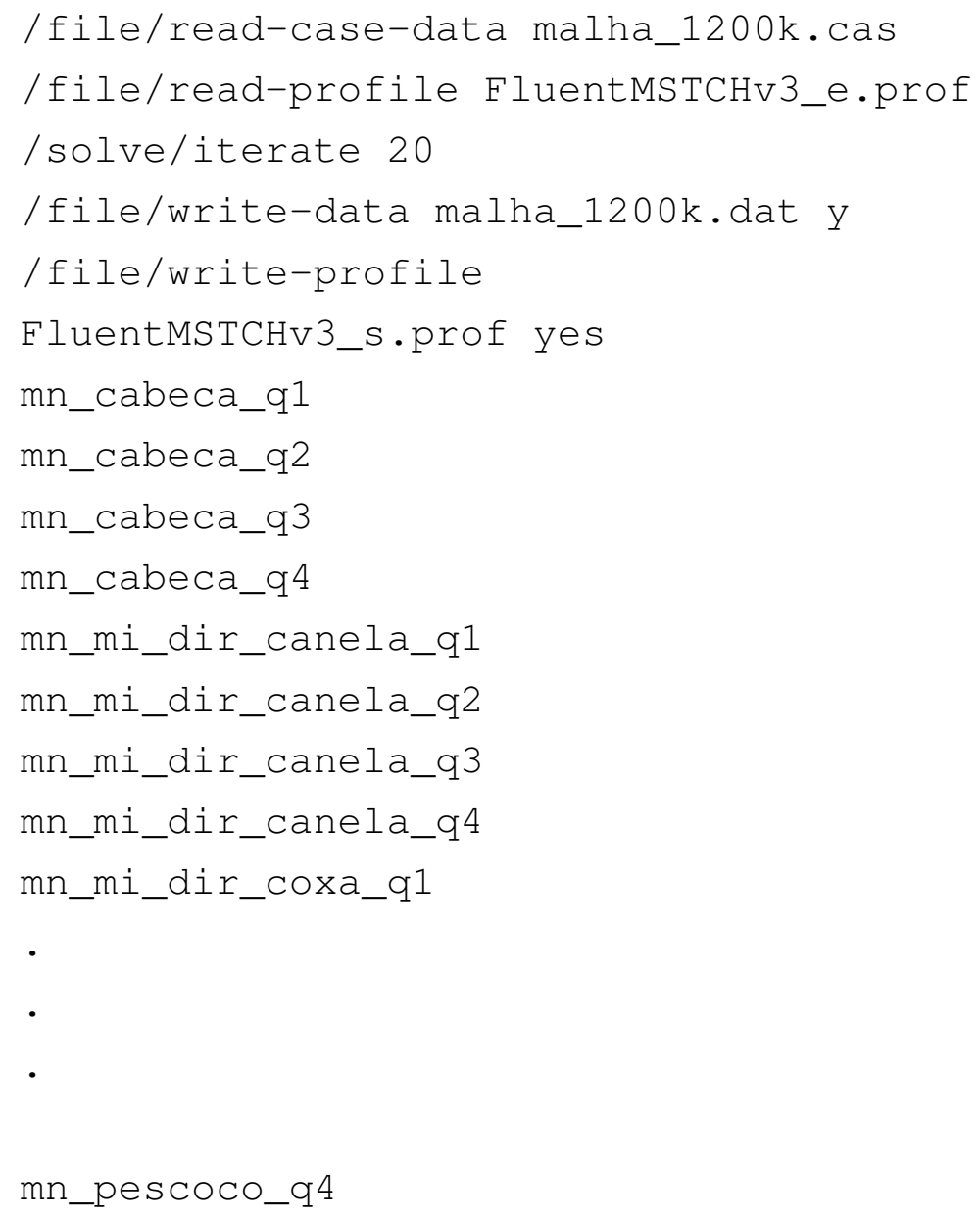




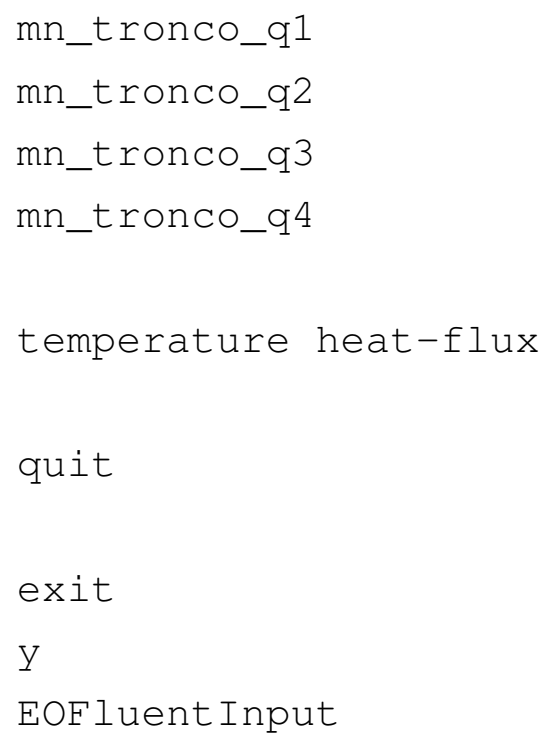

As próximas linhas de comando executam o simulador do MSTCH. O arquivo FluentMSTCHv3_s.prof é renomeado profilee.txt para que possa ser lido no MSTCH. Ao final do processo iterativo no MSTCH, o arquivo profiles.txt com as novas temperaturas superficiais é renomeado FluentMSTCHv3_e.prof para retroalimentar a simulação de CFD.

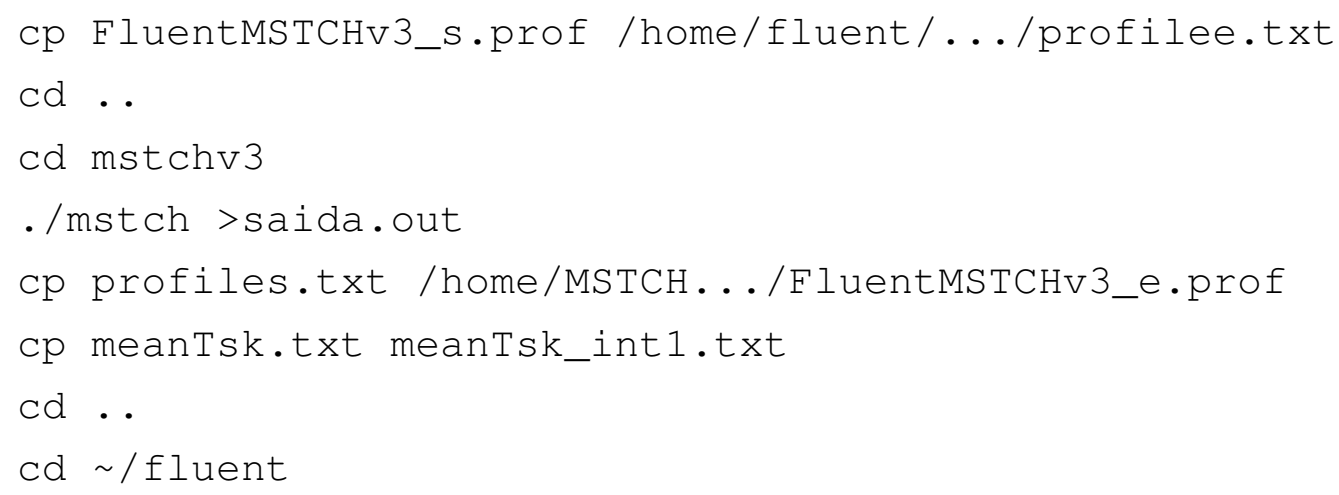

A etapa seguinte executa o simulador Fluent@ uma segunda vez. O ciclo é repetido até que as temperaturas calculadas em interações consecutivas atinjam um resíduo mínimo estipulado pelo analista. 


\section{Referências Bibliográficas}

Blazek(2001) J. Blazek. Computational Fluid Dynamics: Principles and Applications. Elsevier. Citado na pág. 18

Cebeci et al.(2005) T. Cebeci, J. P. Shao, F. Kafyeke, e E. Laurendeau. Computational Fluid Dynamics for Engineers. Springer and Horizons Publishing, third edition edição. Citado na pág. 19

de Dear et al.(1997) R. J. de Dear, E. Arens, Z. Hui, e M. Oguro. Convective and radiative heat transfer coefficients for individual human body segments. International Journal of Biometeorology, 40:141-156. Citado na pág. viii, ix, 41, 44, 46, 48, 50, 76, 77

de Moura(2009) D. de Moura. Condições do escoamento e de conforto térmico em cabine de aeronave. Dissertação de Mestrado, São Paulo: Escola Politécnica da USP. Citado na pág. 3

de P. Xavier(2000) A. A. de P. Xavier. Predição de conforto térmico em ambientes internos com atividades sedentárias - teoria física aliada a estudos de campo. página 251p. Citado na pág. 11

Fanger(1967) P. O. Fanger. of thermal comfort: Introduction of a basic comfort equation. ASHRAE Trans, 73(2)(2051):III4.1-4.9. Citado na pág. 6

Fanger(1972) P. O. Fanger. Thermal Comfort Analysis and Applications in Environmental Engineering. McGraw-Hill, New York. Citado na pág. 1, 11, 12, 13, 41

Ferreira(2001) M. S. Ferreira. Um Modelo do Sistema Térmico do Corpo Humano. Tese de Doutorado, São Paulo: Escola Politécnica da USP. Citado na pág. 3, 11, 12, 15, 38, 39, 40, 42

Ferreira(1997) M. S. Ferreira. Um modelo do sistema termorregulador do corpo humano: Exposição a ambientes quentes. Dissertação de Mestrado, São Paulo: Escola Politécnica da USP. Citado na pág. 3

Ferreira e Yanagihara(2009) M. S. Ferreira e J. I. Yanagihara. A transient threedimensional heat transfer model of the human body. International Communications in Heat and Mass Transfer, 36:718-724. Citado na pág. 18

Ferziger e Peric(2002) J. H. Ferziger e M. Peric. Computational Methods for Fluid Dynamics. Springer, third edition edição. Citado na pág. 18

Fiala et al.(1999) D. Fiala, K. J. Lomas, e M. A. Stohrer. A computer model of human thermoregulation for a wide range of environmental conditions: the passive system. Journal of Applied Physiology, 87(5):1957-1972. Citado na pág. 11, 12, 15 
Fluent Inc.(2006) Fluent Inc. FLUENT 6.3 User's Guide, 2006. Citado na pág. 23, 27, 29, $30,31,54$

Fortuna(2000) A. O. Fortuna. Técnicas Computacionais para Dinâmica dos Fluidos: Conceitos Básicos e Aplicações. EDUSP, segunda edição. Citado na pág. 23

Gagge et al.(1971) A. P. Gagge, J. A. J. Stolwijk, e Y. Nishi. An effective temperature scale based on a simple model of human physiological response. ASHRAE Transactions, 77:247-262. Citado na pág. 2, 11, 12

Gao e Niu(2005) N. P. Gao e J. L. Niu. Cfd study of the thermal environment around a human body: A review. Indoor and Built Environment, 14:1:5-16. Citado na pág. 7, 8, 13, $15,27,73$

Guan et al.(2003c) Y. Guan, M. H. Hosni, W. J. Jones, e T. P. Gielda. Literature review of the advances in thermal comfort modeling. ASHRAE Trans., 109(2):908-916. Citado na pág. 1

Hottel e Sarofim(1967) H. C. Hottel e A. F. Sarofim. Radiative Transfer. McGraw-Hll. Citado na pág. 34

Ichihara et al.(1995) M. Ichihara, M. Saitou, S. Tanabe, e M. Nishimura. Measurement of convective heat transfer coefficient and radiative heat transfer coefficient of standing human body by using thermal manikin. Proceedings of the anual meeting of the architectural institute of Japan, páginas 379-380. Citado na pág. 76

Kilic e Sevilgen(2008) M. Kilic e G. Sevilgen. Modelling airflow, heat transfer and moisture transport around a standing human body by computational fluid dynamics. International Communications in Heat and Mass Transfer, 35:1159-1164. Citado na pág. 7, 14, 27

Kurazumi et al.(2008) Y. Kurazumi, T. Tsuchikawa, J. Ishii, K. Fukagawa, Y. Yamato, e N. Matsubara. Radiative and convective heat transfer coefficients of the human body in natural convection. Building and environment, 43:2142-2153. Citado na pág. 76

Leite(2003) B. C. C. Leite. Sistema de Ar Condicionado com Insuflamento pelo Piso em Ambientes de Escritórios: Avaliação do Conforto Térmico e Condições de Operação. Tese de Doutorado, São Paulo: Escola Politécnica da USP. Citado na pág. 3

Maliska(2004) C. R. Maliska. Transferência de Calor e Mecânica dos Fluidos Computacional. LTC, segunda edição edição. Citado na pág. 6, 17, 23, 33

Modest(2003) M. F. Modest. Radiative Heat Transfer. Academic Press. Citado na pág. vii, 34,36

Murakami et al.(2000) S. Murakami, S. Kato, e J. Zeng. Combined simulation of airflow, radiation and moisture transport for heat release from a human body. Building and Environment, 35:489-500. Citado na pág. vii, 7, 14, 15, 58, 74

Nilsson(2007) H. O. Nilsson. Thermal comfort evaluation with virtual manikin methods. Building and Environment, 42:4000-4005. Citado na pág. vii, 13

Nishi e Gagge(1970) Y. Nishi e A. P. Gagge. Direct evaluation of convective heat transfer coefficient by naphthalene sublimation. Journal of applied physiology, 29:830-838. Citado na pág. 76 
Pope(2000) S. B. Pope. Turbulent Flows. Cambridge University Press. Citado na pág. 24

Romero(2004) M. A. Romero. Arquitetura, conforto e eficiência energética. Anais do SANNAR 2004, páginas 1-14. Citado na pág. 4

Shephard e Georges(1991) M. S. Shephard e M. K. Georges. Automatic threedimensional mesh generation by the finite octree technique. Numerical Methods in Engineering, 32:709-749. Citado na pág. 19

Siegel e Howell(1992) R. Siegel e J. R. Howell. Thermal Radiation Heat Transfer. Hemisphere Publishing Corporation, third edition edição. Citado na pág. 33

Sorensen e Voigt(2003) D. N. Sorensen e L. K. Voigt. Modelling flow and heat transfer around a seated human body by computational fluid dynamics. Building and Environment, 38:753-762. Citado na pág. 8, 15, 58

Stamou e Katsiris(2006) A. Stamou e I. Katsiris. Verification of a cfd model for indoor airflow and heat transfer. Building and Environment, 41:1171-1181. Citado na pág. 8

Stancato(2009) F. Stancato. Análise do Ambiente Térmico de Cabine de Aeronave. Tese de Doutorado, São Paulo: Escola Politécnica da USP. Citado na pág. 3, 63

Tanabe et al.(2002) S. Tanabe, K. Kobayashi, J. Nakano, Y. Ozeki, e M. Konishi. Evaluation of thermal comfort using combined multi-node thermoregulation $(65 \mathrm{mn})$ and radiation models and computational fluid dynamics (cfd). Energy and Buildings, 34:637-646. Citado na pág. vii, $11,12,14,15,16$

Tennekes e Lumley(1972) H. Tennekes e J. L. Lumley. A First Course in Turbulence. MIT press. Citado na pág. 24

Tribess(2008) A. Tribess. Análise de Ambiente Térmico em Ambientes Climatizados, Tese de Livre Docência. Tese de Doutorado, São Paulo: Escola Politécnica da USP. Citado na pág. 1

Versteeg e Malalasekera(2007) H. K. Versteeg e W. Malalasekera. Computational Fluid Dynamics - The Finite Volume Method. Pearson, second edition edição. Citado na pág. vii, $18,19,20,21,24,28,29,32,33$

Wilcox(1994) David C. Wilcox. Turbulence Modeling for CFD. DCW Industries, Inc, second printing edição. Citado na pág. 8, 24

Yang et al.(2009) J. Yang, S. Kato, e J. Seo. Evaluation of the convective heat transfer coefficient of the human body using the wind tunnel and thermal manikin. Journal of asian architecture and building engineering, 8:563-569. Citado na pág. 76

Yang et al.(2007) T. Yang, P. C. Cropper, M. J. Cook, R. Y., e D. Fiala. A new simulation system to predict human-environment thermal interactions in naturally ventilated buildings. Preceedings: Building Simulation. Citado na pág. 14, 15

Zhai et al.(2007) Z. Zhai, Z. Zhang, W. Zhang, e Q. Chen. Evaluation of various turbulence models in prediction airflow and turbulence in enclosed environments by cfd: Part 1 summary of prevalent turbulence models. HVACR Research, 13(6). Citado na pág. 9, 73 
Zhang et al.(2007) Z. Zhang, W. Zhang, Z. Zhai, e Q. Chen. Evaluation of various turbulence models in prediction airflow and turbulence in enclosed environments by cfd: Part 2 - comparison with experimental data from literature. HVACR Research, 13(6). Citado na pág. vii, $8,9,10$ 